\title{
Towards a testing strategy for the identification of respiratory sensitizing chemicals
}

Citation for published version (APA):

Dik, S. (2018). Towards a testing strategy for the identification of respiratory sensitizing chemicals.

[Doctoral Thesis, Maastricht University]. Off Page Amsterdam. https://doi.org/10.26481/dis.20181116sd

Document status and date:

Published: 01/01/2018

DOI:

10.26481/dis.20181116sd

Document Version:

Publisher's PDF, also known as Version of record

\section{Please check the document version of this publication:}

- A submitted manuscript is the version of the article upon submission and before peer-review. There can be important differences between the submitted version and the official published version of record.

People interested in the research are advised to contact the author for the final version of the publication, or visit the DOI to the publisher's website.

- The final author version and the galley proof are versions of the publication after peer review.

- The final published version features the final layout of the paper including the volume, issue and page numbers.

Link to publication

\footnotetext{
General rights rights.

- You may freely distribute the URL identifying the publication in the public portal. please follow below link for the End User Agreement:

www.umlib.nl/taverne-license

Take down policy

If you believe that this document breaches copyright please contact us at:

repository@maastrichtuniversity.nl

providing details and we will investigate your claim.
}

Copyright and moral rights for the publications made accessible in the public portal are retained by the authors and/or other copyright owners and it is a condition of accessing publications that users recognise and abide by the legal requirements associated with these

- Users may download and print one copy of any publication from the public portal for the purpose of private study or research.

- You may not further distribute the material or use it for any profit-making activity or commercial gain

If the publication is distributed under the terms of Article $25 \mathrm{fa}$ of the Dutch Copyright Act, indicated by the "Taverne" license above, 
TOWARDS A TESTING STRATEGY

FOR THE IDENTIFICATION OF

RESPIRATORY SENSITIZING CHEMICALS

Sander Dik 
ISBN: 978-94-6182-918-4

Cover design, layout \& printing: Off Page, Amsterdam

Copyright $\odot 2018$ Sander Dik

All rights reserved. No parts of this book could be reproduced or transmitted in any form or by any means without prior permission of the author. 


\title{
TOWARDS A TESTING STRATEGY FOR THE IDENTIFICATION OF RESPIRATORY SENSITIZING CHEMICALS
}

\author{
PROEFSCHRIFT
}

ter verkrijging van de graad van doctor aan de Universiteit Maastricht, op gezag van de Rector Magnificus, Prof.dr. Rianne M. Letschert volgens het besluit van het College van Decanen, in het openbaar te verdedigen op vrijdag 16 november 2018 om 14.45 uur

door

Sander Dik

Geboren te Oss, Op 18 december 1988 
Promotor

Copromotor

Beoordelingscommissie
Prof. dr. Henk van Loveren

Dr. Janine Ezendam, RIVM, Bilthoven

Prof. dr. Frans Ramaekers (Voorzitter)

Dr. Fleur van Broekhuizen, RIVM, Bilthoven

Prof. dr. Ir. Dick Heederik, Universiteit Utrecht

Prof. dr. Jos Kleinjans

Prof. dr. Geertjan Wesseling 


\section{TABLE OF CONTENTS}

$\begin{array}{lll}\text { Chapter } 1 & \text { General introduction and outline } & 7\end{array}$

Chapter 2 Evaluation of in silico models for the identification of respiratory sensitizers functionality

Chapter 3 Can the direct peptide reactivity assay be used for the identification of respiratory sensitization potential of chemicals?

Chapter 4 Development of an in vitro test to identify respiratory sensitizers in bronchial epithelial cells using gene expression profiling

Chapter 5 Development of a testing strategy for respiratory sensitization

Chapter 6 Summary and discussion

Addendum Nederlandse samenvatting $\quad 106$

Valorisation paragraph to the $\mathrm{PhD}$ thesis $\quad 110$

References

Dankwoord

List of Publications

Curriculum vitae 



\section{H A P T E R 1}

GENERAL INTRODUCTION

AND OUTLINE 



\section{GENERAL INTRODUCTION AND OUTLINE}

\section{Asthma and the workplace}

One of the most common chronic diseases of the airways is asthma. According to the World Health Organization, 235 million people are suffering from this chronic disease at the end of 2017 [1]. A commonly known form of asthma is caused by inhalation of pollen or dust mite. These substances induce inflammatory and bronchoconstrictive responses in the lungs resulting in the symptoms of asthma such as sneezing, wheezing, coughing, shortness of breath and chest tightness. Respiratory diseases however are not only common due to indoor exposures to dust mite or outdoor exposures to pollen. These diseases also frequently occur due to workplace exposure to allergens. Examples of traditional industries with high-risk towards asthma are mining, farming, manufacturing work and health care [2]. More recently, occupational cleaning and public administration are also considered occupational settings with an increased risk of obtaining asthma $[3,4]$.

Work-related respiratory diseases can be roughly divided into work-aggravated asthma, irritant-induced asthma and occupational asthma. Work-aggravated asthma is the stimulation of pre-existing asthma of an individual by exposure to work-related substances. Irritant-induced asthma is caused by substances that induce respiratory disease-like symptoms, but no immunological effects are involved. Occupational asthma is acquired solely due to exposure and sensitization to an allergen on the work floor. It is very difficult to determine an average incidence of OA due to several factors, such as underreporting of the condition in some regions and difficulties in correctly diagnosing OA [5]. During diagnosis of OA, a physician inquires whether asthma-like symptoms always start while at work, and if there are any potential airborne chemicals present at the workplace. Diagnosis of OA usually includes a lung function test to measure the capacity of the lungs and an allergy test to confirm whether the individual is allergic to the suspected causative chemical. This can be done using a skin prick or patch test or through a bronchial provocation test in which the reaction of the lungs after inhalation of the chemical is measured. If the symptoms also occur during days not present at work, it might be that the individual suffers from work-aggravated asthma (e.g. the individual already has asthma, which is worsened due to inhalation of an irritating compound at work) [6]. The difference between occupational asthma and work-aggravated asthma is not always easy to determine. Several medical tests may be required to discriminate between occupational asthma and work-aggravated asthma, and these tests are normally only available in specialized medical units [7]. A rough estimate would be that approximately $5-25 \%$ of all adult asthma cases are due to occupational exposure [8-11].

More than 400 substances are known that can cause OA in workers in different occupations $[8,12,13]$. These substances are divided into two categories based on their molecular weight; high molecular weight (HMW) and low molecular weight (LMW), e.g. a molecular mass higher or lower than $1 \mathrm{kD}$, respectively [14]. HMW substances 
comprise approximately 300 of the 400 known substances that can cause OA. Examples of professions in which workers can be exposed to HMW substances that cause OA are bakers [15], which can be exposed to flour dust, and animal workers [16], which can be exposed to animal protein allergens. Typical examples of the remaining 100 LMW chemicals that can cause OA are glutaraldehyde [17], methyl methacrylate [18], persulfates [19] and isocyanates [20]. Exposure to these types of chemicals occurs for example in health care workers and hairdressers. The socioeconomic consequences for those individuals affected by OA can be severe [21]. Some respiratory sensitizers are considered as being substances of very high concern by the Regulation concerning the Registration, Evaluation, Authorization and Restriction of Chemicals (REACH), as they are considered to have an equivalent level of concern compared to carcinogens and mutagens [22]. One recent example is the proposal to include the respiratory sensitizer ethylenediamine as a substance of very high concern [23]. This consideration implies that more strict regulation is required for this chemical which in turn could lead to improved worker protection.

The following example from medical literature clearly shows how exposure to a respiratory allergen can impact an individual's life [24]:

An individual worked as an anesthetic nurse in a hospital. The department she worked at performed inhalational anesthesia in patients using the chemical sevoflurane. The applied gases are scavenged during operations, but this procedure is not optimal, so not all sevoflurane is scavenged. Additionally, sevoflurane gases are exhaled by patients during recovery, so the nurse could be exposed to sevoflurane at work. Her problems developed after four years of working with sevoflurane. The nurse experienced work-related breathlessness, wheeze, chest tightness, rhinitis and eye irritation already after a few minutes being present in the operating theatre. These symptoms worsened during the shift and in the following night it waked her two to three times from her sleep. The symptoms improved during days she was not at work or on holidays. She was diagnosed with occupational asthma and subsequently relocated to a different unit that used intravenous anesthetics, which resolved her condition.

Based on this example, three different types of impact on someone's life can be determined. The most obvious are the actual symptoms. Second, this person can never work in, and potentially never visit a hospital that uses sevoflurane vapors again. Finally, in some countries, OA may cause a situation in which workers suffer from employment prejudice [25]. In other words, they will be fired because they cannot work in the location they are supposed to work. Relocation of an OA-diagnosed person after exposure is a possible solution to this problem.

An alternative to retrospectively relocating a worker is to prospectively identify the chemical as a causative agent for asthma. When known, the hospital could have changed the mode of application of the chemical (in the given example by applying 
the anesthetic intravenously instead of as a gas) before the nurse started working with it. To do this, prospective tests that identify the so called respiratory sensitization potential of a chemical (e.g. the ability of a chemical to induce an allergic response in the lungs resulting in the clinical signs of asthma) are required. Before discussing possible testing methods, the underlying biological mechanisms that eventually lead to asthma need to be described. The following section will therefore detail the current understanding of chemical and biological processes involved in respiratory allergy which also explain the observed adverse effects the nurse experienced.

\section{Biological mechanism of respiratory allergy}

The underlying cause of (occupational) asthma is an allergic reaction to a substance in the respiratory tract. As with any type of allergy, respiratory allergy develops in two separate stages. The first stage is called the sensitization phase in which the immune system is primed to the inducing allergen. These substances are therefore called respiratory sensitizers. The second phase is called the elicitation phase.

Once a respiratory sensitizer is inhaled, it encounters the pulmonary epithelium. It was found that that airway epithelium is fundamentally abnormal in asthma and it was suggested that the barrier function of the epithelium is compromised through defective tight junction formation [26]. More recent studies also show the importance of pulmonary epithelial cells and their barrier function in relation to asthma $[27,28]$. After the respiratory sensitizer has bound or passed the pulmonary epithelium, it generally first needs to be recognized by dendritic cells (DCs) to initiate the sensitization phase. In the case of HMW substances, the DC can directly detect and process the allergen. However, LMW chemicals are too small to be recognized directly by DCs. To acquire immunogenic potential, a LMW chemical must first covalently bind to a protein forming a hapten-protein conjugate [29]. This is considered the molecular initiating event. The hapten-protein conjugate is then recognized as exogenous and subsequently processed by a DC. The DC then migrates from the site of exposure to a local draining lymph node where the antigen is presented to T lymphocytes. A T cell that possesses an antigen receptor specifically matching the antigen presented by the DC is subsequently activated. This triggers the selective expansion of responsive $\mathrm{T}$ helper 2 cells. In addition, the hapten-protein conjugate can also be recognized by $B$ cells. When B cells are stimulated by a Th2 cell through interleukin (IL)- 4 and IL-13, immunoglobulin (Ig) class switching from IgM to IgE occurs on B cells that match the antigen. Combined with the pool of memory $\mathrm{T}$ cells, the individual is now sensitized and primed towards the LMW chemical [30]. Sensitization of an individual can occur after a relatively high peak exposure [31] or after a longer period of low-level exposure to a chemical. Sensitization by LMW chemicals is therefore assumed to only be achieved after a certain threshold of exposure has been reached [32]. However, the determination of chemical thresholds for respiratory sensitization is of yet very difficult [32]. These described steps have recently been put together in an adverse 
outcome pathway for respiratory sensitization to organize information that may better inform the understanding of sensitization of the respiratory tract [33].

Once an individual is sensitized, subsequent exposure to very low concentrations of the same chemical can cause an asthmatic reaction. This is the second stage, which is called the elicitation phase. Upon subsequent exposure, the hapten-protein conjugate binds and cross-links the complementary IgE antibody produced by B-cells during the sensitization phase on the plasma membrane of mast cells. The mast cells then release biologically active mediators leading to the immediate symptoms of allergy $[30,34]$. This reaction can already occur several minutes after exposure, as also described in the illustrated case study. A secondary delayed reaction is possible through recognition of the hapten-protein conjugate by memory T cells. Once bound, they start to proliferate and release pro-inflammatory cytokines, for example leading to the release of inflammatory mediators from eosinophils [30]. This process requires some time before the clinical effects become apparent.

\section{Route of exposure and IgE involvement}

The described process from respiratory sensitization to a clinical response is a simplification of the entire pathway involved. Several key elements remain uncertain, which hampers the development of prospective testing methods for respiratory sensitization. Two major issues in literature that contribute to the difficulty of developing widely accepted testing methods for respiratory sensitization are the route of exposure and the involvement of IgE.

As the name suggests, respiratory allergy involves the inhalation of a chemical to cause the clinical signs of asthma in the elicitation phase. To reach the elicitation phase, an individual first needs to be sensitized to the chemical. Despite the term respiratory allergy, evidence suggests that human skin exposure to a respiratory sensitizer can induce sensitization of the individual (individual references reviewed by Kimber et al. [35], Redlich and Herrick [36] and Cochrane et al. [32]). Several animal studies have been performed using respiratory sensitizers by applying dermal exposure methods $[37,38]$. Based on those studies, it can be concluded that respiratory sensitizers can indeed sensitize a mouse through the skin. It is therefore very well possible that a worker is exposed dermally during work, while the airborne fraction of the chemical is minimal. Only after some time is this minimal concentration sufficient to induce OA symptoms, but the way of exposure (exposure through the lungs or skin) will need to be identified properly by the physician, in addition to the causative chemical, to come to a diagnosis of OA. This introduces an additional factor to be considered by a physician to identify and prevent exposure to the causative chemical.

The involvement of IgE in the process of acquiring $\mathrm{OA}$ is another factor that contributes to the uncertainties in the biological process of respiratory sensitization. Most HMW substances involved in OA induce asthma through an IgE-mediated mechanism as described earlier. Several LMW respiratory sensitizers, such as trimellitic 
anhydride, also induce this type of response [39]. However, other LMW respiratory sensitizers, for example diisocyanates, do not consistently produce IgE specific antibodies [40-42]. This could be attributed to the fact that current technologies are unable to detect these specific IgE antibodies. It could also be an actual lack of IgE antibodies, which would suggest that other (or complimentary) mechanisms are involved in respiratory sensitization such as the involvement of IgG [43].

The route of exposure and the involvement of $\operatorname{IgE}$ antibodies highlight major factors hampering the development of widely accepted testing methods for respiratory sensitization of LMW chemicals; the biological processes involved are not sufficiently elucidated. Currently available assays for respiratory sensitization only cover small aspects of the mostly unknown process of respiratory sensitization. Nevertheless, several in vivo and animal-free methods have been suggested with the aim to predict respiratory sensitization.

\section{Animal and animal-free testing methods to identify respiratory sensitizers}

The only currently available approach to determine if a chemical can cause respiratory sensitization is through retrospective studies of human cases, in which an individual was exposed at the workplace and a diagnosis of occupational asthma was confirmed by a physician. With the aim to prospectively identify respiratory sensitizers, several in vivo, in vitro, in chemico and in silico testing methods have been suggested.

\section{In vivo methods}

The general idea of using an in vivo animal test is that it is a holistic system in which all immunological aspects are integrally involved. However, none of the available animal models mimic all features of human asthma and hence a careful interpretation of data obtained by an animal model is required [44]. Among these in vivo methods are the mouse and rat respiratory local lymph node assays (LLNA), the mouse and rat IgE serum test and the mouse cytokine fingerprinting test (all reviewed by Arts et al. 2007 [45]) and a Brown Norway rat test [46].

The respiratory LLNA described by Arts et al. [37] is similar to the skin LLNA, the only difference being that chemical exposure was done in a head/nose-only situation compared to dermal application of a chemical. Classification of a chemical was done according to the skin LLNA criteria. All tested respiratory sensitizers showed a stimulation index above the pre-determined threshold and therefore the conclusion was that the LLNA can also identify respiratory sensitizers [37]. De Jong et al. [47] showed that skin and respiratory sensitizers are all picked up as sensitizers by the respiratory LLNA but only based on cytokine profiles could they be separated as such. The mouse IgE test, as described by Dearman et al. is suggested to discriminate between skin and respiratory sensitizers based on IgE induction [38]. All chemicals tested induced a proliferative lymphocyte response. The difference between skin and respiratory sensitizers was the lack of IgE induction by skin sensitizers and a substantial 
increase in IgE production by respiratory sensitizers [38]. Since the involvement of IgE in respiratory sensitization is unclear it is uncertain whether a test based on $\operatorname{IgE}$ is the way forward. The difference in IgE production in the mouse IgE test is suspected to be due to a selective Th 1 or Th 2 cell stimulation. This difference in Th 2 and Th1 response was also observed in the mouse cytokine fingerprinting assay, however, this result was not exclusive [48]. The skin sensitizer DNCB showed at least in part an increase in cytokines associated with respiratory sensitization while the respiratory sensitizer TMA also showed an increase in cytokines associated with skin sensitization. Van Och et al. [49] showed dose-dependent cytokine profiles in a BALB/c mice modified LLNA. It was found that a distinction between skin and respiratory sensitizers based on Th1 and Th2 responses could be made, but that significantly higher concentrations of the test chemicals had to be used. Pauluhn et al. (2002) [46] applied a Brown Norway rat model that allowed for an analysis of specific and non-specific airway hyperreactivity and pulmonary inflammation processes, such as specific endpoints determined in bronchoalveolar lavage, lung weights and inspiratory and expiratory air flows. This was done using inhalation challenges of trimellitic anhydride as a respiratory sensitizer. Their findings support the conclusion that the Brown Norway rat model is suitable for identifying TMA as a respiratory sensitizer.

It is clear that animal models have the potential to be used for the identification of respiratory sensitizers. However, none of the available animal tests have been formally validated nor are any widely accepted for identifying respiratory sensitizers. This is due to the uncertainties that remain in the biological processes involved, as well as the fact that none of the animal models fully reflect the human situation. Additionally, the urge to test more respiratory sensitizers in animal models is currently lacking as it is the general trend to replace animal testing with alternative testing methods when possible.

\section{Alternative testing methods}

Three types of alternative testing methods for the identification of respiratory sensitizers have been described in literature. These are in silico, in chemico and in vitro methods. The in silico methods are (quantitative) structure relationship (QSAR) models and come in two different varieties. The first are models that use an algorithm to identify substructures of chemicals that are statistically more prominent in a set of respiratory sensitizers compared to non-sensitizers. This approach was for example used by Cunningham et al. [50]. The second type of tools are models that use reactivity alerts associated with respiratory sensitization. This approach was for example used by Enoch et al. [51]. Several reactivity domains were described that are theoretically able to covalently bind proteins, which is a known key element in the respiratory sensitization pathway. If one or more reactivity domains can be assigned to a test chemical, it is considered a respiratory sensitizer. The development of the available in silico models was done using a variety of chemicals. They have been reported to identify the respiratory sensitization potential of chemicals with accuracies varying 
from $69 \%$ to $94 \%$. However, none of the models can be compared directly with each other due to the differences in their selection criteria for respiratory sensitizers and non-sensitizers.

The second alternative testing method for LMW respiratory sensitization that is suggested is the direct peptide reactivity assay (DPRA). This assay can be considered the practical variant of a structural alert SAR model, as it directly measures reactivity of a test chemical towards a model peptide, as a measure of protein reactivity. This method was first developed and currently accepted as an OECD guideline for testing the skin sensitization potential of chemicals [52]. The method uses two model peptides to mimic the available reactive sites on human proteins to which a chemical should bind, which is required for the induction of skin sensitization due to LMW chemicals [29]. In case of respiratory sensitization, a model peptide with varying reactive amino acids was tested [53]. When the model peptide is mixed with a reactive chemical, a covalent bond is formed between them, thus lowering the amount of freely available peptide. Both lysine- and cysteine-containing peptides were found to be commonly depleted by respiratory sensitizers. In the OECD Skin Sensitization Guideline [52], this is quantified using HPLC-UV and the percentage of peptide depletion is used to classify a test chemical. This approach was recently adopted with the aim to identify respiratory sensitizers as well [54]. Interestingly, that study also proposed that the difference between skin and respiratory sensitizers could be determined using the DPRA. Skin sensitizers would preferentially bind the cysteine-containing peptide, whereas respiratory sensitizers would preferentially bind the lysine-containing peptide [54]. The implication of this finding resulted in several discussions trying to link this chemical difference to the biological difference of Th1 versus Th2 responses [35]. So far, this was not fully successful due to the uncertainties in the biological pathways involved after exposure.

Finally, several in vitro studies are published with the aim to find a set of biomarkers that can discriminate between respiratory sensitizers and respiratory non-sensitizers (as reviewed in for example [35, 55]). Different types of studies were performed; single cell line studies, in vitro 3D model studies and an ex-vivo study. The single cell line studies used different cell types, such as bronchial and alveolar epithelial cells, macrophages and dendritic cells [56-58]. An example of a 3D model using primary human airway epithelial cells that can be differentiated into a variety of cells leading to the 3D culture can be found in [59]. The ex vivo study used human precision-cut lung slices, which were obtained from patients undergoing lung surgery [60]. In all cases, the cells were exposed to a limited number of respiratory sensitizers. Overall, the conclusion of most studies was that the methods described need further evaluation and validation before they can be used for the prediction of respiratory sensitization potential of chemicals. In addition, the biological relevance of the obtained biomarkers is in most cases unclear. So up to this moment the contribution of in vitro methods to the biological understanding of respiratory sensitization is also limited. 


\section{Objective and outline of this thesis}

Occupational asthma due to low molecular weight chemicals is a prevalent form of asthma and its socioeconomic implications can be severe. Currently, identification of respiratory sensitizers can only be done retrospectively. This is because widely accepted predictive methods to conclude on the respiratory sensitization potential of LMW chemicals are currently lacking. Several methods have been developed for this toxicological endpoint, but the uncertainties in the biological processes involved in- and difficulties with diagnosis of respiratory sensitization currently hinder further development and acceptance of these methods for toxicity testing. To this end, the aims of the studies outlined in this thesis were to optimize the currently existing testing methods for the identification of respiratory sensitizers and to contribute to a better understanding of the biological processes of respiratory allergy.

Chapter 2 evaluates several SAR models available for the prediction of respiratory sensitization potential and comments on the applicability domains of each SAR model. This chapter presents the benefits of applying a tiered testing strategy based on some of the available SAR models. This was done as none of the individual SAR models were deemed sufficiently accurate to predict the respiratory sensitization potential of LMW chemicals. Chapter 3 describes the application of a modified DPRA for predicting the respiratory sensitization potential of chemicals. It specifically addresses the addition of applying of mass spectrometry to the DPRA to increase our knowledge of the reaction chemistry involved in forming sensitizer-protein haptens. Chapter 4 describes an in vitro study that aimed to identify the role of the pulmonary epithelial barrier in LMW respiratory sensitization in an effort to elucidate part of the biological pathways involved in respiratory sensitization. Classification of the tested respiratory sensitizers and non-sensitizers using the identified genes is also discussed in this chapter in an effort to develop a predictive in vitro method. Based on the results of these chapters, an attempt to combine the output of the described methods in a testing strategy is described in chapter 5. The aim is similar to that in chapter two; to evaluate the added value of combining multiple test results compared to the results of an individual method. In this case however, information on both chemical as well as biological aspects of respiratory allergy is combined. Finally, chapter 6 provides an overview and general discussion of the studies. In addition, it also provides future recommendations for the use and further development of alternative methods in respiratory sensitization. 




\section{H A P T E R 2}

EVALUATION OF IN SILICO MODELS FOR THE IDENTIFICATION OF RESPIRATORY SENSITIZERS

Sander Dik, Janine Ezendam, Albert R. Cunningham, C. Alex Carrasquer, Henk van Loveren and Emiel Rorije 


\section{ABSTRACT}

Low molecular weight (LMW) respiratory sensitizers can cause occupational asthma but due to a lack of adequate test methods, prospective identification of respiratory sensitizers is currently not possible. This paper presents the evaluation of Structure-Activity Relationship models (SARs) as potential methods to prospectively conclude on the sensitization potential of LMW chemicals. The predictive performance of the SARs calculated from their training sets was compared to their performance on a dataset of newly identified respiratory sensitizers and non-sensitizers, derived from literature. The predictivity of the available SARs for new substances was markedly lower than their published predictive performance. For that reason, no single SAR model can be considered sufficiently reliable to conclude on potential LMW respiratory sensitization properties of a substance. The individual applicability domains of the models were analyzed for adequacies and deficiencies. Based on these findings, a tiered prediction approach is subsequently proposed. This approach combines the two SARs with the highest positive and negative predictivity taking into account model specific chemical applicability domain issues. The tiered approach provided reliable predictions for one third of the respiratory sensitizers and non-sensitizers of the external validation set compiled by us. For these chemicals, a positive predictive value of $96 \%$ and a negative predictive value of $89 \%$ was obtained. The tiered approach was not able to predict the other two thirds of the chemicals, meaning that additional information is required and that there is an urgent need for other test methods, e.g. in chemico or in vitro, to reach a reliable conclusion. 


\section{INTRODUCTION}

Occupational asthma $(\mathrm{OA})$ is a form of respiratory allergy that is characterized by bronchial constriction and bronchial hyperresponsiveness after inhalation of a sensitizing compound at the workplace. These compounds are distinguished into high molecular weight (HMW) or low molecular weight (LMW) respiratory sensitizers $[14,61]$. In many industrialized countries, OA is a major problem because it has serious medical and socioeconomic consequences [21] and is implicated in 10 to $17 \%$ of the total adult asthma cases $[8,9]$. To date, more than 400 substances are known to cause OA, of which a substantial part are LMW respiratory sensitizers $[8,12]$.

Over the past years, several new LMW respiratory sensitizers have been identified based on human case studies showing that the chemical caused OA [61-63]. This illustrates the importance of prospective identification of respiratory sensitizers to devise protective measures for workers. Many occupational asthmagens are also respiratory sensitizers, but not all asthmagens induce immunological mediated hypersensitivity. An occupational asthmagen might also induce non-immunological hypersensitivity such as an irritant effect on the lung. This difference is difficult to distinguish in a clinical setting (Burge et al., 2012), so determining whether an occupational asthmagen is a true respiratory sensitizer is challenging.

In several chemical legislations, including the European Regulation on Classification, Labeling and Packaging of substances and mixtures (CLP) [64], REACH (Registration, Evaluation and Authorization of Chemicals) [65], as well as the Globally Harmonized System on classification and labeling of chemicals (GHS) [66], respiratory sensitization is considered an important toxicological end-point. REACH specifically provides guidance regarding testing for respiratory sensitization. However, the guidance is still limited and concludes that there is a lack of widely accepted means of testing for respiratory sensitization. Some predictive animal [45] and non-animal [54, 67] test methods for the identification of respiratory sensitizers have been described in the literature, but these are not widely accepted yet, nor close to the point where they could enter formal validation.

In recent years, much progress has been made regarding animal-free predictive tests methods for several toxicological endpoints, for example skin sensitization [68]. More recently, some of these skin sensitization methods have been adapted in such a way that they might be able to identify respiratory sensitizers. Among these methods are cell-based methods [67], an in chemico method measuring peptide reactivity [54], and several in silico approaches (Structure-Activity Relationships (SARs)). The latter are computer-based models or alerts that predict respiratory sensitization based on theoretical properties such as electrophilicity [29], mechanism of reactivity [69] and/or the presence of specific chemical substructures [50, 70-72]. These SARs have been reported to identify respiratory sensitizers and respiratory non-sensitizers with accuracies varying from $69 \%$ to $94 \%$. 
None of the available SAR models for respiratory sensitization are generally accepted for regulatory purposes. Nevertheless, the models, based on their published performances, seem to hold promise for providing a fast and economic way to identify the respiratory sensitization potential of new substances. The aim of the current study was to evaluate the predictive performance of the SARs using a set of respiratory sensitizers and non-sensitizers that were new to the existing SAR models. Additionally, it was explored whether combining the best performing SARs in a tiered approach has added value in terms of predictivity.

\section{MATERIALS AND METHODS}

\section{SAR models for predicting respiratory sensitization}

A literature search was conducted to find SAR models developed for the prediction of respiratory sensitization potential. Both PubMed and Google Scholar were searched for publications between 1990 and 2013 using the following terms: computational, model, respiratory sensitization, SAR, QSAR. Based on title and abstract, three SARs were found; Graham using MultiCASE software [70], Cunningham using cat-SAR [50] and Jarvis using a logistic regression model [71]. These models identify substructures of the chemicals in the respective model training sets, associated with the potential of the chemicals to cause respiratory sensitization. A new chemical is analyzed for the presence of fragments identified from the training set. The presence of activating and inactivating fragments is then used in a computer-optimized algorithm to generate a prediction for the chemical. In addition to these three SAR models, two sets of structural alerts to identify respiratory sensitizers were evaluated: the combined respiratory sensitization and occupational asthma knowledge databases of the Derek Nexus expert system [73] and a set of alerts proposed in a paper by Enoch et al. [51]. For this paper, the alert databases are applied as SAR models i.e. they are also used to predict the absence of respiratory sensitization potential. These five models are shortly described below.

1. Graham et al. [70] used 40 respiratory sensitizers identified from case studies and 40 respiratory non-sensitizers selected on their negative human skin sensitization data to develop a model using the MultiCASE software [74]. An updated implementation of this MultiCASE model to reflect new insights in structure information was developed by the Danish Environmental Protection Agency (DK EPA) to generate information on respiratory sensitization potential. Predictions from the MultiCASE model were obtained from the model developers directly. Several, but not all, predictions are also publically available in an online database [75]. There are no original published data available for the predictive performance of MultiCASE based on the 80 chemicals from Graham, the MultiCASE implementation training set was obtained through personal communication. 
2. The cat-SAR model [50] used the same training set as Graham et al. [70], but applies a different algorithm. Predictions can be obtained from the model developers directly.

3. Jarvis et al. [71] designed a SAR model based on 78 respiratory sensitizers from case studies and a set of 301 respiratory non-sensitizers based on occupational exposure limits. The model is available as a web-based interface [71].

4. The Derek Nexus knowledge base [73] (from this point on referred to as Derek) contains data from published sources. Derek is continuously updated using new data; hence, for the purpose of this study, the training set of Derek is defined as all chemicals that have contributed to defining the respiratory sensitization alerts up to December 2013.

5. Enoch etal. [51] proposed 52 mechanism-based alerts for respiratory sensitization, all based on an analysis of organic chemistry related to the molecular initiating event of covalent binding to proteins. Their training set contained 104 respiratory sensitizers and 82 respiratory non-sensitizers using the same criteria for chemical selection as Jarvis et al. [71].

\section{Compilation of a set of identified respiratory (non-)sensitizers}

To evaluate the performance of the SARs, a dataset of organic LMW chemicals was compiled using the original training sets of the individual SARs and complementary literature sources $[62,76]$. Only organic molecules with a molecular weight lower than $1 \mathrm{kD}$ were selected for this study. All sources considered chemicals as respiratory sensitizers or occupational asthmagens either based on criteria of the US Department of Health and Human Services "Guidelines for Diagnosis and Treatment of Asthma" [77], or because a case of OA was reported in a peer-reviewed report [51, 71]. An additional 17 respiratory sensitizers were identified from the complementary literature sources. For the purpose of this paper, it was assumed that all occupational asthmagens are also respiratory sensitizers.

The criteria defining respiratory non-sensitizers also varied between the SAR models. A chemical was considered a respiratory non-sensitizer when it was either present in the 1994 edition of the UK Health \& Safety Executive's document Occupational exposure limits and no cases of OA were reported in the UK [51,71], or if a substance tested negative for human allergic contact skin sensitizing ability [70]. The first criterion is based on the assumptions that (i) the presence of an occupational exposure limit is evidence that humans have had fairly extensive industrial inhalational exposure, and (ii) a lack of reports on OA due to exposure to these chemicals therefore suggests a lack of respiratory sensitizing potential [51,71]. The second criterion is based on the mechanistic assumption that human skin non-sensitizers will also not be able to induce respiratory sensitization $[50,70]$.

The set of respiratory non-sensitizers was subsequently expanded by adding 168 chemicals that tested negative in the murine Local Lymph Node Assay (LLNA) [78], 
that were not already found in other literature sources and for which structure information was available. These chemicals were included as they are assumed to be lacking the potential to cause respiratory sensitization, as previously suggested among others by Dearman et al. [79]. In total, a dataset of 138 respiratory sensitizers and 521 respiratory non-sensitizers was compiled from all sources to evaluate the predictive performance of the selected models. The list of all chemicals, including their individual references, is given in supplementary table 1 .

\section{Model predictions}

The output of the five SARs is either numerical or textual. MultiCASE predictions are summarized as: POS(itive), NEG(ative) or EQU(ivocal). MultiCASE also applies a strict applicability domain (AD) call as determined by an $\mathrm{AD}$ algorithm from the DK EPA [personal communication]. MultiCASE out-of-domain and equivocal predictions were excluded from our evaluation. The model of Jarvis and the cat-SAR model generate a numerical value between zero and one and both models use a cut-off value of 0.5 to distinguish predicted respiratory sensitizers from non-sensitizers. Derek generates a textual prediction (certain, plausible, probable, equivocal, doubted, improbable, or nothing to report) based on the presence or absence of alerts and the certainty of the evidence used to define the alert. Compounds predicted as 'certain', 'plausible' or 'probable' were considered predicted respiratory sensitizers. Predictions of 'equivocal' were excluded from our analysis. All other outcomes were interpreted as the chemical being predicted a respiratory non-sensitizer. The 52 alerts from Enoch were coded into a manually operable software implementation using Accord for Excel [80]. The presence of any of the 52 alerts was used as an indication that a chemical is predicted to be a respiratory sensitizer, and the absence of all 52 alerts was interpreted as the chemical being predicted a respiratory non-sensitizer. Both Derek and Enoch do not support the interpretation that the absence of any alert indicates that a chemical is a respiratory non-sensitizer, but this was nevertheless used to evaluate the ability of Derek and Enoch to predict the absence of respiratory sensitization potential.

All predictions from all models, as provided in supplementary table 1, were obtained by either applying the model manually or by personal communication with the respective model developers.

\section{Characterization of the predictive performance of respiratory sensitization models}

The predictive performances of the models were characterized using Cooper statistics [81]; sensitivity (correctly predicted respiratory sensitizers as a fraction of the total number of true respiratory sensitizers), specificity (correctly predicted respiratory non-sensitizers as a fraction of the total number of true respiratory non-sensitizers), positive predictive value (PPV, correctly predicted respiratory sensitizers as a fraction of all positive predictions) and negative predictive value (NPV, correctly predicted respiratory non-sensitizers as a fraction of all negative predictions). Sensitivity and 
specificity are an indication of the diagnostic performance of a model [82]; PPV and NPV are a measure of the reliability of a prediction from a model. PPV and NPV are however dependent on the ratio of (true) respiratory sensitizers and non-sensitizers in a dataset, as opposed to sensitivity and specificity. To compare the PPV and NPV derived from different testing datasets, the datasets were scaled to an equal ratio of sensitizers and non-sensitizers. A formal description of these statistics, specifically the use of scaled PPV and NPV, can be found in e.g. [83]. The Jarvis and MultiCASE models were not always able to provide a prediction because these models did not accept all structure information. Furthermore, in the case of cat-SAR, when no fragments associated with activity or inactivity were identified in a test compound, no prediction was made (i.e., cat-SAR does not make default predictions based on lack of evidence). These missing predictions were not taken into account when calculating the statistics.

The performance of each model is visualized in Receiver Operating Characteristic (ROC) plots [84]. These plots illustrate the performance of a model in terms of True Positive Rate (sensitivity) and True Negative Rate (1-specificity), or alternatively, in terms of PPV and 1-NPV. The upper left corner position represents perfect predictive performance. A point on the diagonal represents predictive performance similar to flipping a coin, and the lower right corner position represents a perfect, but inverted, predictive performance. Points above the diagonal therefore represent models that perform better than random. A larger orthogonal distance from the diagonal indicates better predictive performance. This allows for easy visual comparison of the predictive performance of the models.

\section{Evaluation of the predictive performance}

In order to compare the five models, different subsets from the compiled dataset were defined and for each set Cooper statistics were calculated (Table 1). The definitions of the different subsets and their abbreviated names are:

- DD: the Development Dataset is specific for each individual model, and consists of the training set chemicals from each model as published (Jarvis, Cunningham), as obtained through personal communication (Jarvis, MultiCASE) or in the case of Derek as obtained from the incorporated knowledge editor in the Derek Nexus software [73]. The Cooper statistics for the DD were compared to the Published Statistics (PS) to see whether the PS could be reproduced.

- TD: the Test Dataset was specifically designed for each individual model, and consists of all chemicals from our database that were not present in the training set of that specific model. The TD was used to evaluate the prospective predictive performance of a model for a set of unknown chemicals.

- WD: the Whole Dataset consists of all chemicals in our database, regardless whether a chemical was used in the training set of a model or not. The WD was used to compare the overall performance of the models with each other. 
Our manual implementation of the Jarvis model and Enoch alerts, as well as the predictions for the model training sets obtained from the model developers directly, resulted in some differences in predictions with respect to the original published data. In these cases, the manually obtained predictions were used for further evaluations. In addition, for a few chemicals there was conflicting data on whether a chemical is considered a respiratory sensitizer or a non-sensitizer according to the individual model developers. In this case, a positive assignment in the training set of one model overruled a negative assignment for the same chemical from the other model (worst-case approach). These chemicals are commented on in supplementary table 1. The individual models were also analyzed for specific chemical structure applicability domain adequacies and/or deficiencies, using the WD.

\section{Tiered testing approach}

As a proof of concept, a tiered testing approach selecting predictions with the highest reliability was developed. Two models generating predictions on respiratory sensitization potential with the highest reliability were thus selected. The model with the highest predictive value, positive or negative, is selected for the first tier of the approach. The second tier consists of the model with the highest complementary predictive value (if tier 1 consist of the model with the highest PPV, the second tier consist of the model with the highest NPV and vice versa). Additionally, the tiered approach was optimized by compensating for some of the models' deficiencies in their respective applicability domains and by complementing the tiered approach using the adequacies of another model. Combined, the tiered approach is designed to only conclude on the respiratory sensitization potential for those substances where the models are thought to be highly reliable.

\section{RESULTS}

\section{Reproducibility of Published Statistics}

The Published Statistics (PS) from the respective publications based on the individual training sets are given for each model in table 1 . The final column in Table 1 shows the actual number of predictions generated for a specific dataset over the total number of chemicals present in the specific datasets. A complete overview of the calculations leading to the Cooper statistics for each model and for each dataset can be found in supplementary tables 2 to 6 .

The Development Dataset (DD) statistics for each model were compared to the respective Published Statistics (PS), except for Derek and MultiCASE for which no published predictive performance is available (Table 1). The PS of cat-SAR, Jarvis and Enoch were reproducible within $10 \%$ difference. In general, our implementation of the models or the inconsistencies of the reported predictions with those obtained directly from the model developers do not appear to influence the performance of 
Table 1. Cooper statistics for all models and for all chemical datasets

\begin{tabular}{|c|c|c|c|c|c|c|}
\hline Model & Dataset $^{\mathrm{a}}$ & Sensitivity & Specificity & $\mathrm{PPV}^{\mathrm{b}}$ & $\mathrm{NPV}^{\mathrm{b}}$ & Predicted/Total \\
\hline \multirow[t]{4}{*}{ MultiCASE } & PS & $-c$ & $-{ }^{c}$ & $-c$ & $-c$ & $-{ }^{c}$ \\
\hline & $\mathrm{DD}$ & 1.00 & 1.00 & 1.00 & 1.00 & $74 / 80$ \\
\hline & TD & 0.82 & 0.86 & 0.85 & 0.83 & $192 / 579$ \\
\hline & WD & 0.91 & 0.89 & 0.89 & 0.91 & $266 / 659$ \\
\hline \multirow[t]{4}{*}{ cat-SAR } & PS & 0.94 & 0.87 & 0.88 & 0.94 & $75 / 80$ \\
\hline & $\mathrm{DD}$ & 0.97 & 0.97 & 0.97 & 0.97 & $72 / 80$ \\
\hline & $\mathrm{TD}$ & 0.80 & 0.32 & 0.54 & 0.61 & $382 / 579$ \\
\hline & WD & 0.85 & 0.39 & 0.58 & 0.72 & $454 / 659$ \\
\hline \multirow[t]{4}{*}{ Jarvis } & PS & 0.69 & 0.93 & 0.90 & 0.75 & $379 / 379$ \\
\hline & DD & 0.68 & 0.93 & 0.91 & 0.75 & $379 / 379$ \\
\hline & $\mathrm{TD}$ & 0.69 & 0.67 & 0.67 & 0.68 & $275 / 280$ \\
\hline & WD & 0.69 & 0.82 & 0.79 & 0.72 & $654 / 659$ \\
\hline \multirow[t]{4}{*}{ Enoch } & PS & 0.91 & 0.91 & 0.91 & 0.91 & $186 / 186$ \\
\hline & DD & 0.89 & 0.93 & 0.92 & 0.90 & $186 / 186$ \\
\hline & $\mathrm{TD}$ & 0.62 & 0.86 & 0.82 & 0.69 & $473 / 473$ \\
\hline & WD & 0.83 & 0.87 & 0.87 & 0.83 & $659 / 659$ \\
\hline \multirow[t]{4}{*}{ Derek } & PS & $-c$ & $-c$ & $-c$ & $-c$ & $-c$ \\
\hline & DD & 1.00 & $-d$ & $-d$ & $-d$ & $25 / 25$ \\
\hline & $\mathrm{TD}$ & 0.19 & 0.99 & 0.96 & 0.55 & $634 / 634$ \\
\hline & WD & 0.33 & 0.99 & 0.98 & 0.60 & $659 / 659$ \\
\hline
\end{tabular}

a Abbreviations of the datasets: PS: Published Statistics; DD: Development Dataset; TD: Test Dataset; WD: Whole Dataset.

b The PPV and NPV are scaled to a ratio of 50:50 respiratory sensitizers : non-sensitizers.

c There are no original published statistics available for MultiCASE and Derek.

d Statistical value not calculable due to the absence of respiratory non-sensitizers for the specific dataset.

the models significantly. The statistics from the DD are therefore used as a point of reference for further comparisons.

\section{Evaluation of model predictive performance}

The overall performance of the models was calculated using the Whole Dataset (WD) (Table 1). In all cases, the predictivity for this dataset was lower than for the DD, with the exception of the sensitivity of the Jarvis model, which remained the same for the WD compared to the DD. MultiCASE had the largest number of equivocal, out-of-domain or non-predicted substances, 399 out of 659 (61\%), because the MultiCASE implementation of the DK EPA is the only model to apply a rigorous 
applicability domain check. The ability of the models to predict new substances was evaluated by comparing the Test Dataset (TD) statistics to the DD (Table 1). In all cases, the TD statistics were below the $\mathrm{DD}$, again with the exception of the sensitivity of Jarvis. The TD versus DD comparison is illustrated using ROC plots, showing the sensitivity versus 1-specificity (Figure 1) and for the purpose of this study more relevant PPV versus 1-NPV (Figure 2), excluding Derek as for this model only sensitivity could be calculated for the DD. In both figures, the TD performances of all SARs are closer to the diagonal than the DD. The ROC plots also show that the sensitivity of Enoch and the specificity of cat-SAR decreased most when comparing TD to PS (Figure 1). The PPV and NPV of the cat-SAR model decreased the most when comparing TD to PS (Figure 2).

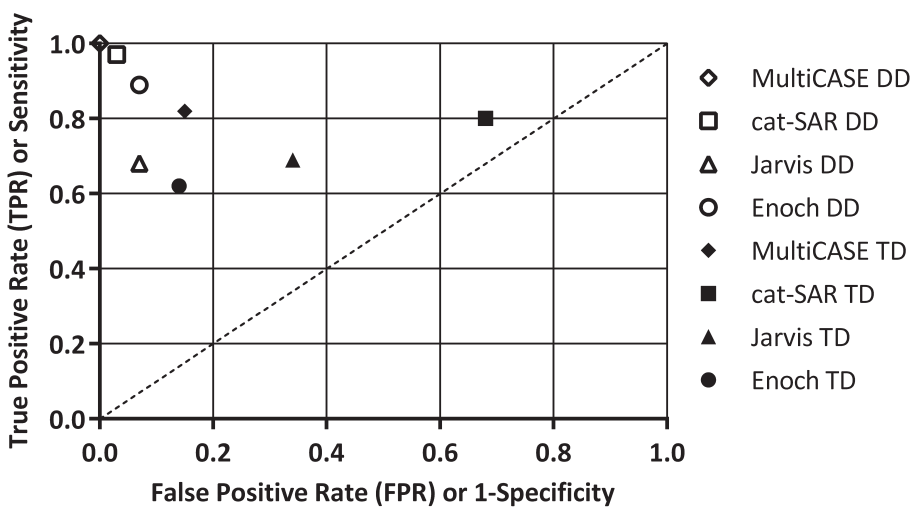

Figure 1. ROC plot using sensitivity versus 1-specificity for the Development Dataset (open markers) and the calculated statistics based on the Test Dataset (solid markers).

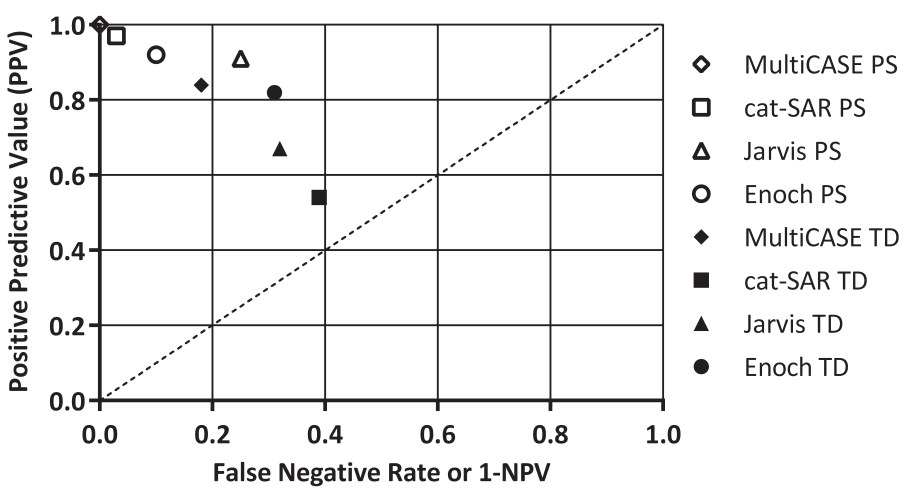

Figure 2. ROC plot using PPV versus 1-NPV for the Development Dataset (open markers) and the calculated statistics based on the Test Dataset (solid markers). 


\section{Chemical applicability domain}

For 26 out of the total 138 respiratory sensitizers, all models gave a positive prediction. The 26 respiratory sensitizers for which all models agreed included nine isocyanates, six anhydrides and six penicillin-like chemicals. For 76 of the 521 respiratory non-sensitizers all models agreed on a negative prediction. Of the 76 respiratory non-sensitizers on which all five models agreed, 31 contained an acetate group, 14 an alcohol group and 11 a ketone group. The other chemicals for which the models agreed on a positive or negative prediction did not share any obvious commonalities in chemical structure. There were no chemicals predicted incorrectly by all models. Therefore, it was analyzed if there were specific chemical classes predicted incorrectly by the individual models. Classes that were often incorrectly predicted by one or more models were: Acrylates, ethanolamines, quinolines, cyclohexenes and carboxylic acids. They are qualitatively discussed in the following sections. Figure 3 shows the shared chemical substructure for these chemical classes.

Acrylates

There are eight respiratory sensitizers and six non-sensitizer present in the WD containing an acrylate functionality. The acrylate and methacrylate alerts from Enoch identify all fourteen chemicals in this class as respiratory sensitizers. Therefore, this alert is defined too general. On the other hand, Derek did not predict any substances in this class to be a respiratory sensitizer, due to the absence of an acrylate alert. MultiCASE correctly classified six acrylates, but did not make a prediction for the other eight acrylates. The cat-SAR model predicted all but one acrylate to be non-sensitizers, with the one positive prediction correct. Jarvis has both correct and incorrect predictions for the acrylate respiratory sensitizers and non-sensitizers.<smiles>[R]OC(=O)C([R])=C</smiles>

Acrylates<smiles>[R]S(N)(=O)=O</smiles>

Sulfonamides<smiles>[R]C(=O)O</smiles>

Carboxilic acids<smiles>[R]N([R])[CH]C([2H])O</smiles>

Ethanolamines<smiles>[R]c1nc2c([R])c([R])c([R])c([R])c2c([R])c1[R]</smiles>

Quinolines

Figure 3. Chemical query structures of the classes observed to be predicted with low reliability by one or more of the SARs. $\mathrm{R}=\mathrm{C}$ or $\mathrm{H}$. 


\section{Ethanolamines}

The WD contains seven ethanolamines that are all confirmed respiratory sensitizers. Derek is the only model that did not correctly identify these, as six out of seven ethanolamines did not contain any Derek alert. Derek does not have an ethanolamine alert and no other alerts were found for these chemicals. Derek correctly predicted the seventh ethanolamine as a respiratory sensitizer based on the 1,2-diamine alert. It can therefore be concluded that ethanolamines present a knowledge gap in the Derek model.

\section{Quinolines}

All quinolines in the WD are respiratory non-sensitizers. Both Enoch and Derek do not contain a quinoline alert and therefore all quinolines are correctly predicted to be non-sensitizers. On the other hand, the cat-SAR model incorrectly predicted all seven quinolines to be respiratory sensitizers indicating that this model is not able to make reliable predictions for this chemical class. MultiCASE did not generate any predictions within the applicability domain for the quinolines.

\section{Cyclohexenes}

Seven out of twenty-one cyclohexenes in the WD are respiratory sensitizers. Enoch contains a cyclohexene alert and therefore predicts all twenty-one chemicals to be respiratory sensitizers. This indicates that the cyclohexene alert of Enoch is defined too broadly. Derek correctly identifies two cyclohexene respiratory sensitizers, but this is based on an anhydride alert. The other cyclohexenes are all predicted to be respiratory non-sensitizers by Derek.

\section{Carboxylic Acids}

There are 25 respiratory sensitizers and 36 non-sensitizers containing a carboxylic acid functionality in the WD. This chemical group attracted attention because all MultiCASE predictions for this chemical class were positive. A MultiCASE prediction was produced for 34 ( 18 respiratory sensitizers and 16 non-sensitizers) out of the total of 61 carboxylic acids. When inspecting these 34 acid-containing chemicals, only four contain a functional group that is potentially reactive towards proteins (5-Hydroxy-4-nitrobenzoic acid, Clopyralid, p-Aminobenzoic acid and anthranilic acid). The other carboxylic acid containing chemicals do not appear to have any other reactive functionality. The MultiCASE predictions for carboxylic acid containing substances are therefore considered unreliable (false positives), and apparently the applicability domain does not indicate these substances (carboxylic acids) to be out of domain.

\section{Statistical applicability domain}

When analyzing the individual Cooper statistics for each model, some models predict respiratory sensitization potential with a high reliability (indicated by a high PPV) while other models predict the absence of respiratory sensitization potential with a high reliability (as indicated by a high NPV). Figure 4 shows that there is no single model 


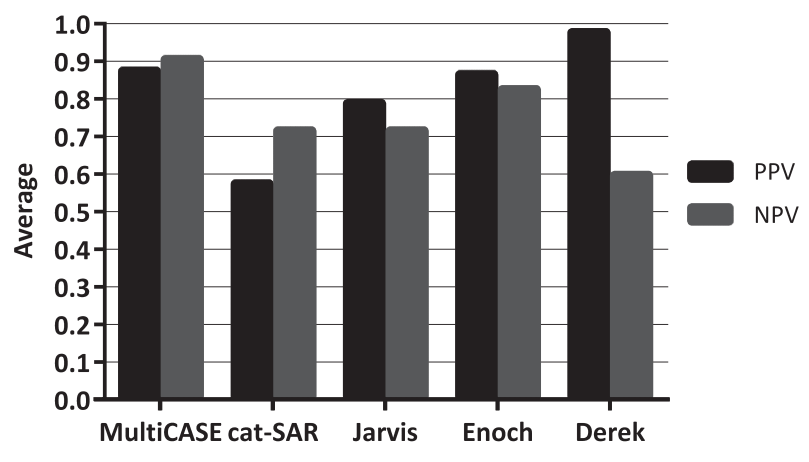

Figure 4. The calculated PPV and NPV based on the Whole Dataset for each model.

that has both a higher PPV and NPV compared to the other models. The PPV of Derek is the highest of all models for the TD as well as the WD, which demonstrates that Derek gives the most reliable prediction of a substance being a respiratory sensitizer. MultiCASE has the highest NPV for both the WD and the TD, indicating that this model gives the most reliable prediction for respiratory non-sensitization. The PPV's and NPV's calculated to determine the best predicting models were scaled to a prior probability of $50 \%$ (an assumption that every compound in 'chemical space' has a $50 \%$ probability of being a respiratory sensitizer).

\section{Tiered approach}

Combining the chemical and statistical applicability domain information, a two-tiered approach based on the existing SAR models was developed and specifically optimized to generate only highly reliable predictions on respiratory sensitization. The model with the highest predictive value for the WD, which is the PPV of Derek, is selected to predict respiratory sensitization potential in the first tier. MultiCASE has the highest NPV for the WD and is therefore selected to predict the absence of respiratory sensitization potential in the second tier. A calculation of the PPV's and NPV's over the whole range of prior probabilities from 0 to 1 shows that Derek always has the highest PPV and MultiCASE always has the highest NPV (Supplementary figures 1 and 2). The selection of Derek and MultiCASE is therefore warranted.

The observed deficiency in the chemical applicability domain of Derek (ethanolamines) can be compensated by adding the ethanolamine alert as defined by Enoch to further improve the tiered approach. It makes sense to use the strengths of other models to complement the tier 1 model (Derek in our tiered approach). To improve tier 1 of the approach, all alerts from Enoch that have a PPV equal to or higher than the PPV from Derek, based on at least 5 chemicals, were added. These alerts are for ethanolamines, ethylenediamines, lactams, anhydrides and diisocyanates. An additional eight chemicals are correctly predicted as respiratory sensitizers by 
the ethanolamine, ethylenediamine and lactam alerts. The anhydride and isocyanates alerts do not add any new predictions to tier 1 compared to Derek. No other alerts or predictions from the other SAR models are found sufficiently reliable to complement Derek.

In tier 1 of the approach, chemicals predicted positive are accepted to be respiratory sensitizers, because of the high PPV of Derek and the selected additional alerts from Enoch. These chemicals therefore do not need to proceed to tier two. Derek predicts 50 of the 659 chemicals in the WD to be respiratory sensitizers. Four of these fifty are false positive predictions (Atrazine, piperazine $\mathrm{HCl}$ and two drug intermediates). The added Enoch alerts to the first tier result in the correct identification of an additional eight respiratory sensitizers. In total, 54 true respiratory sensitizers and 4 false positive respiratory non-sensitizers are identified in tier 1. In tier 2, MultiCASE predicts 175 of the remaining 601 chemicals to be respiratory non-sensitizers; five of these are false negatives (Styrene, 3-carene, p-phenylene diamine, indigotine and TBTU). Exclusion of predictions for carboxylic acid compounds, which were found unreliable, was not relevant for the tiered approach. All remaining carboxylic acid compounds after tier 1 were predicted as respiratory sensitizers by MultiCASE, but only negative predictions of MultiCASE were accepted as sufficiently reliable in tier 2. The complete tiered approach is illustrated in Figure 5. 426 chemicals (65\% of the WD) could not be classified with sufficient reliability by the tiered approach. Based on the 58 positive predictions in the first tier and the 175 negative predictions in the second tier, the scaled PPV and scaled NPV of the tiered approach for the WD are $98 \%$ and $92 \%$ respectively.

The prospective predictive performance of the tiered approach was also estimated using only the TD. Because the TD's from Derek and MultiCASE are not identical, the estimation of the prospective performance is based on only those chemicals that were part of both TD's. This reduced Test Dataset contains 572 chemicals, for which Derek generated 19 positive predictions. Four of those predictions are incorrect. Six additional respiratory sensitizers are identified using the additional alerts from Enoch. For the remaining 547 chemicals, MultiCASE gives 140 negative predictions of which five are false negative. Combined, the tiered approach reliably predicts 165 out of 572 (29\%) chemicals from the reduced Test Dataset with a scaled PPV and NPV of $96 \%$ and $86 \%$ respectively. The tiered approach therefore performs only slightly less in predicting new chemicals compared to the performance on the WD.

Figure 6 shows the ROC plot using PPV and 1-NPV of the WD for all individual models, and the tiered approach. The orthogonal distance of the tiered approach to the diagonal is $12 \%$ larger than for MultiCASE and even 54\% larger than for Derek, which were individually the best performing models for NPV and PPV. The tiered approach therefore has a significantly improved predictive performance compared to any of the individual models. This is achieved by accepting that no sufficiently reliable prediction can be obtained for $65 \%$ of the chemicals. 


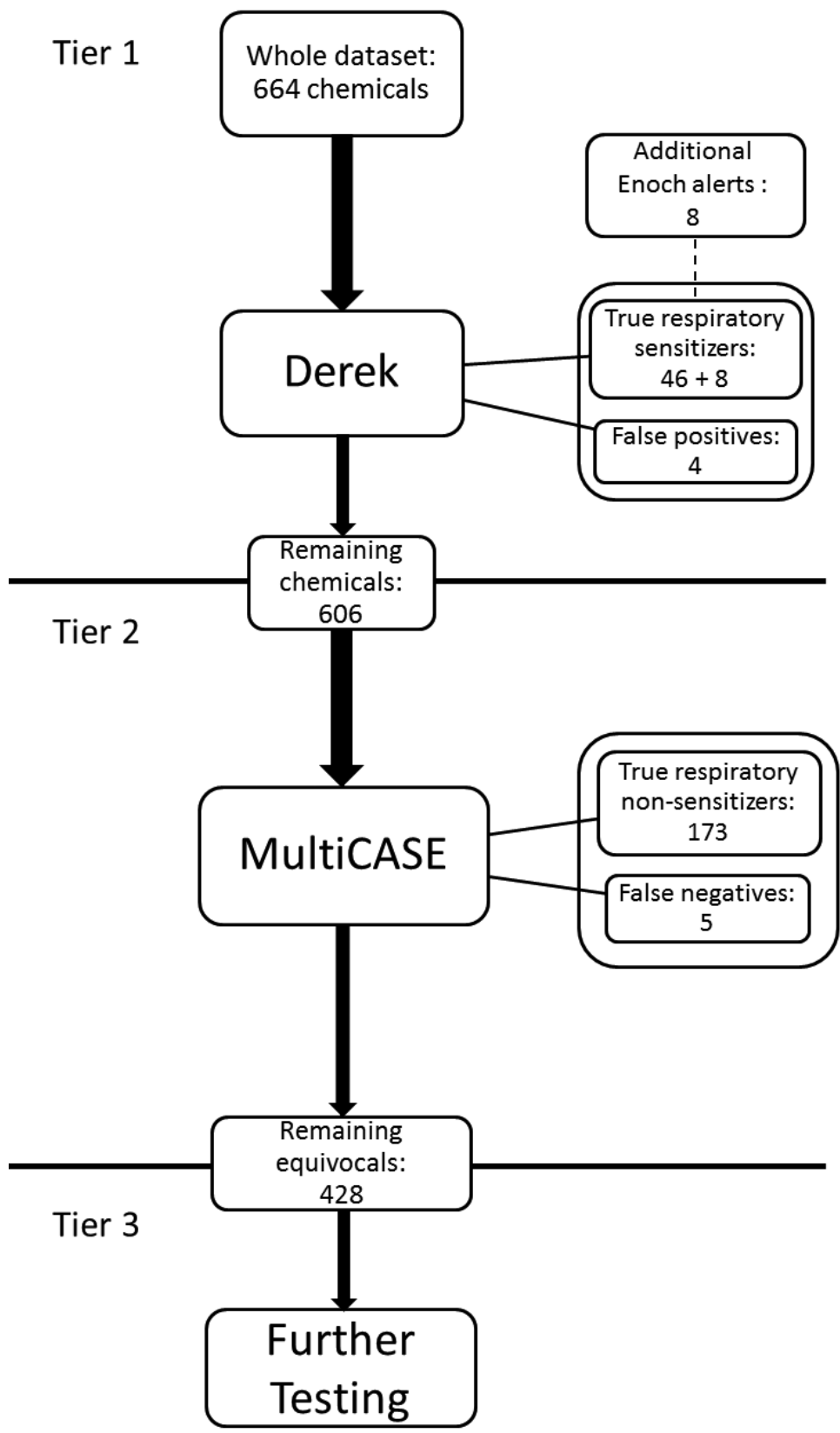

Figure 5. Illustration of a tiered approach using the model with the highest PPV and the model with the highest NPV. The identified deficiencies and adequacies in the applicability domain of the selected models are also taken into account. 


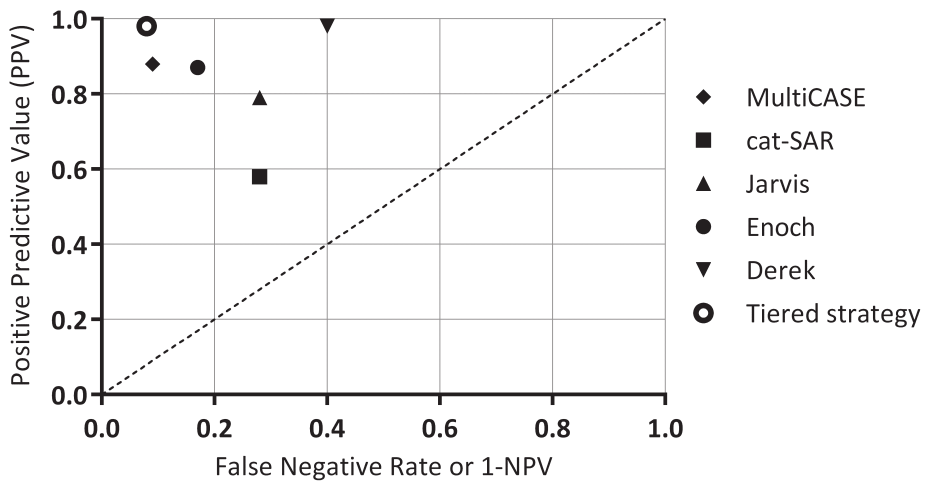

Figure 6. Performance of the individual models and the tiered approach based on the Whole Dataset.

\section{DISCUSSION}

The results of the current study show that the predictive performances of the tested SARs are considerably lower for a new set of chemicals compared to the performance on their own training datasets. It can be concluded that no single SAR model is sufficiently reliable to predict respiratory sensitization. To examine if these models could be improved, one of the aims of this study was to identify deficiencies in the chemical and statistical applicability domains of the existing SARs. One or more models were observed to be less reliable for five chemical classes compared to their overall performance on the WD. This knowledge can be used to improve specific models. The absence of an ethanolamine alert in Derek is an example of this. Additionally, Derek generated four false positive predictions. One is for piperazine dihydrochloride. Its chemical structure makes this substance inherently a respiratory sensitizer, as piperazine in its neutral state is considered a true respiratory sensitizer. Possibly the fact that the substance is presented as a salt reduces its (respiratory) bioavailability so much that it is not able to exert its sensitization potential in vivo. Two other false positives of Derek are precursors in the synthesis of the drug Pazopanib. They were categorized to be respiratory non-sensitizers based on negative test data in the LLNA, but predicted to be respiratory sensitizers due to the presence of a halo-diazine or triazine ring. This alert might therefore need additional evaluation, or limitation of its applicability domain. The fourth false positive of Derek is atrazine, for which no explanation could be determined. There are no apparent explanations for the five misclassifications of MultiCASE.

MultiCASE predicted several carboxylic acid-containing chemicals to be respiratory sensitizers while they are non-sensitizers. One explanation for the observed misclassifications in this group is the possibility that these acid-containing chemicals act as respiratory tract irritants, instead of respiratory sensitizers, as the underlying 
mechanisms are difficult to distinguish in a clinical setting [85]. Carboxylic acid-containing chemicals are most likely a group of occupational asthmagens that do not induce hypersensitivity of the lung through an immunological reaction. Enoch et al. [51] also specifically states that carboxylic acids are possibly incorrectly identified as true respiratory sensitizers instead of occupational asthmagens causing a non-immunological hypersensitivity reaction. Additionally, carboxylic acids lack a chemical mechanism through which they can covalently bind to proteins [51], which is required for a chemical to cause sensitization [86]. The carboxylic acid containing respiratory sensitizers that were correctly predicted by MultiCASE contained one or more other functionalities that are probably responsible for the sensitizing capabilities of those chemicals. For these reasons, theoretical predictions of respiratory sensitization potential for this class of chemicals might in general be unreliable. Additionally, more insight in the cause of occupational asthma (immunological versus non-immunological) is still needed for these substances.

The criteria used for defining respiratory non-sensitizers in the original model publications differed considerably. Jarvis and Enoch used occupational exposure limits (OELs) to define respiratory non-sensitizers while cat-SAR and MultiCASE used a mechanistic explanation that negative human skin sensitization data implied that the chemical would also be a respiratory non-sensitizer. Additionally, based on the work of Dearman et al. [79], a large set of LLNA negative skin sensitizers were added to the dataset by us, to further increase the number of chemicals for evaluation of the SAR models. These different assignment definitions of respiratory non-sensitizers have their limitations. For example, Jarvis and Enoch implicitly assume that sensitized workers who are exposed to a LMW respiratory sensitizer will always report to a clinic. However, this might not always be true. This is demonstrated by Malo [25] who showed that many workers do not apply for compensation because the financial benefits are often very low and applying for compensation may even cause a situation where workers might suffer employment prejudice. In addition, a correct diagnosis of OA is challenging, because it is difficult to distinguish a case as occupational, instead of non-occupational asthma [87].

One possible argument against the assumption that a negative result for a LMW chemical in the murine LLNA test is predictive of absence of respiratory sensitization potential is that if a chemical does not penetrate the skin, it will not elicit a response in the LLNA test. This does not guarantee that the same chemical, if inhaled, will not induce respiratory sensitization. However, a calculation of the dermal permeability rate (Kp) using MW and octanol-water partition coefficients [88] for all chemicals used in this study reveals that there is no clear difference between the dermal permeability rates of LLNA negative chemicals, human skin negative chemicals, OEL negative chemicals and respiratory sensitizers (data not shown). The low correlation between sensitization potential and generic chemical properties, such as $\mathrm{Kp}$, was for example also shown for aldehydes [89]. This implies that a negative result in the LLNA is not necessarily 
influenced by skin absorption. Additionally, there are no examples of organic LMW respiratory sensitizers that do not also give a positive result in the LLNA. Therefore, it is a plausible assumption that chemicals in the Whole Dataset that give a negative result in the LLNA are also respiratory non-sensitizers.

A calculation of the performances of the SAR models (Supplementary tables 7 to 11) using separate sets of negative respiratory sensitization data (OEL negatives versus LLNA negatives) shows that for Enoch, Derek and cat-SAR there are no significant differences in performance between the OEL negatives and LLNA negatives. Jarvis performs better on OEL negatives, which can be explained because this model is trained using these chemicals. MultiCASE also performs better on OEL negatives, but when examining the predictions of MultiCASE, the majority of false positives within the LLNA negative dataset are carboxylic acid-containing chemicals. As discussed, theoretical predictions for carboxylic acid-containing chemicals should be taken with great care. If these predictions, for this reason, are omitted form the calculations, the performance of MultiCASE on LLNA negatives equals its performance on OEL negatives. The above-mentioned considerations suggest that both sets of chemicals can be used for this study as respiratory non-sensitizers.

This paper shows that taking the most reliable predictions from two complementary models in a tiered approach yields a combined predictive performance that might be considered sufficient for regulatory purposes. However, it needs to be considered that 1 ) for a substantial part of the chemicals information is limited to reach a final conclusion on respiratory sensitization potential and 2) a decision on the mechanistic cause (immunological or non-immunological) of occupational asthma will also require more information. It is doubtful whether a higher reliability is achievable through additional testing for the 233 substances for which the SAR information was considered conclusive, using the tiered approach. However, other test methods, such as in vitro or in chemico methods, could further complement the outcomes of this tiered SAR approach and address other key events involved in respiratory sensitization. As the proposed tiered approach is not conclusive on the respiratory sensitization potential of $65 \%$ of the chemicals tested in this evaluation, additional test methods are clearly needed. Our research is currently aiming at the development of additional animal-free testing methods (in chemico and in vitro) to complement the tiered approach proposed in this paper. The use of an Integrated Testing Strategy incorporating further testing methods will hopefully allow for reliable prediction of the majority of the chemicals not predicted sufficiently reliable by the proposed SAR-based tiered approach.

\section{SUPPLEMENTARY MATERIALS}

All supplementary tables and figures that are mentioned in this chapter can be obtained from: https://academic.oup.com/toxsci/article/142/2/385/3064899\#supplem entary-data 




\section{H A P T E R 3}

CAN THE DIRECT PEPTIDE REACTIVITY ASSAY BE USED FOR THE IDENTIFICATION OF RESPIRATORY SENSITIZATION POTENTIAL OF CHEMICALS? 


\section{ABSTRACT}

Prospective identification of low molecular weight (LMW) respiratory sensitizers is difficult due to the current lack of adequate test methods. The direct peptide reactivity assay (DPRA) seems to be a promising method to determine the sensitization potential of chemicals, since it determines the intrinsic characteristic of sensitizers to bind to proteins. It is already applied in the field of skin sensitization and adaptation to respiratory sensitization has started recently. This paper further evaluates the ability of the DPRA to predict the respiratory sensitization potential of chemicals. In addition, the added value of applying HPLC-MS and measurements after 20 minutes and 24 hours of incubation was evaluated. Eighteen respiratory sensitizers (10 haptens, 3 pre- and 5 pro-haptens) and fourteen non-sensitizers were tested with two model peptides. Based on peptide depletion, a prediction model was proposed for the identification of (respiratory) sensitizers. Application of mass spectrometry and measurements at two time-points increased prediction accuracy of the assay by resolving discordant results. The prediction model correctly identified all haptens and pre-haptens as sensitizers. The five pro-haptens were not identified as sensitizers, most likely due to lack of metabolic activity in the DPRA. All but one non-sensitizer were correctly predicted. The model therefore shows an accuracy of $78 \%$ for the tested dataset. Unfortunately, this assay cannot be used to distinguish respiratory from skin sensitizers. To make this distinction, the DPRA needs to be combined with other test methods that are able to identify respiratory sensitizers. 


\section{INTRODUCTION}

Exposure to low molecular weight (LMW) respiratory sensitizers [14] occurs mostly at the workplace, such as in chemical plants and hospitals [18, 20, 24, 90] and can lead to occupational asthma (OA). OA is considered an important occupational health issue [21] which is implicated in roughly $15 \%$ of all adult asthma cases $[8,9]$. There are however no widely accepted methods available to identify potential respiratory sensitizers [91]. This is mainly due to uncertainty in the underlying immunological mechanisms resulting in respiratory sensitization. Some in vivo [45], in vitro [67] and in silico $[50,51,70,71]$ test methods have been described in literature, but none are extensively validated nor widely accepted.

In previous work, we evaluated several in silico models for the prediction of respiratory sensitization potential of chemicals. It was concluded that none of the models should be used individually to predict respiratory sensitization. However, a combination of models in a tiered approach resulted in the generation of highly reliable predictions. The drawback was that only for one third of the chemicals reliable predictions could be generated and for the majority of chemicals subsequent testing methods are required [92]. Hence, in silico models can be used as a first assessment of chemicals in a testing strategy that aims to identify respiratory sensitizers, but clearly there is a need for other (in chemico or in vitro) methods.

One method in development to identify respiratory sensitizers is based on the direct peptide reactivity assay (DPRA) for skin sensitizers. The DPRA measures peptide binding, which is considered the molecular initiating event of the Adverse Outcome Pathway for skin sensitization [93]. It is proposed that the same is true for respiratory sensitization [35]. Therefore, a modified DPRA protocol was developed for identification of respiratory sensitizers [54]. The outcome of these experiments was that respiratory sensitizers give rise to peptide depletion just as skin sensitizers do [54]. However, from a regulatory point of view, it would be preferable to distinguish skin from respiratory sensitizers. This distinction is not easily made, as exemplified in the murine local lymph node assay (LLNA). The LLNA was designed to identify skin sensitizers but in general also tests positive for respiratory sensitizers, The inclusion of an additional read-out in the LLNA, that allows cytokine profiling, makes it possible to distinguish respiratory from skin sensitizers (Vandebriel, et al., 2010) [79].

Using the DPRA, it was suggested that peptide-binding preference allows to make a distinction between respiratory sensitizers and skin sensitizers [54]. Respiratory sensitizers were hypothesized to preferentially bind lysine-containing peptides and skin sensitizers cysteine-containing peptides [54]. However, only anhydrides preferentially bound lysine-containing peptides while the other respiratory sensitizers did not seem to show this preference. In addition, lysine binding preference of respiratory sensitizers was not reproduced by later work from the same authors [94]. These findings do not support a general binding preference of respiratory sensitizers. Therefore, more insights 
in the reaction chemistry of respiratory sensitizers are required if this group is to be identified within the larger group of skin sensitizers.

The standard DPRA protocol as formalized in an OECD Test Guideline for skin sensitization [95] only measures peptide depletion after 24 hours of incubation. Although this should be indicative for reactivity, it does not provide information regarding kinetics, which is shown to correlate with potency in case of skin sensitizers $[96,97]$. Additionally, the use of UV spectrometry does not allow for identification of reaction products. This identification is not required to determine protein reactivity. However, the identification of a reaction product increases the certainty that peptide depletion occurred due to binding of a test chemical to the model peptide. In addition, product formation analysis might provide insights in reaction mechanisms that can contribute to the refinement of in silico reactivity alerts specifically associated with respiratory sensitizers $[51,92,98]$.

The aims of this study were: 1 ) To further investigate the applicability of the DPRA to identify respiratory sensitizers and 2) To evaluate the use of mass spectrometry (MS) and peptide depletion measurements at two time-points to increase the certainty of predictions.

\section{MATERIALS AND METHODS}

\section{Test chemicals and materials}

To evaluate the applicability of the DPRA to identify respiratory sensitization potential, a test set consisting of eighteen respiratory sensitizers and fourteen non-sensitizers was used (Table 1). Fourteen of these respiratory sensitizers and three of these respiratory non-sensitizers were correctly predicted by our previously published in silico tiered approach. The other 15 chemicals were predicted equivocal and therefore require additional information [92]. The criteria for defining substances as respiratory sensitizers or non-sensitizers have been described previously [92]. In short, chemicals were considered respiratory sensitizers based on peer-reviewed case reports of OA $[51,71]$ or based on criteria of the US Department of Health and Human Services "Guidelines for Diagnosis and Treatment of Asthma" [77]. The availability and strength of data on the respiratory sensitizers used in this study is given in Table 1 and is based on the evaluation of 88 chemicals by Bloemen et al. [62] or the individual chemical data files created by Jarvis et al. [71]. The latter includes number of cases and publications for 84 LMW chemicals.

A chemical was considered a respiratory non-sensitizer if the substance tested negative for human allergic contact skin sensitizing ability [70], when it was tested negative in the murine local lymph node assay [92] or when it was present in the 1994 edition of the UK Health \& Safety Executive's document Occupational exposure limits combined with a lack of reported cases of OA in the UK [51, 71]. Resorcinol is considered a respiratory non-sensitizer based on these criteria, but it is also a weak 
skin sensitizer (Basketter, et al., 2007). Additional non-sensitizers that were tested in the current study but not in our in silico evaluation study are mannitol, methyl paraben and lactose. Mannitol is a non-reactive chemical that causes bronchoconstriction through a non-immunogenic mechanism [99]. Methyl paraben has been extensively reviewed and was found to be non-sensitizing in skin or through ingestion [100]. Furthermore, it is structurally similar to propyl paraben which tested negative in the murine LLNA for skin sensitization [101]. Lactose is frequently used as a negative control in inhalation challenge testing.

Two of the respiratory non-sensitizers (acetic acid and adipic acid) were categorized as respiratory sensitizers by references cited in [92], but based on the same study and evidence from in silico analysis by Enoch et al. [51] it can be concluded that these chemicals are more likely to be respiratory irritants instead of true respiratory sensitizers.

The eighteen respiratory sensitizers selected for evaluation in this study can be divided into three categories [102, 103]:

1. Haptens (10): Chemicals that can form a covalent bond with proteins without activation of the chemical.

2. Pre-haptens (3): Sensitizers that need to be transformed by abiotic processes (e.g. oxidation) before they become reactive towards proteins. The pre-haptens selected for this study are chloramine-T, para-phenylenediamine (PPD) and hydroquinone. Chloramine-T becomes reactive after it is dissolved in water; PPD and hydroquinone require oxidation to become reactive towards proteins. These pre-haptens were included to examine whether auto-oxidation and hydrolysis occur to a significant degree during the tests.

3. Pro-haptens (5): Sensitizers that require metabolization by enzymes (metabolic activation) before they become reactive towards proteins. The pro-haptens selected for this study are diethanolamine, dimethylethanolamine, ethanolamine, ethylenediamine and triethylenetetramine. They all contain one or more amine groups (primary, secondary and tertiary amines), which theoretically should undergo oxidative deamination before they become reactive towards proteins $[29,51]$.

The following test chemicals were obtained from Merck (Darmstadt, Germany): Acetic acid and Diethanolamine. Vanillin was obtained from Acros Organics (Morris Plains, NY, USA) and chlorendic anhydride was obtained from Brunschwig Chemie (Amsterdam, The Netherlands). All other test chemicals were obtained from Sigma-Aldrich (St. Louis, MO, USA).

Ammonium acetate, ammonium hydroxide, sodium phosphate monobasic and sodium phosphate dibasic, used for preparation of the buffer solutions were obtained from Sigma-Aldrich (St. Louis, MO, USA). HPLC grade acetonitrile (>99.9\%) was 


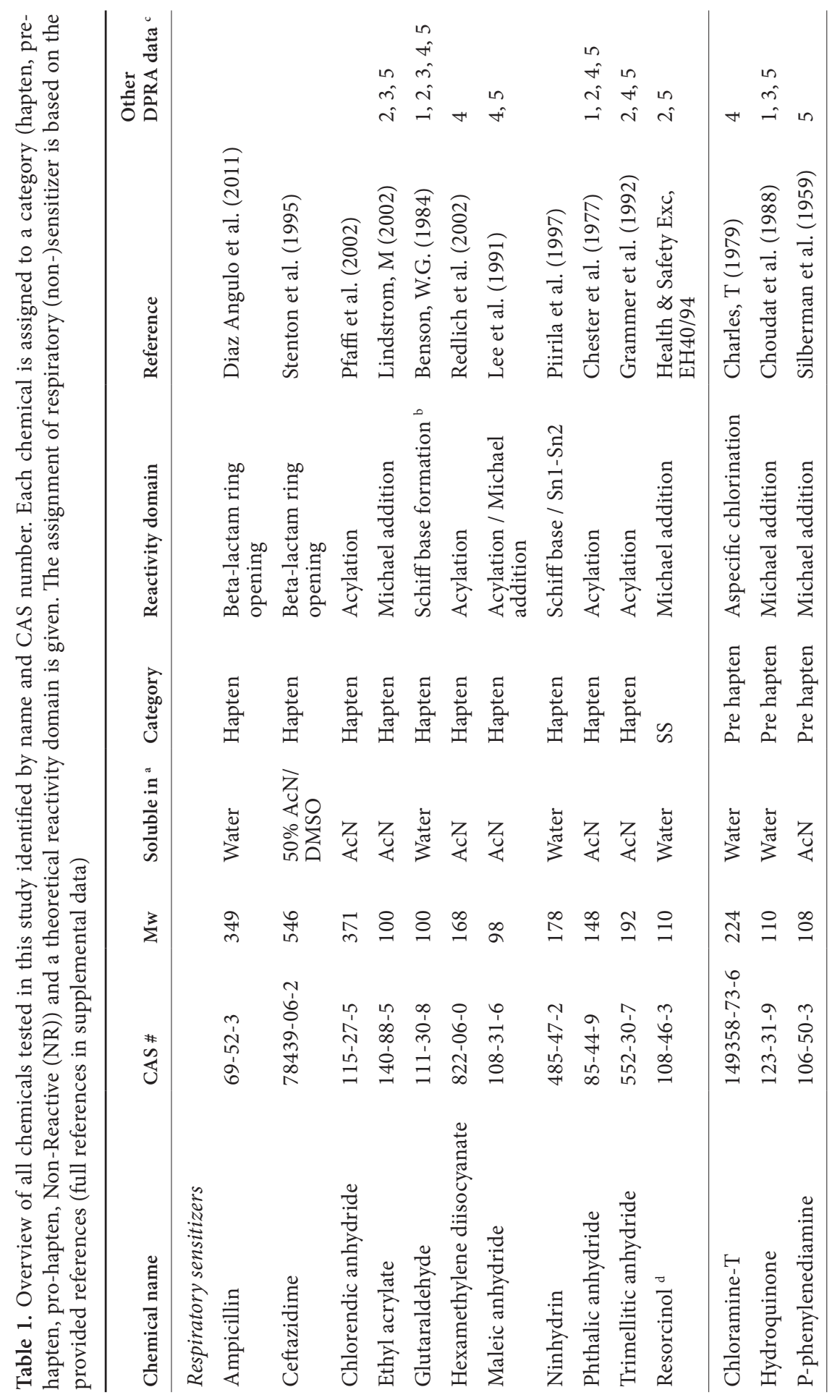




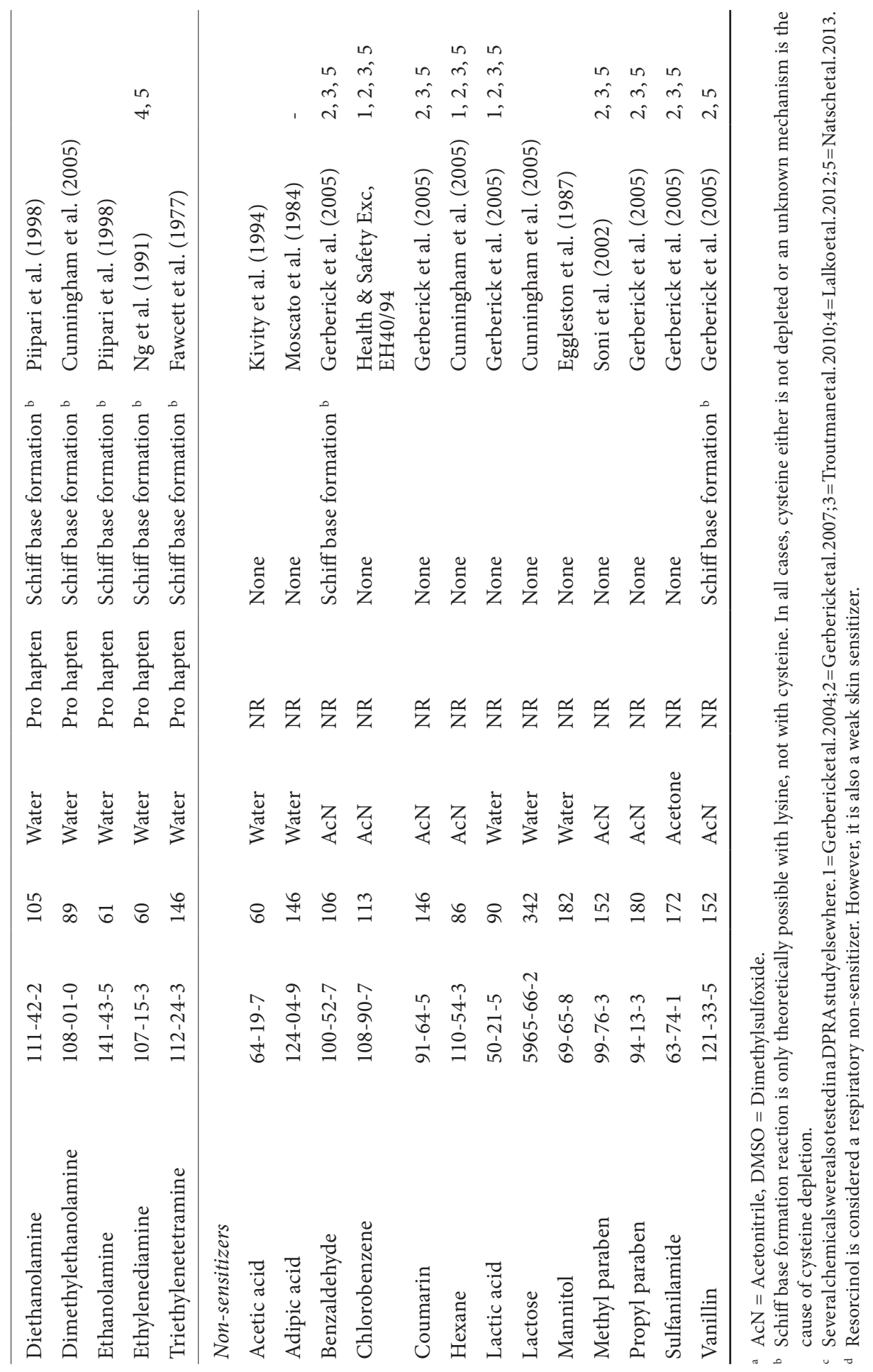

3 
purchased from Biosolve (Valkenswaard, The Netherlands). HPLC grade trifluoroacetic acid (TFA, >99\%) was obtained from Acros Organics (Morris Plains, NY, USA).

The heptapeptides containing lysine (Ac-RFAAKAA-COOH) and cysteine (Ac-RFAACAA-COOH), serving as model proteins in the DPRA, were obtained from JPT Peptide Technologies GmbH (Berlin, Germany) with a purity of $>98 \%$.

\section{Direct peptide reactivity assay}

The DPRA was performed based on protocols described by Gerberick et al. [104] and Natsch et al. [96] using two model peptides. Both peptides consist of six identical amino acids (one arginine, one phenylalanine and four alanine residues) and one amino acid that is different (this amino acid is either cysteine or lysine). Peptide stock solutions were prepared to a final concentration of $0.667 \mathrm{mM}$ in either a $100 \mathrm{mM}$ ammonium acetate buffer ( $\mathrm{pH}$ of 10.2) for the lysine-containing peptide or a $100 \mathrm{mM}$ phosphate buffer ( $\mathrm{pH}$ of 7.5 ) for the cysteine-containing peptide (from now on referred to as lysine and cysteine). Test chemical stock solutions were prepared to a concentration of $100 \mathrm{mM}$ in the appropriate solvents (see Table 1). All stock solutions were prepared 0.5-1 hour before use. Cysteine and lysine solutions were mixed with a test chemical in a ratio of 1:10 $(\mathrm{mol} / \mathrm{mol})$ for cysteine and 1:50 $(\mathrm{mol} / \mathrm{mol})$ for lysine. Each reaction was performed in triplicate. The mixtures were incubated for twenty minutes at $25{ }^{\circ} \mathrm{C}$ before the first analysis. After the first analysis, the mixture was allowed to incubate for 24 hours at $25^{\circ} \mathrm{C}$ before a second analysis was performed.

Separation was achieved using a $0.6 \mathrm{ml} / \mathrm{min}$ flow rate with a gradient of mobile phase A $(0.1 \% \mathrm{vol} / \mathrm{vol}$ TFA in water $)$ and mobile phase B ( $0.085 \% \mathrm{vol} / \mathrm{vol}$ TFA in acetonitrile) over a 9 minute period. The gradient was adjusted from $95 \%$ A/5\% B to $10 \%$ A/90\% $\mathrm{B}$ during the first 7 minutes. This state was not changed for 30 seconds, after which the gradient was returned to $95 \%$ A/5\% B immediately. The column was equilibrated for 1.5 minute before starting the next sample injection. The reaction mixture was analyzed for unreacted peptide and potential reaction products by reverse-phase liquid chromatography-mass spectrometry (LC-MS). The mass spectrum was collected from 300 to 1600 amu using electrospray ionization in positive mode. The data were evaluated using Thermo Xcalibur Quan Browser (v. 3.0.63), which is software for automated peak identification and integration. All peaks were also checked manually and manual peak integration was performed if the automated peak detection failed.

Depletion of cysteine and lysine was measured 20 minutes and 24 hours after incubation with a test chemical. Depletion was quantified by comparing the respective area under the curve (AUC) for the peptide peak in the MS chromatogram after incubation compared to the average AUC of the associated reference control peptides at the same time-point. The percentage change in the AUC is taken as percentage depletion of the model peptides. Three separate reference control peptides were measured prior to each triplicate measurement of a test chemical to allow for 
a time-independent comparison. All calculated negative depletion values were interpreted as $0 \%$ depletion.

All samples were also examined for reaction products. The masses of all newly formed peaks were analyzed using Thermo Xcalibur Qual Browser (v. 3.0.63).

\section{Prediction model}

\section{Cut-off values for depletion}

A prediction model was proposed to distinguish respiratory sensitizers from non-sensitizers based on the OECD (Organisation for Economic Co-operation and Development) Test Guideline (TG) 442C for the DPRA [95]. This test guideline predicts skin sensitization potential of chemicals based on the mean depletion value of lysine and cysteine after 24 hours of incubation. In cases where co-elution occurs with only the lysine peptide, a cysteine-only prediction model is used. The OECD TG 442C [95] defines two cut-off values to discriminate non-sensitizers from skin sensitizers. In the model using the mean of cysteine and lysine, the cut-off is set at $6.38 \%$. For the cysteine-only model the cut-off is set at $13.89 \%$. No lysine-only model is provided.

In contrast to the procedure from the OECD TG, the current study aimed to identify respiratory sensitizers, and therefore the depletion of each model peptide was evaluated separately in all cases. Cut-off values for cysteine and lysine depletion were chosen in order to give the prediction model the highest average positive predictive value (PPV) and negative predictive value (NPV) based on our dataset. This approach was chosen to be in line with our previous work [92]; when a prediction is made, the certainty that it is a correct prediction (positive and negative) should be as high as possible. The highest average PPV and NPV were obtained when for cysteine the cut-off was set between $14 \%$ and $22 \%$, and for lysine between $18 \%$ and $19 \%$. Following a conservative approach for the prediction model, they were subsequently set at the lower reactivity cut-off values of $14 \%$ and $18 \%$ respectively.

Prediction model

A test chemical was predicted to be a respiratory sensitizer if two criteria were fulfilled:

- The percentage depletion is above the cut-off value for cysteine (14\%) or lysine $(18 \%)$ in all replicates at $20 \mathrm{~min}$ or $24 \mathrm{~h}$.

- MS analysis confirms the formation of at least one reaction product, of which the mass must exceed the mass of the model peptide alone (see supplemental data for examples).

A test chemical is classified as non-reactive when:

- The percentage depletion of both peptides is below the cut-off value for cysteine and lysine in all replicates at both time-points.

- No reaction products can be found using MS at either time-point. 


\section{Discordant results and MS}

When replicates resulted in discordant results, the MS data were further analyzed to come to a consensus conclusion. Four possible combinations of discordant results are possible, of which the first two were found in this study:

1. Two out of three replicates show sufficient depletion, the third replicate does not. MS analysis reveals the same reaction products in all three replicates.

The chemical is predicted to be a respiratory sensitizer because it is capable of forming the same reaction product(s) in all three replicates; it failed to do so in sufficient amounts in just one sample.

2. Only one replicate shows sufficient depletion, the other two do not. MS analysis does not reveal a possible reaction product.

The observed depletion in one replicate is considered to be an outlier due to the lack of a reaction product in all three replicates and therefore the chemical is considered non-reactive.

3. Two out of three replicates show sufficient depletion, the third replicate does not. MS analysis does not reveal the same or no reaction products in the outlier.

4. Only one replicate shows sufficient depletion, the other two do not. MS analysis reveals one or more reaction products.

Both in cases 3 and 4, the result is equivocal and additional testing is required to conclude on the respiratory sensitization potential for these chemicals.

\section{RESULTS}

\section{Peptide depletion}

Peptide depletion after twenty minutes

Peptide depletion values for all test chemicals after twenty minutes of incubation can be found in Table 2. Of the ten haptens tested, only ampicillin did not induce sufficient peptide depletion after 20 minutes to be considered a respiratory sensitizer by the prediction model. The pre-hapten PPD and all pro-haptens showed lower peptide depletion than the cut-off values for cysteine and lysine. Overall, the non-sensitizers also showed low levels of peptide depletion, including the skin sensitizer resorcinol. For most chemicals, variability within the triplicate measurements was minor ( $\pm 10 \%$ variability in calculated percentage depletion). One notable exception is the non-sensitizer methyl paraben. In this case, one of the cysteine triplicates showed markedly higher depletion compared to the other replicates. This is discussed in the section on discordant results after twenty minutes.

Peptide depletion after 24 hours

Peptide depletion after 24 hours of incubation (Table 3) shows that the respiratory sensitizer ampicillin and the pre-hapten PPD both induced a higher percentage peptide depletion compared to the first time-point. Therefore, based on the 24 hour 
measurement, both ampicillin and PPD are considered respiratory sensitizers by the prediction model. Interestingly, phthalic anhydride, chlorendic anhydride and trimellitic anhydride all show less cysteine depletion after 24 hours of incubation compared to the 20-minute measurements. Whereas all three chemicals showed sufficient depletion to be predicted as respiratory sensitizers after 20 minutes of incubation, chlorendic anhydride would be considered a non-reactive chemical based on only the 24-hour measurement. This shows the added value of measuring peptide depletion at (at least) two time-points, as chlorendic anhydride shows its expected reactivity only at the 20-minute measurement. An explanation for the "reversal" based on our obtained data is not possible to provide, although it could be possible that the anhydride-peptide bonds are slowly hydrolyzed during the incubation period. In contrast to the pre-haptens that showed increased levels of peptide depletion after 24 hours, all pro-haptens failed to induce more than $10 \%$ peptide depletion. This can be attributed to the fact that pro-haptens cannot be activated by the standard DPRA. All non-sensitizers, with the exception of vanillin, are still considered non-reactive after 24 hours as they still do not show levels of peptide depletion above the cut-off values. The depletion of lysine by vanillin was markedly higher after 24 hours compared to 20 minutes of incubation and therefore vanillin is predicted as a respiratory sensitizer by the prediction model. The overall reproducibility of the triplicate measurements after 24 hours is comparable to the 20-minute measurement.

Discordant results after 20 minutes

The 20-minute depletion values show discordant results within the triplicate measurements of ceftazidime, acetic acid, methyl paraben and P-phenylenediamine. The outlier for ceftazidime (only 13\% depletion with cysteine) was found to contain the same reaction products as the other two replicates (24\% and $28 \%$ depletion). Additionally, ceftazidime sufficiently depleted all three lysine replicates. Therefore, ceftazidime was considered a respiratory sensitizer based on peptide depletion after 20 minutes. For methyl paraben and acetic acid, no reaction products could be identified in the outlying samples. After 24 hours, no reaction products in the outlier for methyl paraben could be identified. In the case of acetic acid, after 24 hours, the triplicate measurements of acetic were all negative. Therefore, both chemicals were therefore considered to be non-reactive.

Discordant results after 24 hours

After 24 hours of incubation, ampicillin, resorcinol, mannitol, benzaldehyde and sulfanilamide showed discordant results. One replicate sample of both mannitol and benzaldehyde showed cysteine depletion values above the threshold. However, no reaction products could be identified and therefore these chemicals were considered non-reactive. The same holds true for resorcinol and sulfanilamide, both showing one of the replicate samples with lysine depletion above the lysine threshold. Again, no reaction products could be identified. As resorcinol is a weak skin sensitizer in addition 


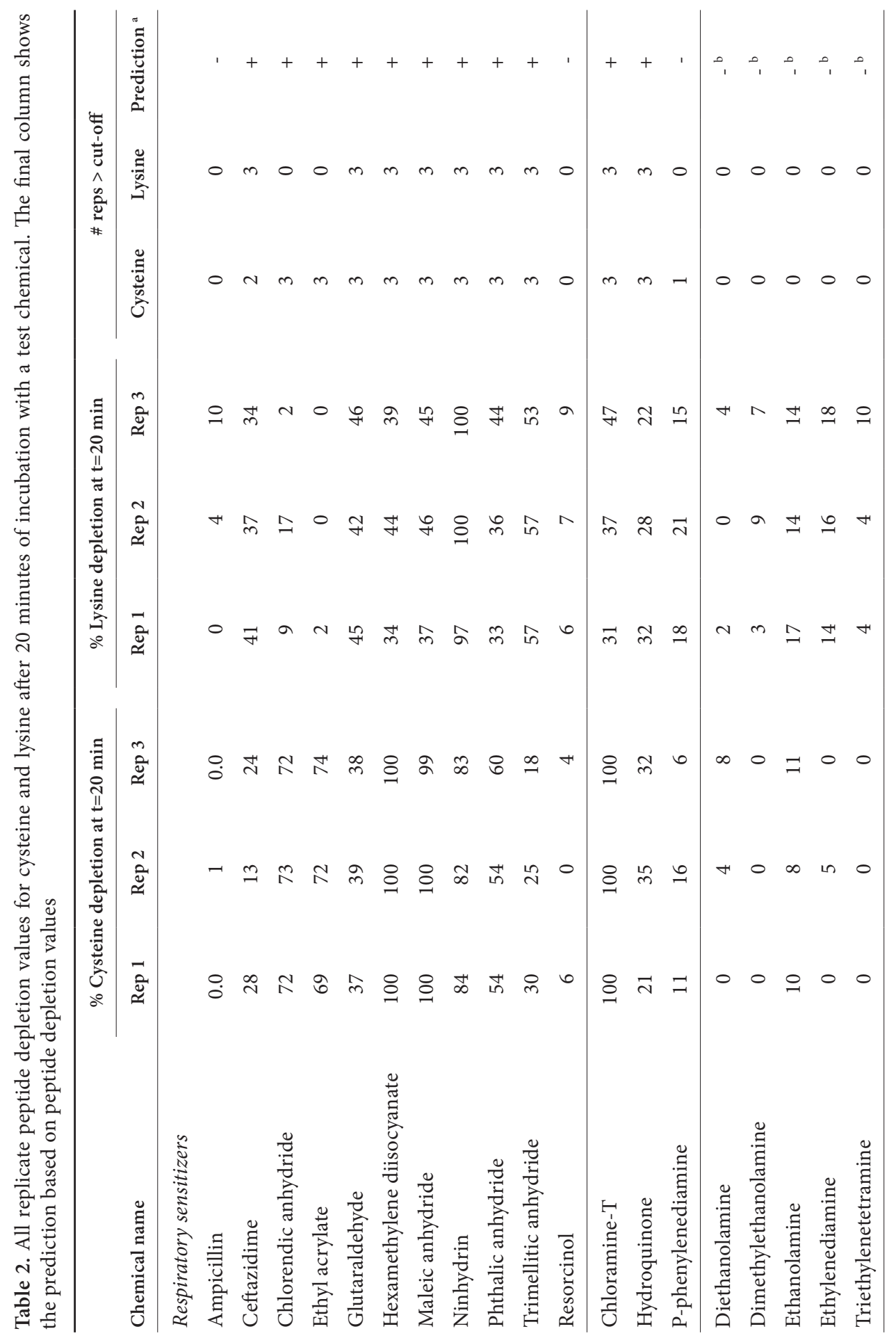




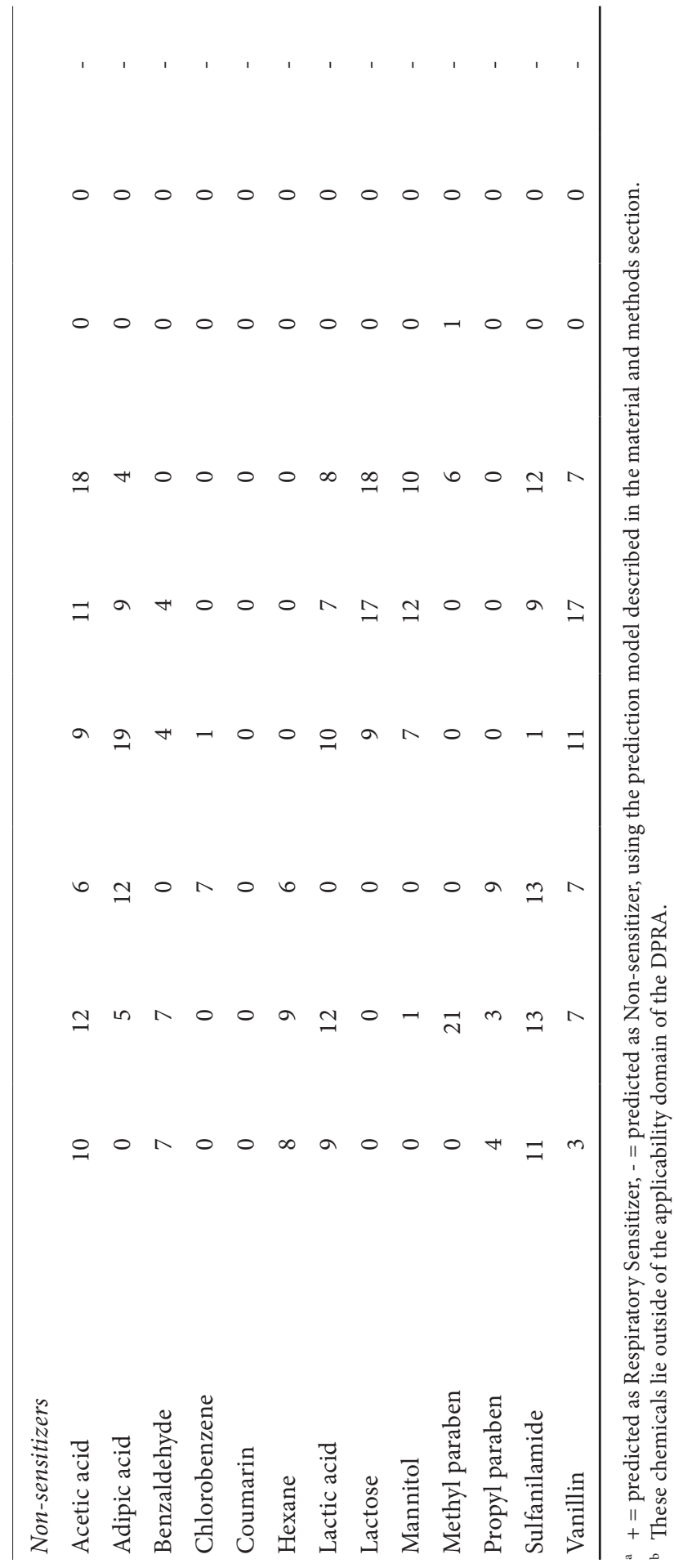




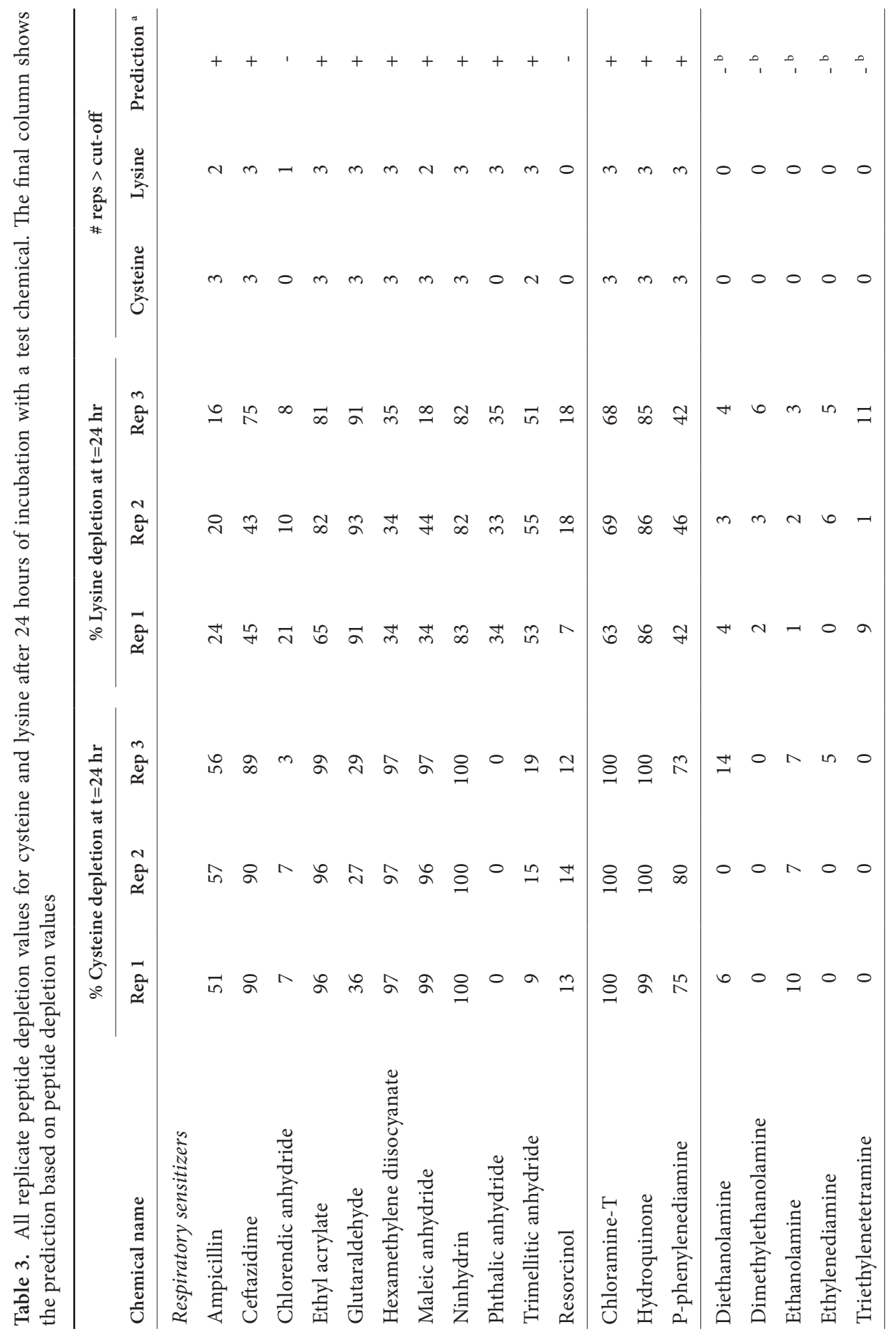




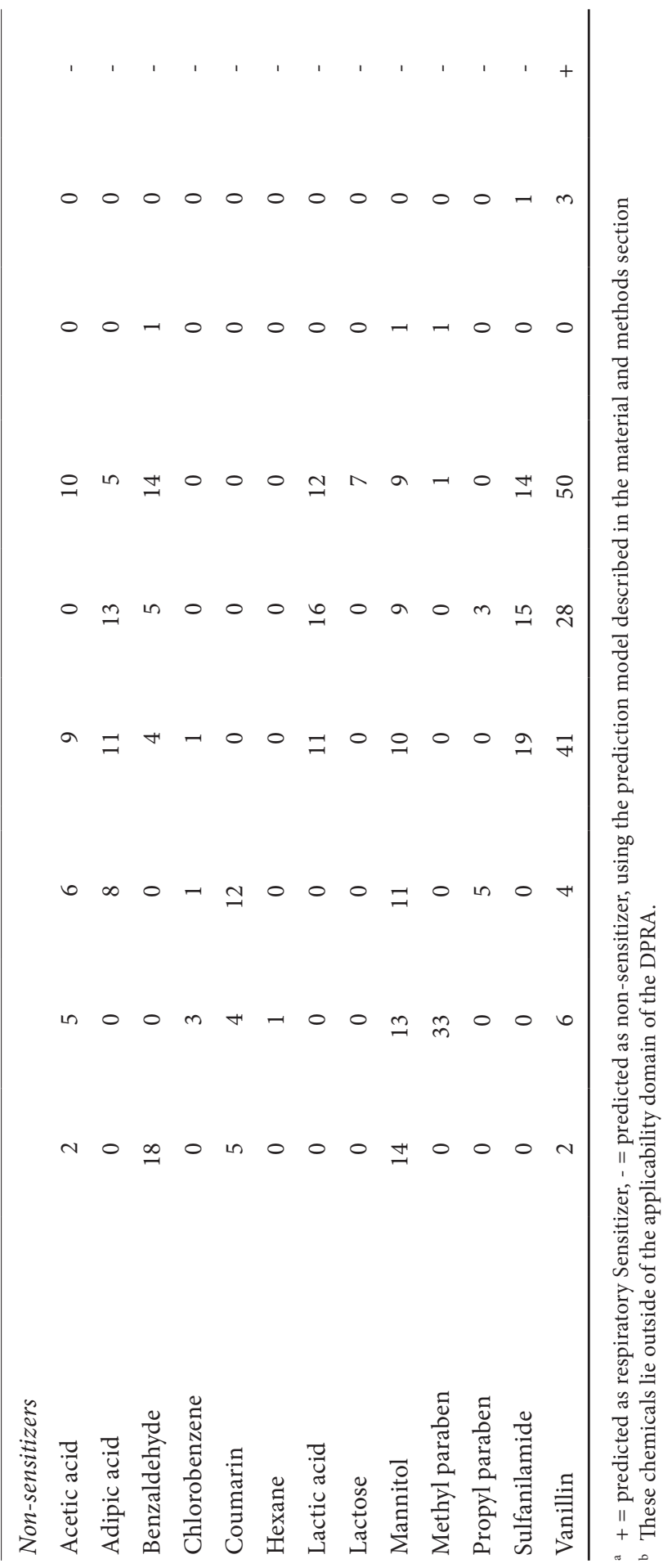


to a respiratory non-sensitizer, a reaction product was expected. However, resorcinol is also not correctly identified as a skin sensitizer by several other testing methods (Basketter et al., 2007). Therefore, resorcinol should be considered a false negative skin sensitizer based on the modified DPRA. Ampicillin failed to induce peptide depletion in one lysine replicate. However, both the presence of a (tentative) reaction product in the sample showing depletion below the threshold, as well as the reactivity towards cysteine depletion lead to the conclusion that ampicillin is a respiratory sensitizer, based on these DPRA results.

\section{Reaction product analysis}

All MS chromatograms were manually checked for newly formed peaks, and their corresponding masses were evaluated. Chemicals for which one or more reaction products were identified are individually discussed in the supplemental data, which also gives all relevant chromatograms, mass spectra and theoretical or proposed reaction mechanisms.

In many cases, the mass of the reaction product(s) agreed with the theoretical mechanism through which the chemical is expected to react with the model peptides. For example, maleic anhydride was expected to react with lysine through an acylation reaction [29] (Figure 1 A.1). The mass of the observed peaks matches the theoretical mass of the lysine model peptide, coupled to maleic anhydride through an acylation reaction (Figure 1 B.1), supporting the theoretical reaction mechanism. More importantly, this demonstrates that depletion of lysine by maleic anhydride is due to a covalent bond between the peptide and the test chemical. In case of cysteine, which also reacts with maleic anhydride through an acylation reaction (Figure 1 A.2 and B.2), a second peak was observed with a mass that corresponds with the reaction product formed through a Michael addition (Figure 1 A.3 and B.3).

For some chemicals, depletion of the model peptides and formation of reaction products was observed, but no reaction mechanism for covalent binding to cysteine or lysine within a peptide is known. Ninhydrin is widely used to confirm the presence of free amino acids, as it reacts with the free N-terminal amine group of an amino acid [105]. The model peptides used in the DPRA do not have a free amine group at the N-terminus, so this reaction would not be possible. Nevertheless, in this study, ninhydrin depleted both cysteine and lysine to a level above the thresholds. Based on MS analysis of the reaction products formed, reaction mechanisms were proposed for the reaction of ninhydrin with both cysteine and lysine containing peptides (supplemental data).

Ceftazidime is an example of a chemical that shows one or more reaction products which could not be attributed to a theoretical mechanism. The expected reaction mechanism is opening of the beta-lactam ring of ceftazidime [106] (Figure 2 A). Incubation of cysteine and ceftazidime resulted in at least three different reaction products (Figure $2 \mathrm{~B}$ ), but none of these have the mass of the theoretical reaction 
A

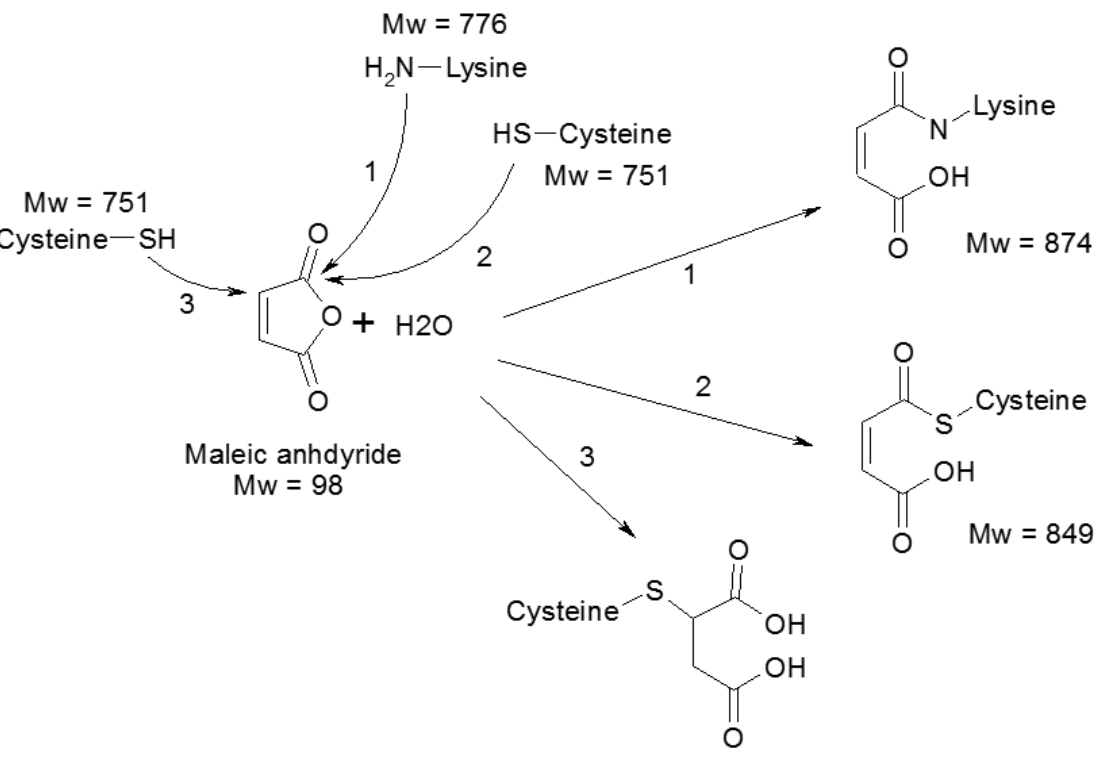

$\mathrm{Mw}=867$

B

1

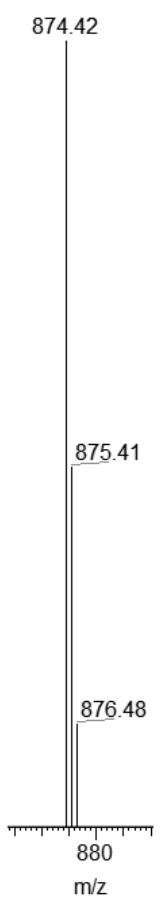

2

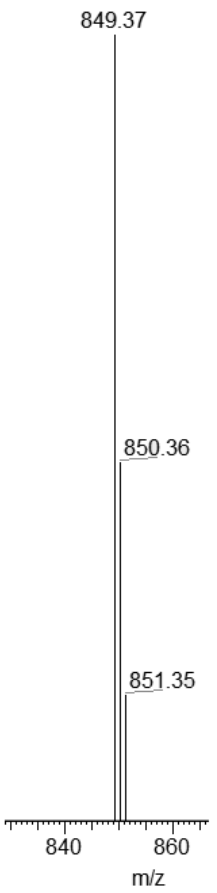

3

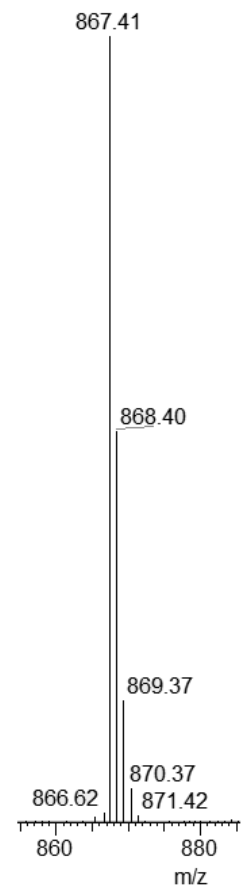

Figure 1. (A) Theoretical reaction mechanisms of maleic anhydride with cysteine and lysine. Reaction 1 and 2 are acylation reactions, reaction 3 is a Michael addition. (B) Mass spectra of the corresponding peaks observed in the mass chromatogram. The observed masses match the theoretical masses given in Figure $1 \mathrm{~A}$. 
A

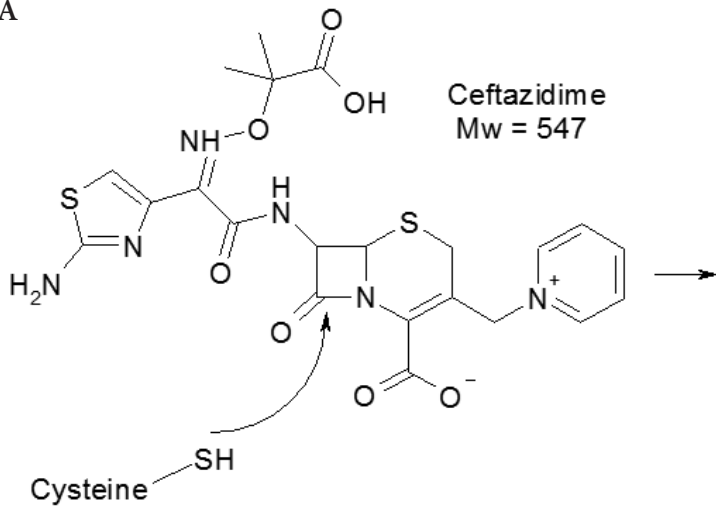

$\mathrm{Mw}=751$

B

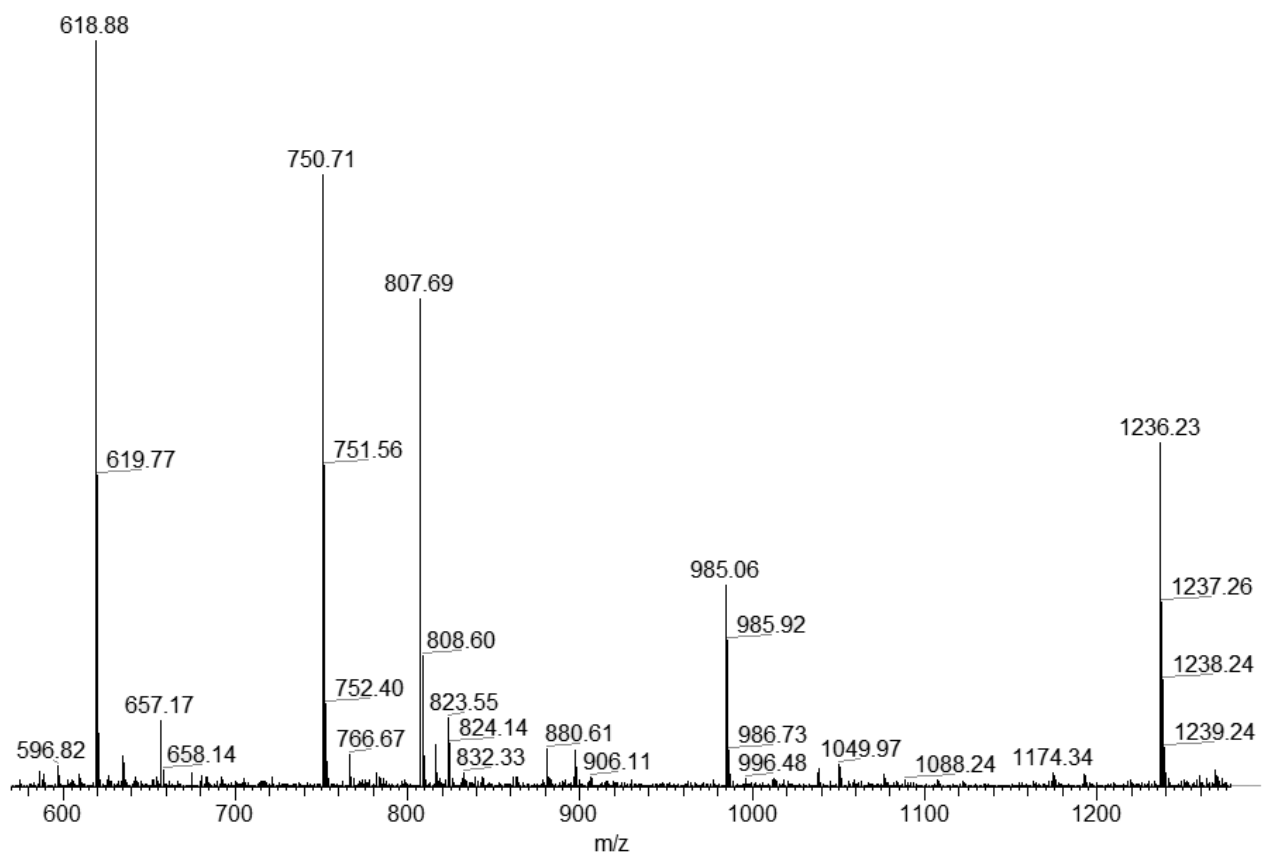

Figure 2. (A) Theoretical reaction mechanism between ceftazidime and cysteine. (B) Pooled mass spectra of the newly formed peaks in the mass chromatogram compared to the control (the mass chromatogram of the control is provided in the supplemental data file). The spectrum shows several reaction products, but the expected mass of 1298 is not found. 
product. Although the three observed reaction products could not be identified, the formation of one or more reaction products still indicates that the observed depletion is due to covalent binding of (part of) the chemical to the model peptides.

Vanillin is the only non-sensitizer that showed reactivity towards lysine (not towards cysteine) and for which also a reaction product was identified using MS (Figure 3). Vanillin is negative in the murine LLNA [101] and was therefore considered to be a non-sensitizer for this study. However, in the DPRA vanillin turned out to be peptide reactive, for which a theoretical mechanism can also be hypothesized (Figure $3 \mathrm{~A}$ ). The reactivity of vanillin toward lysine was supported by the presence of a reaction product, but its mass could not be attributed to the theoretical reaction product (Figure $3 \mathrm{~B}$ ).

\section{Predictive performance}

Using the DPRA-based prediction model, all haptens and pre-haptens were correctly predicted to be respiratory sensitizers. The pro-haptens were not identified as respiratory sensitizers. In addition, with the exception of vanillin, all non-sensitizers were correctly identified using the DPRA-based prediction model. Figure 4 shows the flowchart of the DPRA prediction model based on the selected chemicals. The resulting PPV and NPV of the proposed model for our test set are $83 \%$ and $76 \%$ respectively. The sensitivity and specificity are $72 \%$ and $86 \%$ respectively.

A

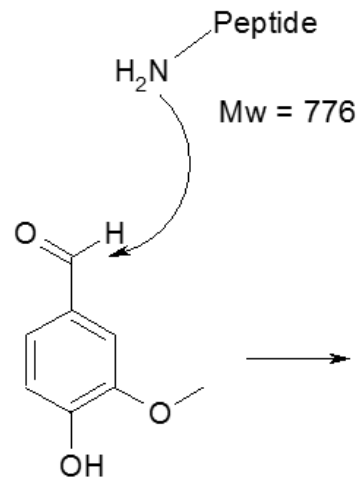

Vanillin

$\mathrm{Mw}=152$
B

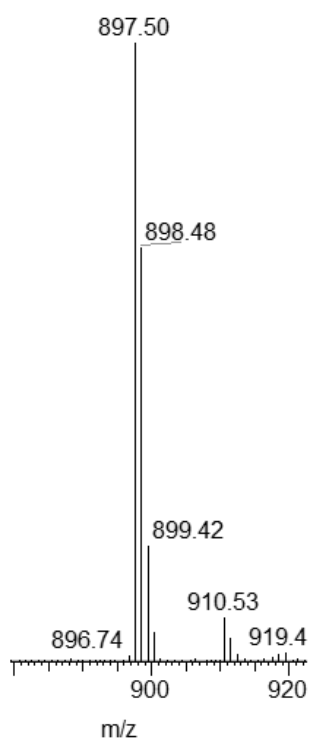

Figure 3. (A) Theoretical reaction mechanism between vanillin and lysine. (B) Mass spectrum of the formed product peak in the mass chromatogram. The theoretical mass is not found; the observed mass cannot be explained. 


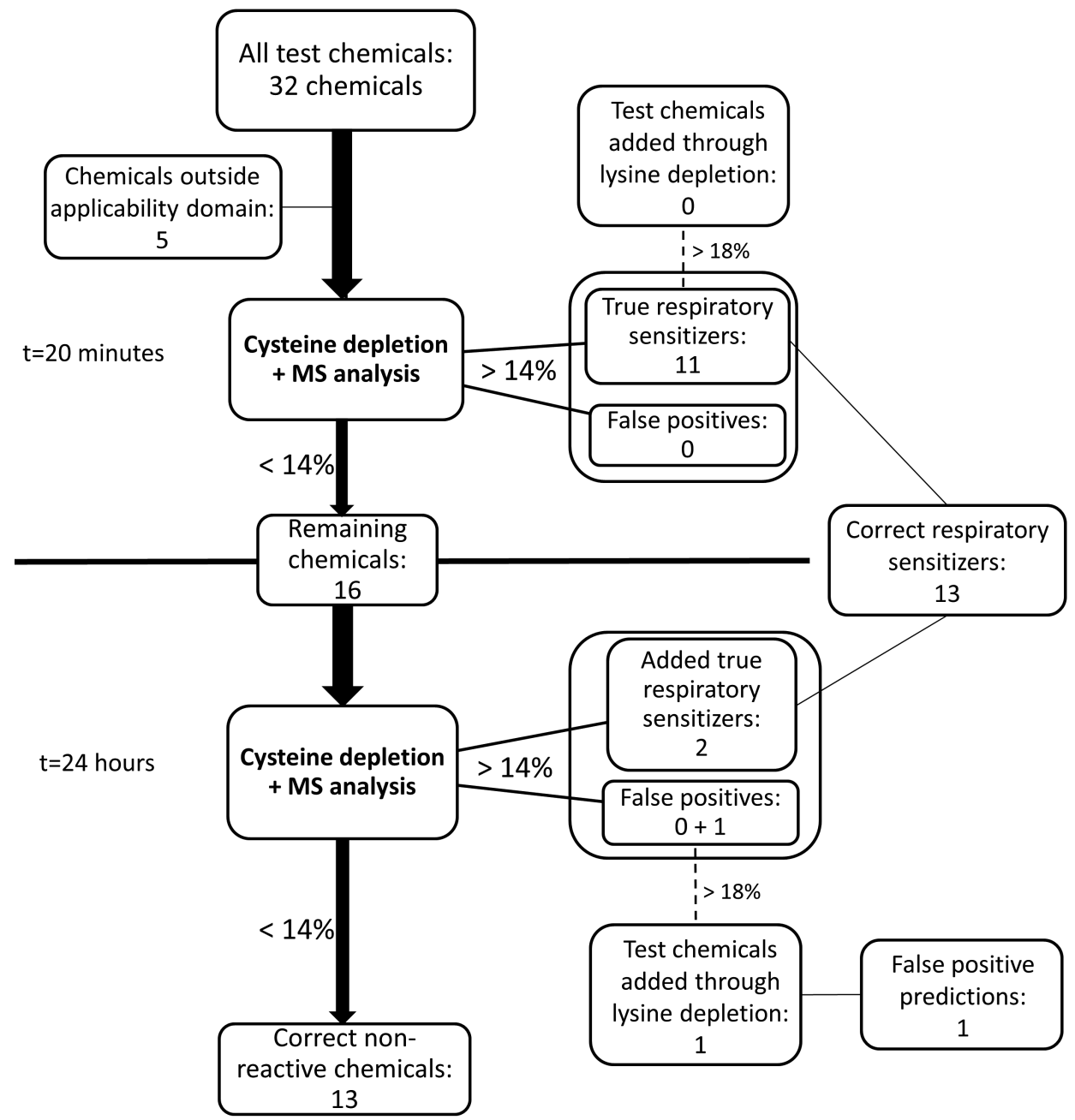

Figure 4. Flowchart of DPRA prediction model for respiratory sensitization. The applicability domain of the DPRA is taken into account (pro-haptens cannot be predicted using this approach).

\section{DISCUSSION}

The aim of this study was to further investigate the applicability of the DPRA to identify respiratory sensitizers. In addition, the benefits of applying mass spectrometry and measurements at two time-points were evaluated.

\section{Peptide reactivity to determine respiratory sensitization potential}

The prediction model proposed in this contribution correctly predicted the sensitization potential of chemicals with an accuracy of $78 \%$. The peptide depletion cut-off values for our dataset are similar to that of the OECD TG [95], which indicates that reactivity of 
a respiratory sensitizer is not necessarily different from a skin sensitizer. However, one study that applied the DPRA for testing skin sensitizers argues that there is a difference between skin- and respiratory sensitizers. They relate this difference to the peptide binding preference of skin- and respiratory sensitizers (Lalko et al. [54]. Although skin sensitizers that are not respiratory sensitizers were not tested in our study, evaluation of our data and that of Lalko et al. (2012a, 2012b) allows for a different interpretation.

Literature evidence for lysine binding preference of respiratory sensitizers

The initial work of Lalko et al. [54] calculated the ratio of lysine:cysteine depletion (Lys:Cys ratio) for their tested chemicals. The average Lys:Cys ratio of respiratory sensitizers was higher compared to the average ratio of skin sensitizers. However, the average Lys:Cys ratio of respiratory sensitizers was dominated by high Lys:Cys ratios of their anhydrides. Out of eight chemicals with a Lys:Cys ratio above 1, five were anhydrides. Our data shows a cysteine binding preference for anhydrides after 20 minutes of incubation. This preference disappears after 24 hours for some anhydrides, but not all. In addition, the work of Lalko et al. [54] showed a clear cysteine binding preference for four out of five diisocyanates (which are known respiratory sensitizers), just as skin sensitizers do. Based on their data, it could be concluded that the observed peptide binding preference is chemical class specific and not a factor determining the additional respiratory sensitization potential of known skin sensitizers. Additionally, the Lys:Cys ratio for the respiratory sensitizers tested by Lalko et al. [54] was 4.6. Using the same calculation criteria, the Lys:Cys ratio of the respiratory sensitizers tested in this study after 20 minutes is 0.9 and 1.2 after 24 hours. A subsequent study evaluating the DPRA for respiratory sensitization by Lalko et al. [94] also could not confirm the initially observed lysine preference.

Some biological studies support this binding preference hypothesis as well (Kimber et al. [35]. However, these studies tested only a limited number of chemicals. One study tested three 2,4-dinitrobenzenes as skin sensitizers and two respiratory sensitizers [107]. It might again be argued that a chemical class-specific effect is found, instead of a general binding preference for skin- and respiratory sensitizers. Another study showed that only few of the available lysine residues in human serum albumin are bound by the respiratory sensitizer hexahydrophthalic anhydride [108] and it can therefore be questioned whether serum albumin conjugation is due to preference for lysine binding or selective amino-acid binding due to available residues [35].

Combined, evidence for lysine-binding preference of respiratory sensitizers can be considered too limited to allow for general conclusions. Therefore, the DPRA is not considered useful as an individual testing method for identifying respiratory sensitizers.

\section{Application of the DPRA within a testing strategy and requirement of lysine depletion}

The DPRA could be used within a testing strategy to supplement in silico methods to determine the protein reactivity of a substance. Chemicals that show positive responses could for example be prioritized for testing in in vitro and/or in vivo testing methods that 
are able to determine the respiratory sensitization potential of a chemical. If the DPRA is to be used in this setup, it can be argued that a lysine-containing peptide is not necessary to conclude on the sensitization potential of LMW organic chemicals. When cysteine depletion was not sufficient to consider a test chemical a sensitizer, lysine depletion did not change the prediction. Applying our depletion cut-off values on the respiratory sensitizers tested by Lalko et al. [54], fourteen out of seventeen respiratory sensitizers would be correctly classified based on cysteine depletion only. The remaining three chemicals are anhydrides for which a reversible mechanism of acylation is proposed in our study (supplementary material), and these would therefore have been picked up by a 20-minute depletion measurement with the cysteine containing model peptide.

Additionally, matching theoretical reaction mechanisms with the mass of an observed reaction product was usually straightforward in the case of cysteine, but not for lysine where in several cases multiple unidentifiable reaction products were observed. This is shown by the false positive prediction of vanillin by our prediction model. When vanillin was mixed with cysteine buffer, a single sharp peak was observed. The resulting chromatogram of vanillin mixed with lysine buffer was very complex and showed several broad and overlapping peaks (data not shown). It is therefore likely that the lysine buffer ( $\mathrm{pH}$ 10.2) reacts with, or modifies vanillin, creating several unidentified products. One of these products might be protein reactive, leading to the observed lysine depletion in the DPRA. However, as this study only used a small dataset, the suggestion that a cysteine-only approach is sufficient for all sensitizers should be examined more carefully before any final conclusions can be drawn.

\section{Added value of mass spectrometry over UV-spectrometry}

The DPRA was shown to allow for accurate predictions of the general sensitization potential of chemicals. The addition of mass spectrometry to the DPRA enabled more accurate and reliable evaluations of the depletion scores. The first advantage of MS over UV is the ability to identify reaction products. The presence of a reaction product that can be linked to the observed peptide depletion increases the confidence in a prediction. Additionally, reaction product analysis allowed for resolving nine discordant results in the triplicate measurements. These data resulted in the correct identification of three non-sensitizers (lactic acid, mannitol and sulfanilamide), which would be identified as false-positives by the traditional DPRA approach.

The obtained MS data could also be used to confirm (maleic anhydride), question (ceftazidime) or propose (ninhydrin) a theoretical reaction mechanism. This knowledge can be used to improve existing in silico prediction models that incorporate reaction mechanism information, such as the reactivity alerts of Enoch $[51,98]$.

\section{Kinetics}

Depletion measurements after 20 minutes and 24 hours showed that both are required to conclude on the sensitization potential of chemicals. Pre-haptens like PPD and 
ampicillin were only predicted to be protein reactive based on peptide depletion after 24 hours of incubation. Other chemicals, such as chlorendic anhydride, already showed sufficient peptide depletion after 20 minutes of incubation. However, chlorendic anhydride did not show sufficient peptide depletion in the measurements after 24 hours and would be falsely considered non-reactive if only the 24 hour measurement was used. This shows the need for measuring depletion at more than one time-point.

An additional benefit of measuring at more than one time-point, is that the kinetics of a reaction can be described. Some chemicals show high depletion levels but reach those values only after 24 hours (PPD, ceftazidime, ampicillin), while other chemicals already show high depletion levels after 20 minutes (maleic anhydride, ninhydrin, HDI). Natsch et al. ([96] and Chipinda et al. [97] showed a correlation between kinetics and potency of skin sensitizers. The current study shows significant differences in reactivity of chemicals both in terms of peptide depletion and kinetics. However, no relevant potency information is available for respiratory sensitizers, making it impossible to evaluate a possible correlation between the reactivity of respiratory sensitizers in the DPRA and their respiratory sensitization potency in vivo. Based on the experience from skin sensitization [96, 97], it seems likely that for example ninhydrin and HDI will be much more potent respiratory sensitizers than e.g. ceftazidime and ampicillin. Regardless whether a chemical is suspected to be a skin or a respiratory sensitizer, our study and that of Natsch et al. (2008) show the potential of further distinguishing sensitizers that are reactive or highly reactive based on the amount of depletion after a short period of incubation.

\section{CONCLUSIONS}

This paper showed that a modified version of the DPRA protocol for skin sensitization results in reliable predictions on the sensitization potential of low molecular weight organic chemicals, except for those that require metabolic conversion. However, distinction between skin- and respiratory sensitizers using this test is not possible. The test can potentially be incorporated in a testing strategy for respiratory sensitization to allow for prioritization for further testing of chemicals that test positive in this assay. Such chemicals should then be tested in for example an in vitro or in vivo assay to eventually conclude on their respiratory sensitization potential. Applying MS and measurements at two different time-points increased the accuracy of the assay, therefore increasing the value of the modified DPRA within a testing strategy. However, the development of such a strategy tests awaits a widely accepted test for respiratory sensitization.

\section{SUPPLEMENTARY MATERIALS}

All supplementary tables and figures that are mentioned in this chapter can be obtained from: https://academic.oup.com/toxsci/article/153/2/361/2579092\#supplem entary-data 



\section{H A P T E R 4}

DEVELOPMENT OF AN IN VITRO TEST TO IDENTIFY RESPIRATORY SENSITIZERS IN BRONCHIAL EPITHELIAL CELLS USING GENE EXPRESSION PROFILING

Sander Dik, Jeroen L.A. Pennings, Henk van Loveren and Janine Ezendam 


\section{ABSTRACT}

Chemicals that induce asthma at the workplace are substances of concern. At present, there are no widely accepted methods to identify respiratory sensitizers, and classification of these substances is based on human occupational data. Several studies have contributed to understanding the mechanisms involved in respiratory sensitization, although uncertainties remain. One point of interest for respiratory sensitization is the reaction of the epithelial lung barrier to respiratory sensitizers. To elucidate potential molecular effects of exposure of the epithelial lung barrier, a gene expression profile was created based on a DNA microarray experiment using the bronchial epithelial cell line $16 \mathrm{HBE} 140$. The cells were exposed to 12 respiratory sensitizers and 10 non-sensitizers. For statistical analysis, we used a class prediction approach that combined three machine learning algorithms, leave-one-compoundout cross validation, and majority voting per tested compound. This approach allowed for a prediction accuracy of $95 \%$. Identified predictive genes were mainly associated with the cytoskeleton and barrier function of the epithelial cell. Several of these genes were reported to be associated with asthma as well. Taken together, this indicates that pulmonary barrier function is an important target for respiratory sensitizers and associated genes can be used to predict the respiratory sensitization potential of chemicals. 


\section{INTRODUCTION}

Asthma induced by low molecular weight (LMW) chemicals [14] at the workplace is a common type of allergy, as $15-20 \%$ of all asthma cases are due to this type of exposure. Occupational asthma is described for several work environments, such as hospitals [24] and hair salons [19], and the socioeconomic- and medical impact is significant [8,9]. There are currently no widely accepted tests available to identify respiratory sensitizers. This is partly due to the absence of validated predictive in vitro and in vivo tests. This can be attributed to the lack of mechanistic insight in the pathways involved.

By reviewing all relevant data regarding the mechanism of respiratory sensitization, Kimber et al. [35] aimed to apply the general principles of modeling an Adverse Outcome Pathway (AOP) for chemical respiratory allergy. The molecular initiating event of LMW respiratory allergy is covalent binding of the chemical to a protein after exposure, forming a hapten that can be recognized by dendritic cells [35]. There are two types of methods currently available to determine the chemical reactivity of LMW chemicals to covalently bind proteins. The first are (quantitative) structure activity relationship (QSAR) models using chemical reactivity alerts associated with protein binding and respiratory sensitization. A study implementing QSAR models to predict respiratory sensitization was performed by Dik et al. [92]. The second method is the direct peptide reactivity assay (DPRA) for respiratory sensitizers [54], which correlates peptide depletion by a chemical with the reactivity of the chemical.

The cellular response to a hapten in case of a respiratory sensitizer is similar to skin sensitization [109]; dendritic cells recognize the hapten and start to produce inflammatory cytokines [35]. In case of respiratory sensitization, this usually leads to the initiation of Th2-type responses (individual references are evaluated by [35]). The Th2-response then causes sensitization through an IgE mediated mechanism. The involvement of IgE in the sensitization process remains unclear however, as some patients have detectable IgE antibodies specific for the chemical, whereas other patients do not (individual references are evaluated by Kimber et al. [35]. Although much research has focused on the process of respiratory sensitization, several biological aspects are still not (fully) understood.

Next to the cellular response of dendritic cells, cellular responses in keratinocytes are identified as a key event in the AOP for skin sensitization [109]. Keratinocytes are considered essential for the generation of danger signal, necessary for the adaptive immune response towards skin sensitizers [110]. In case of respiratory sensitization, once a respiratory sensitizer is inhaled, it comes into contact with the pulmonary epithelium. Holgate et al. [26] found that airway epithelium is fundamentally abnormal in asthma and suggested that the barrier function of the epithelium is compromised through defective tight junction formation. Studies that are more recent also show the importance of pulmonary epithelial cells and their barrier function in relation to asthma $[27,28]$. Therefore, lung epithelial cells are considered to be an important 
target of in vitro research. Verstraelen et al. [55] studied the applicability of different epithelial cell types as models for the identification of respiratory sensitizers. Among these are bronchial cells (for example BEAS-2B cells) or alveolar cells (for example A549 cells). Both cell lines have already been used to identify biomarkers associated with respiratory sensitizers $[57,58]$. These cells have various benefits compared to other cell lines, as discussed by Verstraelen et al. [55]. However, these cells do not or only slightly have the ability to form tight junctions. As a decreased barrier function is an important aspect of asthma, we selected a cell line capable of forming proper tight junctions. The $16 \mathrm{HBE} 14 \mathrm{o}^{-}$cell line was considered appropriate in this regard as it has the ability to form tight junctions and a proper barrier as measured by the trans-epithelial electrical resistance [111].

The aim of this study was to evaluate the predictive performance of a set of gene profiles to identify respiratory sensitizers. Additionally, these gene profiles were evaluated to identify molecular pathways induced by respiratory sensitizers to elucidate the role of bronchial epithelial cells in chemical respiratory sensitization.

\section{METHODS}

\section{Cell culture}

The human bronchial epithelial cell line 16HBE14o- was obtained as a kind gift from Dr. Gruenert (National Institutes of Health [NIH], San Francisco, CA). Cells were grown to $80-90 \%$ confluence in DMEM/F12 cell culture media supplemented with 100 $\mathrm{U} / \mathrm{ml}$ Penicillin/Streptomycin solution (Gibco) and 10\% Fetal Bovine Serum (FBS; Greiner)(complete medium). Cells were cultured in plastic culture flasks (Greiner) and were maintained at $37^{\circ} \mathrm{C}$, in a humidified atmosphere of $5 \% \mathrm{CO} 2$ in air.

\section{Chemical exposure}

The chemicals used in this study were twelve respiratory sensitizers (belonging to five different chemical subclasses) and ten respiratory non-sensitizers that are not skin sensitizers. The chemicals tested in this study can be found in Table 1, which shows the identity of the chemical, whether the chemical is a respiratory sensitizer (RS), respiratory irritant (RI) or non-sensitizer (NS) (based on our previous work [92]), the vehicle in which the test chemicals were dissolved and the final exposure concentration. The respiratory sensitizers consisted of five chemical classes: Isocyanates, acid anhydrides, amines, salts and aldehydes. All chemicals were obtained from Sigma Aldrich (Zwijndrecht, The Netherlands).

The final exposure concentrations were determined by calculating the concentration that results in a decrease of cell viability to $80 \%$ (CV80), based on a colorimetric assay using the tetrazolium dye MTT [112] (data not shown). The highest concentration tested was $4 \mathrm{mM}$. If a chemical did not show toxicity at this concentration, experiments were conducted using $4 \mathrm{mM}$. 
Table 1. Overview of all chemicals tested in this study, identified by name and CAS number. The vehicle in which each chemical was dissolved (dimethylsulfoxide (DMSO) or Hanks Balanced Salt Solution (HBSS)) as well as the exposure concentration (CV80) is also provided

\begin{tabular}{|c|c|c|c|c|}
\hline Chemical & Abbreviation & CAS number & Vehicle & $\mathrm{CV} 80(\mathrm{mM})^{\prime}$ \\
\hline \multicolumn{5}{|l|}{ Respiratory sensitizers } \\
\hline Hexamethylene diisocyanate & HDI & $822-06-0$ & DMSO & 1.10 \\
\hline Toluene diisocyanate & TDI & $584-84-9$ & DMSO & 0.15 \\
\hline Maleic anhydride & MA & $108-31-6$ & DMSO & 2.65 \\
\hline Phthalic anhydride & $\mathrm{PA}$ & $85-44-9$ & DMSO & 1.33 \\
\hline Trimellitic anhydride & TMA & $552-30-7$ & DMSO & 2.73 \\
\hline Ethylene diamine & ED & $107-15-3$ & HBSS & 4.00 \\
\hline Triethylenetetramine & TETA & $112-24-3$ & HBSS & 4.00 \\
\hline Ethanolamine & Etha & $141-43-5$ & HBSS & 4.00 \\
\hline Sodium hexachloroplatinate & $\mathrm{HcPt}$ & $16929-58-7$ & HBSS & 0.42 \\
\hline Chloramine- $\mathrm{T}$ & Chlor-T & $127-65-1$ & HBSS & 1.83 \\
\hline Glutaraldehyde & Glut & $111-30-8$ & HBSS & 0.19 \\
\hline Formaldehyde & Form & $50-00-0$ & HBSS & 0.11 \\
\hline \multicolumn{5}{|l|}{ Respiratory irritants } \\
\hline Acrolein & Acro & $107-02-8$ & HBSS & 0.04 \\
\hline Methyl salicylate & MS & $119-36-8$ & DMSO & 1.17 \\
\hline Epichlorohydrin & EPI & $106-89-8$ & HBSS & 0.08 \\
\hline Sodium dodecyl sulfate & SDS & $151-21-3$ & HBSS & 0.11 \\
\hline \multicolumn{5}{|l|}{ Respiratory non-sensitizers } \\
\hline Glycerol & GLY & $56-81-5$ & HBSS & 4.00 \\
\hline Lactose & LAC & $63-42-3$ & HBSS & 4.00 \\
\hline Mannitol & MAN & $69-65-8$ & HBSS & 4.00 \\
\hline Vanillin & VAN & $121-33-5$ & DMSO & 4.00 \\
\hline Saccharin & SAC & $81-07-2$ & DMSO & 4.00 \\
\hline Lactic acid & LAA & $50-21-5$ & HBSS & 4.00 \\
\hline
\end{tabular}

* In all cases where the CV80 is 4.00 , the chemical was not found to be toxic at this concentration.

Before exposure, cells were diluted to a concentration of $6^{\star} 10^{5}$ cells $/ \mathrm{ml}$ fresh complete medium, seeded into 6 -wells plates ( $4 \mathrm{ml}$ per well; Costar, VWR) and incubated at $37^{\circ} \mathrm{C}$ in a humidified atmosphere of $5 \% \mathrm{CO} 2$ in air for 24 hours to form a monolayer. The cells were subsequently washed with HBSS and exposed to chemicals in medium without FBS or solvent controls without FBS for 4 hours. The DMSO or HBSS content in all samples was $1 \%$. At the end of the exposure, $700 \mu$ l RNAprotect 
cell reagent (Qiagen, Westburg, the Netherlands) was added to each well. Cells were resuspended and stored at $-20^{\circ} \mathrm{C}$ until further analysis within the same week.

\section{RNA isolation}

RNA was isolated by using an RNeasy Plus Mini Kit (cat.no. 74134, Qiagen) according to the manufacturer's instructions. RNA concentrations and qualities were determined using a NanoDrop Spectrophotometer (Isogen-Life Sciences) and an Agilent 2100 Bioanalyzer (Agilent), respectively. All RNA samples were diluted in RNase-free water to a concentration of $200 \mathrm{ng} / \mu \mathrm{l}$ in $15 \mu \mathrm{l}$ and stored at $-80^{\circ} \mathrm{C}$. Control RNA samples from HBSS and DMSO exposed cells were included in the analysis as well.

\section{DNA Microarray analysis}

RNA samples were further processed for hybridization to Affymetrix HT HG-U133+PM plates at the Microarray department (MAD) of the University of Amsterdam, The Netherlands. Amplification, labeling and hybridization was performed according to Affymetrix protocols, using an automated Affymetrix Genechip console. Samples were randomized prior to processing and hybridization. Array plates were scanned with a Genechip HT array plate scanner and analyzed with the Affymetrix HT software suite. Quality control and normalization of Affymetrix CEL files were performed using the ArrayAnalysis website (www.arrayanalysis.org/) [113], using the Robust Multichip Average (RMA) method [114] and the MBNI custom CDF version 14 [115]. Normalized data consisted of Log2 transformed signal values for 18909 genes.

\section{Statistical analysis}

Further statistical analysis including classification was performed in R (www.r-project. org) (version 3.0.3) [116]. Values were corrected for the vehicle-exposed samples to obtain log2-ratios for compound exposure data.

Next, the chemicals were classified as either respiratory sensitizers or non-sensitizers (respiratory irritants + non-sensitizers). Classification was done using a leave-onecompound-out cross-validation approach, employing methods described previously $[117,118]$. In this approach, each time the replicate samples for one compound are used as a test set, while the data for the other compounds serve as a training set. A classification algorithm is trained on the training set data, including gene selection and parameter settings, and this algorithm is then applied to predict the class of the test set samples. This is repeated until each compound has been classified. The classification of a compound was based on the prediction for the majority of the replicate samples.

To obtain a predictive gene set that is not only dependent on a single classification algorithm, three different algorithms were applied to the data, each of which working in a different way. The first is Support Vector Machine (SVM) [119], which creates a separating hyperplane in a multidimensional space. The second algorithm used 
is Random forests (RF) [120], which uses a combination of prediction trees. Lastly, Prediction Analysis for Microarrays in R (PAM) [121], uses shrunken centroids to classify samples. Finally, to reduce the algorithm dependent class prediction, the outcomes of the three classifier algorithms were combined to a single overall class prediction. The prediction accuracy for the test set samples was calculated as the average of all compound predictions.

\section{Gene signature identification}

For each of the 22 training sets a set of predictive genes was obtained using the leaveone-compound-out approach. Although the gene lists differ for each compound that is left out, overlap in the genes exists. This overlap is used to identify consistent predictive genes for each algorithm. Therefore, for each algorithm, genes that were present in at least 11 of the gene lists were selected as a consensus gene set for that algorithm. Additionally, other consensus gene sets were defined using more stringent approaches, namely genes present in two and three of the lists, thus forming consensus gene sets across multiple algorithms.

Functional annotation and overrepresentation analysis was performed using DAVID [122], using functional databases such as Gene Ontology (GO) and the Kyoto Encyclopedia of Genes and Genomes (KEGG) . Functional terms were clustered using the DAVID clustering option.

For genes identified as part of at least one consensus gene set, expression changes compared to controls were visualized in a heatmap combined with hierarchical clustering (Euclidean distance, Ward linkage method).

\section{RESULTS}

\section{Classification and biomarker selection}

The three statistical algorithms (SVM, RF and PAM) were used individually to classify the test chemicals as respiratory sensitizers or non-sensitizers. SVM correctly identified all respiratory sensitizers and misclassified only the irritant acrolein as respiratory sensitizer. Therefore, the accuracy of SVM is 95\% (Table 2A). The corresponding consensus gene set for SVM contained 83 genes.

RF identified a consensus set of 75 genes to discriminate respiratory sensitizers from non-sensitizers. As SVM, RF did not correctly classify acrolein. In addition, the respiratory sensitizer chloramine- $\mathrm{T}$ was incorrectly predicted as non-sensitizer. This resulted in an accuracy of $91 \%$ (Table 2B).

PAM misclassified acrolein, chloramine- $T$ and the respiratory sensitizer glutaraldehyde. The accuracy of PAM is $86 \%$ (Table $2 \mathrm{C}$ ), with a corresponding consensus gene set of 6 genes.

The three individual statistical algorithms in total found 117 unique genes (Figure 1) that were able to discriminate respiratory sensitizers from non-sensitizers. 
Table 2. Predictions by statistical algorithm, based on the consensus genes found by (A) SVM, (B) RF and (C) PAM, to discriminate respiratory sensitizers from non-sensitizers. RS = Respiratory sensitizer, NS = Non-sensitizer

\begin{tabular}{|c|c|c|c|c|}
\hline \multicolumn{3}{|l|}{ A } & \multicolumn{2}{|c|}{ SVM (83 genes) } \\
\hline & & & RS & NS \\
\hline & & & 13 & 9 \\
\hline \multirow{2}{*}{ Human } & RS & 12 & 12 & 0 \\
\hline & NS & 10 & 1 & 9 \\
\hline
\end{tabular}

Accuracy 95\%

False prediction:

False negative

$$
\text { // Acrolein }
$$

\begin{tabular}{|c|c|c|c|c|}
\hline \multicolumn{3}{|l|}{ B } & \multicolumn{2}{|c|}{$\mathrm{RF}$ (75 genes) } \\
\hline & & & RS & NS \\
\hline & & & 12 & 10 \\
\hline \multirow{2}{*}{ Human } & RS & 12 & 11 & 1 \\
\hline & NS & 10 & 1 & 9 \\
\hline
\end{tabular}

Accuracy 91\%

False prediction:

False negative

Chloramine-T

False positive

// Acrolein

\begin{tabular}{|c|c|c|c|c|}
\hline \multicolumn{3}{|l|}{$\mathrm{C}$} & \multicolumn{2}{|c|}{ PAM (6 genes) } \\
\hline & & & RS & NS \\
\hline & & & 11 & 11 \\
\hline \multirow{2}{*}{ Human } & RS & 12 & 10 & 2 \\
\hline & NS & 10 & 1 & 9 \\
\hline
\end{tabular}

Accuracy $86 \%$ $\begin{aligned} 100 \% & \text { Sensitivity } \\ 90 \% & \text { Specificity } \\ 92 \% & \text { PPV } \\ 100 \% & \text { NPV }\end{aligned}$

92\% Sensitivity

90\% Specificity

92\% PPV

$90 \% \quad \mathrm{NPV}$
83\% Sensitivity

90\% Specificity

91\% PPV

$82 \% \quad \mathrm{NPV}$

False prediction:

False negative

False positive

Chloramine-T //

Acrolein

Glutaraldehyde 


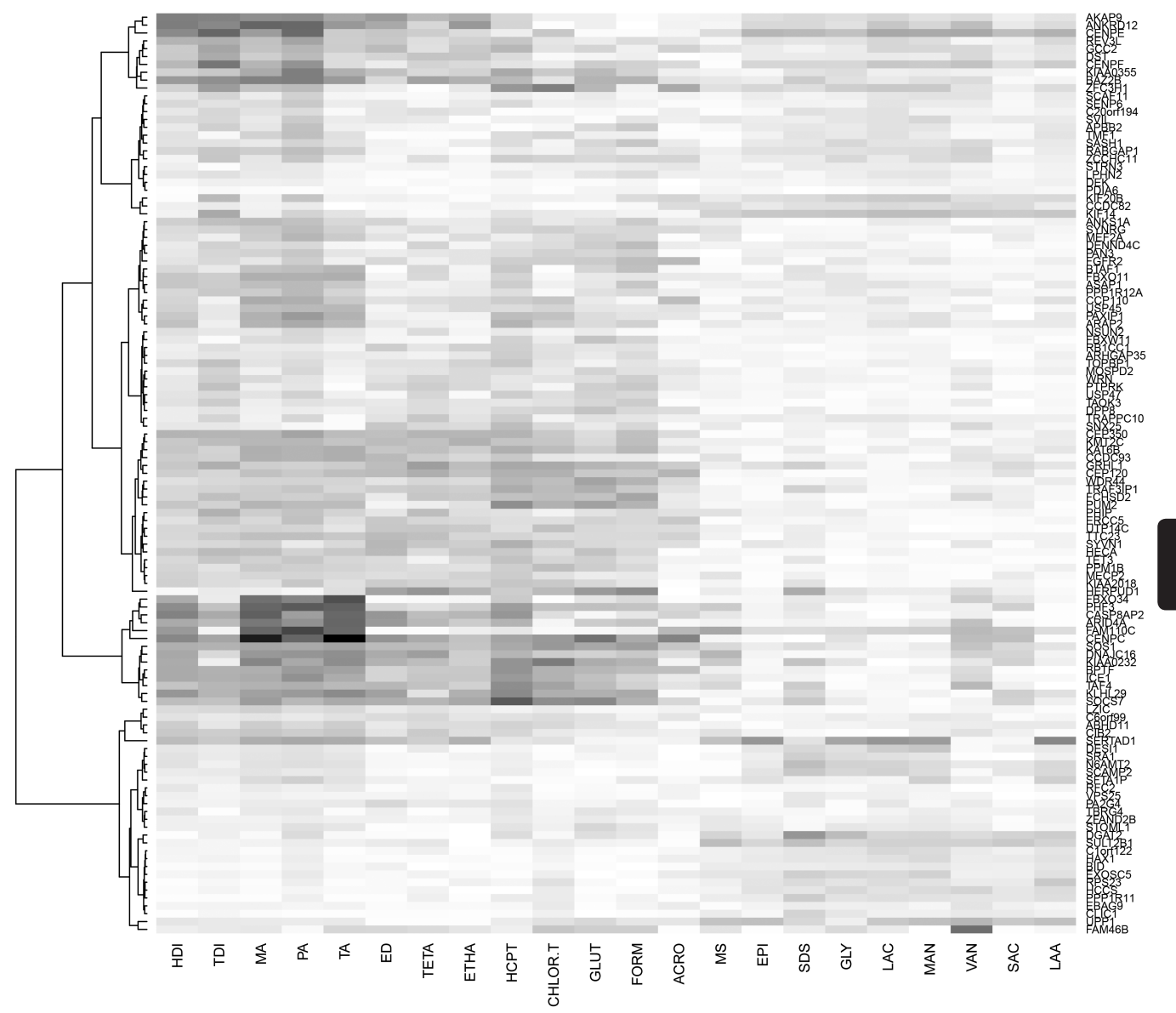

Figure 1. Heat map of all 117 unique genes found by one or more statistical algorithms. Up-regulation of genes is colored in red, down-regulation of genes is colored in blue. Abbreviations of the chemicals can be found in Table 1 .

Next, the algorithms were combined by majority voting class prediction, which resulted in an accuracy of $91 \%$. Chloramine- $T$ and acrolein were both misclassified (Table 3A). In addition, the robustness of the classifications was evaluated by reducing the number of genes. For this purpose, only genes that were selected by at least two algorithms were used to predict the test chemicals, again by majority voting of the three algorithms into a single predictor. In total, 42 genes are overlapping between at least two of the three signature sets (Figure 2). The predictive performance of these genes on our test set is $100 \%$ accurate (Table $3 \mathrm{~B}$ ). Finally, predictions on all test set chemicals were also generated based on the five genes that are selected by all three algorithms. This resulted in a slightly lower accuracy (95\%), as acrolein was not correctly identified as a non-sensitizer (Table 3C). 


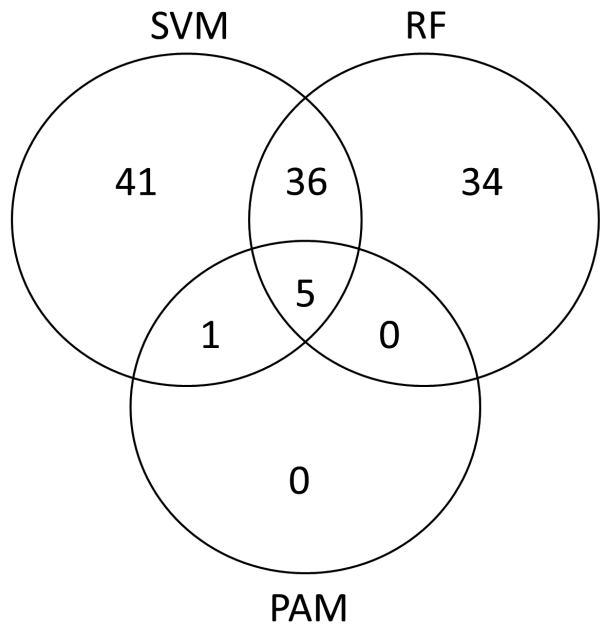

Figure 2. Venn diagram showing the number of genes and overlap found by the different algorithms.

To confirm the statistical robustness of the consensus gene sets, the above steps were repeated for a scrambled dataset, in which each chemical was randomly assigned as a respiratory sensitizer or non-sensitizer. Chemicals in the same chemical subclass could not be assigned the same random label (e.g. if maleic anhydride was assigned the label of non-sensitizer, phthalic anhydride was assigned the label of respiratory sensitizer). Then the analysis was performed again, with the aim to find consensus genes for each statistical algorithm to distinguish randomly assigned respiratory sensitizers from randomly assigned non-sensitizers. The outcome for all three algorithms was significantly lower compared to the original performance (SVM 23\%, RF 27\%, PAM 5\%). Due to inconsistency between predictions per algorithm, majority voting resulted in an accuracy performance of only 5\%. Based on the significantly lower performance of all algorithms including the majority voting approach, and the consistent results obtained in the original analysis, it can be concluded that the observed consensus genes in the original analysis are robust.

\section{Biological function of genes}

DAVID was used to functionally annotate the 117 unique genes found by at least one of the algorithms. The most prominent associated processes were (Table 4): Cytoskeleton (20 genes, 17\%), DNA binding (19 genes, 16\%), protein transport (6 genes, $5 \%$ ).

Table 4 summarizes the genes that were detected in at least two of the three algorithms. These genes were associated with cytoskeleton, DNA binding, protein transport and with NF-kB signaling. Only five genes were retrieved by all three algorithms (GCC2, KIAA0355, FCHSD2, ANKRD12, BAZ2B). A biological function is known for GCC2 and BAZ2B. GCC2 is involved in Golgi structure maintenance and 
Table 3. Prediction results using majority voting of the three algorithms (SVM, RF and PAM) based on (A) all 117 unique genes selected by at least one of the algorithms; (B) genes selected by at least two of the three algorithms; (C) The five genes selected by all three algorithms. $\mathrm{RS}=$ respiratory sensitizer, NS = non-sensitizer.

\begin{tabular}{|c|c|c|c|c|}
\hline \multicolumn{3}{|l|}{ A } & \multicolumn{2}{|c|}{ Prediction } \\
\hline \multirow{2}{*}{\multicolumn{3}{|c|}{ Majority voting based on 117 genes }} & RS & NS \\
\hline & & & 12 & 10 \\
\hline \multirow{2}{*}{ Human } & RS & 12 & 11 & 1 \\
\hline & NS & 10 & 1 & 9 \\
\hline
\end{tabular}

Accuracy $86 \%$

False prediction:

False negative

Chloramine- $\mathrm{T}$

False positive

// Acrolein

\begin{tabular}{|c|c|c|c|c|}
\hline \multicolumn{3}{|l|}{ B } & \multicolumn{2}{|c|}{ Prediction } \\
\hline \multirow{2}{*}{\multicolumn{3}{|c|}{ Majority voting based on 42 genes }} & RS & NS \\
\hline & & & 12 & 10 \\
\hline \multirow{2}{*}{ Human } & RS & 12 & 12 & 0 \\
\hline & NS & 10 & 0 & 10 \\
\hline
\end{tabular}

Accuracy $100 \%$

False prediction:

False negative

False positive

\begin{tabular}{|c|c|c|c|c|}
\hline \multicolumn{3}{|l|}{$\mathrm{C}$} & \multicolumn{2}{|c|}{ Prediction } \\
\hline \multirow{2}{*}{\multicolumn{3}{|c|}{ Majority voting based on 5 genes }} & RS & NS \\
\hline & & & 13 & 9 \\
\hline \multirow{2}{*}{ Human } & RS & 12 & 12 & 0 \\
\hline & NS & 10 & 1 & 9 \\
\hline
\end{tabular}

Accuracy 95\%

False prediction:

False negative

False positive

Acrolein

\section{2\% Sensitivity \\ 90\% Specificity \\ 92\% PPV \\ 90\% NPV}

100\% Sensitivity

100\% Specificity

$100 \%$ PPV

$100 \% \quad \mathrm{NPV}$
100\% Sensitivity

90\% Specificity

92\% PPV

$100 \%$ NPV

Acrolein 
AP-1 mediated vesicle tethering [123] and BAZ2B is involved in chromatin remodeling [124] and was categorized by DAVID to DNA binding. A general overview of all 117 genes with their fold-changes can be found in the supplemental data.

Table 4. Overview of all genes identified by one or more of the statistical algorithms that are associated with Cytoskeleton, DNA binding, Protein transport, NF-kB and the remaining genes that are identified by all three algorithms. Genes are identified by GeneID, Symbol and full name.

\begin{tabular}{|c|c|c|c|}
\hline GeneID & Symbol & $\begin{array}{l}\text { Found by which } \\
\text { algorithm }(s)\end{array}$ & Full name \\
\hline \multicolumn{4}{|c|}{ Genes associated with Cytoskeleton } \\
\hline 1062 & CENPE & SVM, PAM & Centromere protein $\mathrm{E}, 312 \mathrm{kDa}$ \\
\hline 2909 & ARHGAP35 & SVM, RF & Rho GTPase activating protein 35 \\
\hline 4659 & PPP1R12A & SVM, RF & Protein phosphatase 1 , regulatory subunit $12 \mathrm{~A}$ \\
\hline 6654 & SOS1 & SVM, RF & Son of sevenless homolog 1 (Drosophila) \\
\hline 7486 & WRN & SVM, RF & Werner syndrome, RecQ helicase-like \\
\hline 9928 & KIF14 & SVM, RF & Kinesin family member 14 \\
\hline 153241 & CEP120 & SVM, RF & Centrosomal protein $120 \mathrm{kDa}$ \\
\hline 667 & DST & SVM & Dystonin \\
\hline 1063 & CENPF & SVM & Centromere protein F, 350/400ka (mitosin) \\
\hline 9738 & CCP110 & SVM & CP110 protein \\
\hline 9857 & CEP350 & SVM & Centrosomal protein $350 \mathrm{kDa}$ \\
\hline 10142 & AKAP9 & SVM & A kinase (PRKA) anchorprotein (yotiao) 9 \\
\hline 10456 & HAX1 & SVM & HCLS1 associated protein X-1 \\
\hline 23637 & RABGAP1 & SVM & RAB GTPase activating protein 1 \\
\hline 6840 & SVIL & $\mathrm{RF}$ & Supervillin \\
\hline 9585 & KIF20B & $\mathrm{RF}$ & Kinesin familymember 20B \\
\hline 11073 & TOPBP1 & $\mathrm{RF}$ & Topoisomerase (DNA)II binding protein 1 \\
\hline 26146 & TRAF3IP1 & $\mathrm{RF}$ & $\begin{array}{l}\text { TNF receptor-associated factor } 3 \text { interacting } \\
\text { protein } 1\end{array}$ \\
\hline 54521 & WDR44 & $\mathrm{RF}$ & WD repeat domain 44 \\
\hline 642273 & FAM110C & $\mathrm{RF}$ & Family with sequence similarity 110 , member $C$ \\
\hline \multicolumn{4}{|c|}{ Genes associated with DNA binding } \\
\hline 29994 & BAZ2B & SVM, RF, PAM & Bromodomain adjacent to zinc finger domain, 2B \\
\hline 4204 & MECP2 & SVM, RF & Methyl CpG binding protein 2 \\
\hline 4205 & MEF2A & SVM, RF & Myocyte enhancer factor $2 \mathrm{~A}$ \\
\hline 5926 & ARID4A & SVM, RF & A T rich interactive domain $4 \mathrm{~A}$ (RBP1-like) \\
\hline 205717 & KIAA2018 & SVM, RF & KIAA2018 \\
\hline 5980 & REV3L & SVM & $\begin{array}{l}\text { REV3-like, catalytic subunit of DNA } \\
\text { polymerase zeta (yeast) }\end{array}$ \\
\hline
\end{tabular}


Table 4. (continued)

\begin{tabular}{llll}
\hline GeneID & Symbol & $\begin{array}{l}\text { Found by which } \\
\text { algorithm(s) }\end{array}$ & Full name \\
\hline 5982 & RFC2 & SVM & Replication factor C (activator 1) 2, 40kDa \\
7110 & TMF1 & SVM & TATA element modulatory factor 1 \\
7913 & DEK & SVM & DEK oncogene \\
9044 & BTAF1 & SVM & BTAF1 RNA polymerase II, B-TFIID \\
& & transcription factor associated, 170kDa & Steroid receptor RNA activator 1 \\
10011 & SRA1 & SVM & K (lysine) acetyltransferase 6B \\
23522 & KAT6B & SVM & Grainyhead-like 1 (Drosophila) \\
29841 & GRHL1 & SVM & Striatin, calmodulin binding protein 3 \\
29966 & STRN3 & SVM & Myeloid/lymphoid or mixed-lineage leukemia 3 \\
58508 & KMT2C & SVM & Centromere protein C1 \\
1060 & CENPC & RF & Excision repair cross-complementing rodent \\
2073 & ERCC5 & RF & repair deficiency, complementation group 5 \\
& & Rromodomain PHD finger transcription factor \\
2186 & BPTF & RF & $\begin{array}{l}\text { TAF4 RNA polymerase II, TATA box binding } \\
\text { protein (TBP)-associated factor, 135kDa }\end{array}$ \\
6874 & TAF4 & RF &
\end{tabular}

Genes associated with Protein transport

\begin{tabular}{|c|c|c|c|}
\hline 10066 & SCAMP2 & SVM, RF & Secretory carrier membrane protein 2 \\
\hline 11276 & SYNRG & SVM, RF & Synergin, gamma \\
\hline 83891 & SNX25 & SVM, RF & Sorting nexin 25 \\
\hline 84313 & VPS25 & SVM, RF & $\begin{array}{l}\text { Vacuolar protein sorting } 25 \text { homolog (S. } \\
\text { cerevisiae) }\end{array}$ \\
\hline 2263 & FGFR2 & SVM & Fibroblast growth factor receptor 2 \\
\hline 7109 & TRAPPC10 & SVM & Trafficking protein particle complex 10 \\
\hline
\end{tabular}

Genes associated with NF- $k B$

\begin{tabular}{llll}
5495 & PPM1B & SVM, RF & Protein phosphatase, Mg2+/Mn2+dependent, 1B \\
23328 & SASH1 & SVM, RF & SAM and SH3 domain containing 1 \\
\hline
\end{tabular}

Other genes found by all three algorithms

\begin{tabular}{llll}
9648 & GCC2 & SVM, RF, PAM & GRIP and coiled-coil domain containing 2 \\
9710 & KIAA0355 & SVM, RF, PAM & KIAA0355 \\
9873 & FCHSD2 & SVM, RF, PAM & FCH and double SH3 domains 2 \\
23253 & ANKRD12 & SVM, RF, PAM & Ankyrin repeat domain 12 \\
\hline
\end{tabular}




\section{DISCUSSION}

Our study aimed to generate a set of genes to discriminate respiratory sensitizers from non-sensitizers. By using three classification algorithms combined with majority voting, an accuracy of $86 \%$ was achieved based on 117 genes. The accuracy could be increased to $>95 \%$ by using only genes that were identified as discriminating by two ( 45 genes) or even three (5 genes) algorithms. After randomly assigning the test chemicals as respiratory (non-) sensitizers, the observed high accuracy was lost. Overall, it can be concluded that our predictions are robust and the benefit of combining multiple prediction algorithms was shown. However, these results should be validated using for example a PCR experiment.

The other aim of this study was to identify molecular pathways induced by respiratory sensitizers in bronchial epithelial cells. Several of the genes found to be regulated after exposure in this study could be associated with the cytoskeleton. Interestingly, of these genes, three (PPP1R12A, SOS1 and AKAP9) can be associated with the function of the epithelial barrier and asthma. PPP1R12A was found to be involved in the regulation of the actin cytoskeleton through the IL-33 signaling pathway [125], which is implicated in airway inflammation [126]. IL-33 stimulation resulted in phosphorylation of PPP1R12A, which is a regulatory subunit of myosin phosphatase [126]. Phosphorylation of PPP1R12A results in the inhibition of its myosin phosphatase activity [127]. The consequence is increased myosin light chain phosphorylation. This results in smooth muscle contraction, which is one of the causes of bronchoconstriction in asthmatics. Interestingly, the actin cytoskeleton regulation pathway described by Pinto et al. [125] contains the Sos peptide which is encoded by SOS1/2. SOS1 has been shown to be implicated in the PI3K/AKT pathway [128], which is also triggered by the IL-33 signaling pathway [125].

The gene AKAP9 was found to be involved in the functionality of the epithelial barrier after exposure to cigarette smoke extract (CSE) [129]. In that study, CSE-exposed 16HBE cells had reduced barrier function and showed reduced protein expression of E-cadherin and AKAP9. AKAP9 mRNA expression was also decreased in primary bronchial epithelial cells from current smokers compared with non/exsmokers [129].

Although the immune system plays a major role in occupational asthma, our data indicates that respiratory sensitizers do not affect immunological pathways in epithelial cells. Our data are in line with other studies that have shown that impairment of the epithelial barrier is a major factor in asthma [27, 28, 130]. Combined, these findings suggest that for predicting respiratory sensitizers, next to genes with a direct immunological function, a predictive gene expression profile can be based on genes representing barrier function. This should however be evaluated in an experimental set-up that represents the biological environment of the pulmonary barrier more accurately, such as in an air-liquid interface. In addition, 
sensitization induced by respiratory sensitizers is thought to be possible through the skin as well (individual references evaluated in for example [35]). Therefore, evaluation of keratinocytes exposed to respiratory sensitizers could also result in an increased understanding of the biological mechanisms involved in respiratory sensitization. It would also allow comparing the affected pathways between skin and pulmonary epithelial cells, gaining insights in the different and/or similar effects due to route of exposure.

As with all animal-free testing and non-testing methods, it can be argued that they only provide information on only one or a few aspects of the biological pathway(s) involved. The notion that multiple animal-free tests should be combined to come to a conclusion on a toxicological end-point received significant amounts of attention after publication of the report Toxicity Testing in the $21^{\text {st }}$ century [131]. The use of integrated testing methods that address different aspects of a biological pathway was clearly shown, for example in the related field of skin sensitization [132, 133]. Based on the AOP for skin sensitization, several testing methods that provide information on one of the key elements of the AOP were successfully combined. In contrast to the field of skin sensitization, which already has a well-defined AOP [109], no accepted AOP currently exists for respiratory sensitization. However, Kimber et al. [35] evaluated several key elements deemed important for the process of respiratory sensitization. The role of the epithelial barrier was, however, not evaluated by that group. We, nevertheless, felt that the epithelial barrier is an important target of the toxicological effects of respiratory sensitizers. One of the aspects that was described by Kimber et al. [35] is the involvement of dendritic cells. The only other study, at the time of writing this paper, that used genes to classify respiratory sensitizers was done by Forreryd et al. [134], using dendritic cells. They generated a set of 389 discriminating genes in the MUTZ-3 cell line, which was subsequently used to classify chemicals as respiratory sensitizers or non-sensitizers with an accuracy of $84 \%$. Both our study (using epithelial cells) and that of Forreryd et al. [134] (using dendritic cells) achieved an accuracy of $\sim 90 \%$ when predicting respiratory sensitization potential of chemicals. This may suggest that both approaches could be used within a testing strategy that incorporates multiple tests each addressing different parts of the (partly unknown) respiratory sensitization pathway. Several other studies also aimed to identify biomarkers that can discriminate respiratory sensitizers from respiratory non-sensitizers [56-60, $135,136]$. Their results can contribute to the development of an AOP for respiratory sensitization. However, our own study together with these studies did not apply their findings to predict either a subset of their test chemicals or a new set of chemicals, so their applicability within a testing strategy for respiratory sensitization will need to be further evaluated. 


\section{CONCLUSION}

This paper described the search for biomarkers that can identify respiratory sensitizers in vitro. Our findings show that the respiratory sensitization potential of chemicals can be accurately predicted using an epithelial cell line. Based on our study and that of the only other study to date that aimed to predict respiratory sensitization potential of chemicals [134], it can be suggested that single cell line studies are suitable to predict respiratory sensitization, even if the genes are not necessarily related to an immunological function. Based on our results and on the other studies on epithelial cells discussed in this paper, the pulmonary barrier should be considered an important target of research in the field of respiratory sensitization.

\section{SUPPLEMENTARY MATERIALS}

The supplementary file mentioned in this chapter can be obtained from: https://www. sciencedirect.com/science/article/pii/S0887233315002696?via\%3Dihub 




\section{H A P T E R 5}

DEVELOPMENT OF A TESTING STRATEGY FOR RESPIRATORY SENSITIZATION

Sander Dik, Janine Ezendam and Henk van Loveren 



\section{INTRODUCTION}

Several attempts have been made to develop methods to prospectively identify respiratory sensitizers. These methods include structure activity relationship models (evaluated in [92]), the (modified) direct peptide reactivity assay [54, 137] and some in vitro models $[55,138]$. Most of these methods show accuracies of over $80 \%$ when predicting low molecular weight (LMW) respiratory sensitizers and may be considered promising. However, uncertainties in the identification of true respiratory sensitizers in a clinical setting and incomplete knowledge of the biological mechanisms involved in respiratory sensitization contribute to the lack of validation of these models. In addition, the majority of these methods have been developed using only a small number of chemicals and need to be further evaluated with larger sets of reference chemicals. Therefore, it can be stated that, although the individual methods show promise to identify respiratory sensitizers, they are not yet sufficiently evaluated for any regulatory body to adopt them as the main test for this toxicological endpoint.

Methods to identify this endpoint are urgently needed as currently it is only possible to conclusively identify LMW respiratory sensitizers after a person has been exposed and adverse effects are observed as a result. In those cases, the exposures have already led to personal adverse effects and associated socioeconomic consequences. In view of the recently proposed adverse outcome pathway for respiratory sensitization [33], it is likely that the limitations of each individual method will be resolved in the future. On the other hand, respiratory allergy is a complex toxicological endpoint, of which the adverse outcome depends on several sequential key elements [33]. A workshop on the assessment of respiratory sensitization was held in 2016, during which it was concluded that a testing strategy comprised of several different methods is necessary to come to a definitive conclusion on the respiratory sensitization potential of chemicals [139]. The European regulation on chemicals (REACH) has also suggested the use of testing strategies for this toxicological endpoint [65].

The individual methods described earlier could well fit in such a testing strategy, as they relate to several key elements of the respiratory sensitization AOP [33]. Two of those key elements are covalent binding of a chemical to proteins and the induction of cellular danger signals. The first is measured by the (Q)SARs and DPRA, the second is partially covered for example by the in vitro model of Dik et al. 2015 [138] as it was shown that genes affected by respiratory sensitizers are involved in the epithelial barrier function and downstream effects after damaging of the barrier itself. Combining individual methods for respiratory sensitization has not yet been attempted due to the described lack of validation of these individual methods. However, the promising results of each individually described method warrants the attempt to evaluate the potential of such a strategy regarding the identification of respiratory sensitizers.

As a starting point, the tiered strategy applied to improve individual in silico (Q) SAR models by Dik et al. 2014 [92] was chosen as it was able to generate reliable 
predictions that are correct for up to $96 \%$ of the predicted chemicals. The downside was the low number of chemicals for which an acceptable prediction could be generated. For the remaining chemicals, more information was deemed necessary. As more information is now available from other testing methods such as the modified DPRA [137] and the in vitro epithelial assay described by Dik et al. 2015 [138], an extended testing strategy is proposed in this chapter to evaluate the usefulness of combining data from testing methods that can be mechanistically linked to the respiratory sensitization AOP [33] as well.

\section{METHODS}

\section{Selection of chemicals}

The number of chemicals that could be evaluated by the SAR approach [92], the modified DPRA [137] and the in vitro [138] model varied greatly. The SAR approach evaluated a total of 659 chemicals, in the modified DPRA 32 chemicals were tested, and with the in vitro epithelial cell assay 22 chemicals were tested. To allow evaluation of all three methods, only those substances for which data was available from all three methods have been used. In total, 11 respiratory sensitizers, two respiratory irritants and six respiratory non-sensitizers were therefore used for the evaluation of the testing strategy.

For these 19 chemicals a conclusion from the SAR approach and the in vitro epithelial cell assay was available. Testing results from our own laboratory for the modified DPRA were only available for 13 out of these 19 chemicals. For the remaining six chemicals, depletion data could be obtained from different sources, which were subsequently interpreted using the same criteria of the modified DPRA applied to the 13 chemicals tested in our laboratory. An overview of the 19 chemicals used for evaluation with the DPRA data sources are presented in Table 1.

\section{Design of the testing strategy}

It was decided to aim for predictions with the highest probability of being correct (highest positive predictive value (PPV) and negative predictive value (NPV)), as was also done for the SAR approach [92]. In addition, it was decided that the currently proposed testing strategy should at least address the molecular initiating event of the LMW respiratory sensitization process; conjugation of a chemical to a protein to form a hapten-protein conjugate $[29,51]$. This event is indeed evaluated by the SAR approach; therefore, it is tier 1 of the currently proposed testing strategy. The downside of the SAR approach was that several chemicals could not be predicted with sufficient certainty. This was due to issues with SAR applicability domains or due to the low predictivity of the applicable SARs. To obtain the required information on the protein conjugation potential for the chemicals for which no prediction with sufficient certainty could be produced, (modified) DPRA data was used instead. 
Table 1. Overview of chemicals used for the evaluation of the proposed testing strategy

\begin{tabular}{|c|c|c|}
\hline Chemical & CAS number & Source of DPRA data \\
\hline \multicolumn{3}{|l|}{ Respiratory sensitizers } \\
\hline Hexamethylene diisocyanate & $822-06-0$ & Dik et al., 2016 \\
\hline Toluene diisocyanate & $584-84-9$ & Lalko et al., 2012 \\
\hline Maleic anhydride & $108-31-6$ & Dik et al., 2016 \\
\hline Phthalic anhydride & $85-44-9$ & Dik et al., 2016 \\
\hline Trimellitic anhydride & $552-30-7$ & Dik et al., 2016 \\
\hline Ethylene diamine ${ }^{1}$ & $107-15-3$ & Dik et al., 2016 \\
\hline Triethylenetetramine ${ }^{1}$ & $112-24-3$ & Dik et al., 2016 \\
\hline Ethanolamine $^{1}$ & $141-43-5$ & Dik et al., 2016 \\
\hline Chloramine- $\mathrm{T}^{2}$ & $127-65-1$ & Dik et al., 2016 \\
\hline Glutaraldehyde & $111-30-8$ & Dik et al., 2016 \\
\hline Formaldehyde & $50-00-0$ & Gerberick et al., 2007 \\
\hline \multicolumn{3}{|l|}{ Respiratory irritants } \\
\hline Methyl salicylate & $119-36-8$ & Gerberick et al., 2007 \\
\hline Sodium dodecyl sulfate & $151-21-3$ & Natsch et al., 2013 \\
\hline \multicolumn{3}{|l|}{ Respiratory non-sensitizers } \\
\hline Glycerol & $56-81-5$ & Gerberick et al., 2007 \\
\hline Lactose & $63-42-3$ & Dik et al., 2016 \\
\hline Mannitol & $69-65-8$ & Dik et al., 2016 \\
\hline Vanillin & $121-33-5$ & Dik et al., 2016 \\
\hline Saccharin & $81-07-2$ & Natsch et al., 2013 \\
\hline Lactic acid & $50-21-5$ & Dik et al., 2016 \\
\hline
\end{tabular}

Since the SAR approach is a non-testing method and neither the SAR approach nor the modified DPRA evaluate the biological aspects of respiratory sensitization, the outcome of tier 1 is chosen to be confirmed in tier 2 by a biological testing method; the in vitro model described by Dik et al. 2015 [138]. This approach therefore provides information on more than one different key elements in the respiratory sensitization AOP [33]. If a prediction on a chemical in tier 1 is confirmed by tier 2 , it was considered a respiratory (non-) sensitizer. When the outcome of both tiers is contradictory, the outcome was considered equivocal and further testing or information is required to come to a conclusion on the respiratory sensitization potential of that chemical. A schematic overview of the proposed testing strategy is given in Figure 1. 


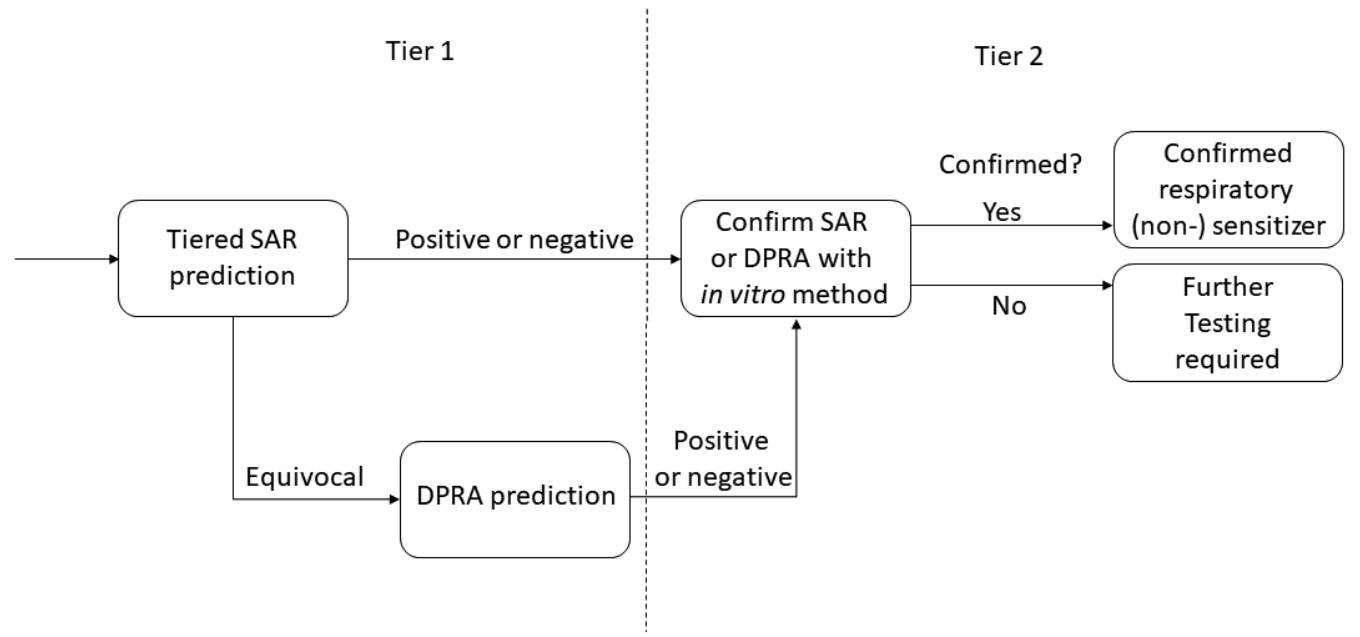

Figure 1. Schematic representation of the proposed testing strategy for evaluation of respiratory sensitization potential of Low Molecular Weight organic chemicals; using the individual test methods presented in this thesis.

\section{RESULTS}

In tier 1, the SAR approach was able to generate a prediction for nine out of eleven respiratory sensitizers, one out of the two respiratory irritants and two out of the six respiratory non-sensitizers. Seven chemicals for which the prediction from the tiered SAR approach was equivocal were all tested in the DPRA, hence all chemicals can be concluded on in the first tier of the testing strategy. As the selection of chemicals was based on availability of test data from the in vitro epithelial cell assay, a prediction by that model is also available for all chemicals. The predictions generated for each chemical by each of the testing methods are given in Table 2. DPRA data for the chemicals that already gave a conclusive prediction using the SAR approach are also given for completeness.

All respiratory sensitizers were correctly predicted as such by the first tier, either by the SAR approach or the modified DPRA. Using only de DPRA test to assess the potential to form hapten-protein conjugates would lead to three false negatives that require metabolic activation (ethylene diamine, triethylenetetramine and ethanolamine) [51]. This can be attributed to the absence of any metabolic competence in the DPRA test. The positive outcomes from tier 1 were all subsequently confirmed by the in vitro model, which apparently does have (some) metabolic competence. The two respiratory irritants were both correctly predicted as respiratory non-sensitizers. Here the DPRA test gave a correct (negative) result for methyl salicylate, the substance for which the SAR strategy produced contradictory information. In the second tier the absence of respiratory sensitization potential for these two respiratory irritants was also confirmed correctly in vitro. Of the six respiratory non-sensitizers, five were correctly predicted as such by the first tier and subsequently confirmed as respiratory non-sensitizers by 
Table 2. Overview of the predictions of each individual (non-)testing method

\begin{tabular}{|c|c|c|c|c|}
\hline \multirow[b]{2}{*}{ Chemical } & \multicolumn{2}{|c|}{ Tier 1} & \multirow{2}{*}{$\begin{array}{c}\text { Tier } 2 \\
\begin{array}{c}\text { In vitro } \\
\text { prediction }\end{array}\end{array}$} & \multirow{2}{*}{$\begin{array}{c}\text { Overall } \\
\text { Conclusion }\end{array}$} \\
\hline & $\begin{array}{c}\text { SAR } \\
\text { prediction }^{*}\end{array}$ & $\begin{array}{c}\text { DPRA } \\
\text { prediction }^{*}\end{array}$ & & \\
\hline \multicolumn{5}{|l|}{ Respiratory sensitizers } \\
\hline Hexamethylene diisocyanate & + & + & + & + \\
\hline Toluene diisocyanate & + & + & + & + \\
\hline Maleic anhydride & + & + & + & + \\
\hline Phthalic anhydride & + & + & + & + \\
\hline Trimellitic anhydride & + & + & + & + \\
\hline Ethylene diamine & + & - & + & + \\
\hline Triethylenetetramine & + & - & + & + \\
\hline Ethanolamine & + & - & + & + \\
\hline Chloramine- $\mathrm{T}$ & + & + & + & + \\
\hline Glutaraldehyde & * & + & + & + \\
\hline Formaldehyde & * & + & + & + \\
\hline \multicolumn{5}{|l|}{ Respiratory irritants } \\
\hline Methyl salicylate & * & - & - & - \\
\hline Sodium dodecyl sulfate & - & - & - & - \\
\hline \multicolumn{5}{|l|}{ Respiratory non-sensitizers } \\
\hline Glycerol & - & - & - & - \\
\hline Lactose & * & - & - & - \\
\hline Mannitol & - & - & - & - \\
\hline Vanillin & * & + & & + \\
\hline Saccharin & * & - & - & - \\
\hline Lactic acid & * & - & - & - \\
\hline
\end{tabular}

A + or - sign indicates that the method provided a positive or negative prediction. An asterisk indicates an equivocal prediction.

the second tier. Vanillin gave contradictory predictions in the different SARs, leading to an equivocal prediction. It is predicted to be a respiratory sensitizer by the modified DPRA, but this is contradicted by a negative outcome in the second tier. The overall prediction for vanillin is therefore considered equivocal. The prediction accuracy of the proposed testing strategy for identification of respiratory sensitization potential of 95\% of the LMW chemicals is considered conclusive, based on predictions that were accepted (not equivocal). For the remaining 5\% it would remain uncertain whether the substance is a respiratory sensitizer, or a non-sensitizer based on the outcome of this testing strategy using three different methods. 


\section{DISCUSSION}

The aim of this chapter was to evaluate whether a testing strategy could be constructed to conclude on the respiratory sensitization potential of LMW chemicals. It is clear from the results that, although the current evaluation is small in its set-up, a testing strategy for the respiratory sensitization potential of LMW chemicals is feasible. An overview of the performance of the proposed testing strategy compared to each individual published (non-)testing method used for the testing strategy is given in Table 3.

When comparing the outcome of the testing strategy to each individual method, the testing strategy outperforms all in terms of number of chemicals for which a prediction could be made as well as for prediction accuracy. Based on this, it can be stated that the proposed testing strategy is statistically adequate to conclude on the respiratory sensitization potential of chemicals. In addition, the SAR approach and the (modified) DPRA included in the testing strategy address the first key event in the process leading to respiratory sensitization; covalent binding of a chemical to a protein $[29,51]$. Furthermore, inclusion of the in vitro method adds a biological parameter to the prediction, which represents the first layer of cells a LMW respiratory sensitizer encounters in the lungs. This aspect can be considered part of another key event in the AOP for respiratory sensitization, generation of danger signals due to damage to the lung epithelium [33].

Although two key events of the AOP for respiratory sensitization are included in the currently proposed testing strategy, another key event is not represented. This is activation and migration of dendritic cells (DCs) [33], as maturation of a DC is an essential event in the sensitization of an organism [140]. One aspect that occurs with activation of the DC is an increase of CD80 and CD86. Recently a study was published that aimed to differentiate skin from respiratory sensitizers using a $3 \mathrm{D}$ coculture which includes DCs [141]. One interesting point from that study is that it was shown that exposure to respiratory sensitizers significantly induced the expression of CD80 and CD86 compared to controls. Although this study was performed using

Table 4. Overview of all Cooper statistics, prediction accuracy and the percentage of chemicals predicted by each individual model evaluated in this thesis and the testing strategy proposed in this chapter

\begin{tabular}{lcccccc}
\hline Model & $\begin{array}{c}\text { Sensitivity } \\
(\%)\end{array}$ & $\begin{array}{c}\text { Specificity } \\
(\%)\end{array}$ & $\begin{array}{c}\text { PPV } \\
(\%)\end{array}$ & $\begin{array}{c}\text { NPV } \\
(\%)\end{array}$ & $\begin{array}{c}\text { \% of chemicals } \\
\text { predicted }\end{array}$ & $\begin{array}{c}\text { Prediction } \\
\text { accuracy (\%) }\end{array}$ \\
\hline SAR tiered approach & 92 & 98 & 98 & 92 & 35 & 96 \\
Modified DPRA & 72 & 86 & 83 & 76 & 100 & 78 \\
In vitro study & 92 & 90 & 92 & 90 & 100 & 86 \\
Testing strategy & 100 & 100 & 100 & 100 & 95 & 100 \\
\hline
\end{tabular}


a minimal amount of chemicals, it could be envisioned that such a test could be used as an addition to the proposed testing strategy as it would include a test that again represents one of the key elements in the respiratory sensitization AOP.

The currently applied in vitro method not only covers an important aspect of the AOP. In addition, it provides a means to potentially test for the requirement of metabolism. Several chemicals that can cause respiratory sensitization require either to be metabolized by enzymes before they become reactive towards proteins or they need to be abiotically transformed (e.g. oxidation or hydrolysis). These chemicals are called pro- and pre-haptens $[102,103]$. Pre-haptens were already shown to be correctly identified by the SAR approach and the modified DPRA $[92,137]$. In addition, the only pre-hapten used in the current chapter, Chloramine-T, was also correctly identified as a respiratory sensitizer by the in vitro epithelial cell assay. For the identification of pro-haptens, an attempt was made to incorporate a metabolic step in the DPRA [94]. However, the results, compared to the non-metabolic DPRA, were not improved and several differences between the two compared methods made interpreting the outcome difficult. The current applicability domain of the DPRA therefore does not include pro-haptens, as no metabolic steps are successfully incorporated in the testing method yet. A metabolic step is also not literally incorporated in the SAR approach. Derek does have the possibility to simulate liver metabolism, but it is not known whether the same metabolic processes take place in the lungs. Hence it is not known whether this option is relevant for respiratory sensitization. On the other hand, some other SAR models were trained using the pre-existing knowledge that for example chemicals with an amine functionality require metabolic activation and hence they are correctly predicted as respiratory sensitizers by those SAR models. This specific class of chemicals (exemplified in this chapter by ethylene diamine, triethylenetetramine and ethanolamine) showed negative results in the DPRA but positive results in the SAR approach (Table 1). Interestingly, amines were considered outside the applicability domain of the Derek SAR model [92] which was the reason the tiered SAR approach integrated the amine structural alert of Enoch et al. 2012 [51]. This alert recognizes pro-haptens with an amine functionality and is based on the theory that they need to be metabolized to glyoxal to become reactive. It is also suggested that testing a theoretical metabolite directly in the DPRA could also lead to the correct identification of a pro-hapten. However, the predictive performance of such an approach is dependent on the ability to identify a pro-hapten a priori [92].

Although in terms of predictivity the issue of chemicals containing an amine functionality such as ethylene diamine, triethylenetetramine and ethanolamine was solved, metabolism in general is not sufficiently covered by any (Q)SAR or chemical assay for respiratory sensitization to date. Since the in vitro assay in tier 2 did correctly identify the amines, it can be stated that it was prudent to include a biological test to confirm the in silico or in chemico results. However, only pro-haptens with an amine functionality were tested in the in vitro method, so no definitive conclusions on 
the metabolic capacity of this testing method is possible. When selecting an in vitro testing method for a testing strategy, it cannot be automatically assumed that it includes a representative metabolizing capacity. For example, the amine-containing respiratory sensitizers ethylenediamine and piperazine were predicted to be sensitizers by the currently applied lung epithelial in vitro test, which suggests that they were metabolized to their reactive species. However, in another published in vitro model using a different cell line, the same amine-containing chemicals were predicted to be non-sensitizers [134]. This result was commented on by stating that both chemicals can induce lung allergy as well as skin allergy, and hence their model is not able to predict chemicals that induce both types of sensitization. However, several of the other predicted respiratory sensitizers that they tested can also cause both skin and respiratory sensitization. Since piperazine and ethylenediamine are both considered to be pro-haptens [51], it is more likely that this specific in vitro model does not have sufficient metabolic capacity to metabolize ethylenediamine and piperazine and as such they are not picked up as respiratory sensitizers. These findings therefore clearly show both the need for the presence of a metabolic predictor in non-testing methods, and/or the presence of metabolic capacity in at least one assay used in a testing strategy, as well as a good description of the (limits of) metabolic capacity of the in vitro assays used.

\section{CONCLUSION}

Based on the statistical performance and the incorporation of testing methods that evaluate different relevant aspects of respiratory sensitization, it can be concluded that the proposed testing strategy is applicable for the prediction of respiratory sensitization potential of LMW chemicals. However, the strategy has a clearly defined applicability domain: it can only confidently predict LMW chemicals that do not require to be metabolized to elicit a response (haptens), as well as pre-haptens and amine-containing pro-haptens. Based on the limited set of chemicals to which the testing strategy was applied, it cannot yet be confirmed nor rejected that the proposed strategy can generate reliable predictions for other chemical classes. To conclude on the more general applicability of the testing strategy, more test data for the modified DPRA, the lung epithelial in vitro assay and potentially the $3 \mathrm{D}$ coculture including DCs on chemicals from other chemical classes is be required. 




\section{H A P T E R 6}

SUMMARY

AND DISCUSSION 



\section{SUMMARY AND DISCUSSION}

The aims of the studies outlined in this thesis were to optimize the currently existing testing methods for the identification of respiratory sensitizers and to contribute to a better understanding of the biological processes of respiratory allergy. In addition, an effort was made to evaluate a testing strategy for the identification of LMW respiratory sensitizers based on data acquired from individual (non-)testing methods.

Chapter 2 describes the evaluation of several in silico models that aim to predict the respiratory sensitization potential of chemicals. These models can be divided into two categories: Models that evaluate the ability of a chemical to covalently bind a protein, which is the molecular initiating event for respiratory sensitization $[33,51]$; and models that statistically relate structural information directly to the occurrence of occupational asthma. The first aim was to evaluate the individual models by comparing the published statistical performance of each model to the performance of the same model using a test set of chemicals which were never seen by that model. In all cases, the performance on the test set was markedly lower. Therefore, it was concluded that none of the individual in silico models are to be used as a stand-alone method to identify respiratory sensitizers and non-sensitizers. The second aim was to combine the best-performing individual models to increase the reliability of a prediction on a chemical. For this purpose, it was chosen to combine those models that individually performed best in correctly identifying respiratory sensitizers or non-sensitizers. In this case, the Derek Nexus knowledge base [73] performed best in correctly identifying respiratory sensitizers and MultiCASE [70] performed best in correctly identifying non-sensitizers. When combined, the predictive performance of the tiered strategy compared to the individual models increased by $54 \%$ and $12 \%$ respectively. The downside of this approach was that a prediction could be generated for only for one third of all chemicals. Hence it was concluded that additional information from other test methods was required to conclude on the respiratory sensitization potential for those chemicals.

To obtain the additional information on the respiratory sensitization potential of (part of) those remaining chemicals, chapter 3 aimed to evaluate and improve the Direct Peptide Reactivity Assay (DPRA) for the identification of respiratory sensitizers and non-sensitizers. The DPRA was chosen as it addresses the molecular initiating event in the AOP for respiratory sensitization [33]. Originally the DPRA was developed for the identification of skin sensitizers [104]. As the molecular initiating event for LMW skin- and respiratory sensitization are both covalent binding to proteins, the DPRA could be a promising method to identify respiratory sensitizers as well. In addition to the standard DPRA protocol, application of mass spectrometry and measurements at different time-points were found to increase the confidence of a prediction of the respiratory sensitization potential of chemicals. It was for example shown that some respiratory sensitizers showed covalent binding after 20 minutes, but not after 24 hours of incubation. If only the 24 -hour measurement were to be available, 
those chemicals would wrongfully be concluded as non-sensitizers. This application of the DPRA resulted in highly confident predictions with a prediction accuracy of $78 \%$ for the tested dataset. In chapter 5, the DPRA results were used to obtain predictions for those chemicals that could not be predicted by the in silico approach. Although the DPRA provides reliable results on many chemicals within its applicability domain, it was also concluded in chapter 3 that the DPRA has some applicability domain issues. For example, pro-haptens such as chemicals containing an amine functionality were not correctly identified as respiratory sensitizers by the DPRA. This is probably due to a lack of metabolism. Lalko et al. 2012 [94] tried to solve this issue by adding a peroxidase system to the DPRA, but it was found that this specific addition did not result in the consistent identification of pro-haptens. Metallic respiratory sensitizers, such as chloroplatinate salts, also cannot yet be identified using the DPRA, as discussed by Basketter et al. 2017 [142], as these type of chemicals cannot covalently bind proteins and are therefore not identified by the DPRA.

As both the in silico models and the DPRA only address the molecular initiating event of respiratory sensitization, chapter 4 describes a study that aimed to predict the respiratory sensitization potential based on a set of regulated genes in lung epithelial cells. Epithelial cells were selected as they are the first type of cells an inhaled chemical comes in contact with in the lungs. Respiratory sensitizers are thought to generate danger signals and proinflammatory mediators necessary to induce an adaptive immune response upon contact with the pulmonary epithelium [33]. Epithelial cells were exposed to different respiratory sensitizers, respiratory irritants and non-sensitizers and a discriminating set of genes were found that can predict the respiratory sensitization potential of chemicals with an accuracy of $95 \%$. These genes were also found related to several biological processes involved in asthma, such as the pulmonary barrier function and regulation of the IL-33 pathway, which is implicated in airway inflammation [126]. On the other hand, no genes relating to the expected danger signals and other immunological pathways were found to be regulated by respiratory sensitizers. These results are in line with other in vitro gene expression studies on this toxicological endpoint $[27,28,130]$. Clearly, more effort is needed to further investigate the usefulness of in vitro models for the identification of respiratory sensitizers.

The conclusion of chapter 4 is that the application of testing strategies is necessary as an individual animal-free method only addresses a small part of the involved biological pathways. This was at that time difficult to envision for respiratory sensitization, as the AOP for respiratory sensitization was not yet clearly defined. Recently however, the respiratory sensitization adverse outcome pathway has been published [33] and chapter 5 therefore describes an attempt to combine the methods described in chapters 2, 3 and 4 into a testing strategy, based partially on the published AOP. It was shown in chapter 5 that the lacking information of the in silico methods could be filled by using the DPRA, and that the outcome of those methods could be verified by our in vitro model. Chapter 5 concludes that by combining these methods, all chemicals tested 
could be predicted with an accuracy of $95 \%$. It should be noted that this performance was only achieved for a small set of chemicals, and that by no means the chosen combination of tests is per definition the best set of tests to combine. Each individual method has its advantages and disadvantages, and these need to be considered properly when any combination of tests is to be chosen. This will be addressed in more detail in the next section.

\section{Advantages and disadvantages of individual methods}

This thesis has evaluated three animal-free testing methods for the identification of LMW respiratory sensitizers; an in silico approach using structure activity relationship models (Q)SARs (chapter 2), an in chemico method based on the DPRA (chapter 3) and a lung epithelial cell-based in vitro method (chapter 4). Each method has its advantages and disadvantages.

In silico methods - (Q)SARs

In terms of complexity and workload, a QSAR is relatively simple to use and can generate many predictions in a short amount of time. In principle any known and untested chemical can be evaluated, as long as the chemical structure is available. It also does not suffer from any practical limitations that other testing methods might have. For example, there will never be problems with dissolving a chemical for a test or chemical interference regarding the read-out of the test. However, QSARs are also most distant from the complex biological situation of an organism. In addition, they are non-experimental testing methods; e.g. there is no physical experimentation involved. A downside of non-experimental testing methods, compared to any experimental testing method, is that a QSAR is heavily limited by the number and variety of chemicals used to develop the model. If a new chemical that is evaluated does not resemble one of the training set chemical structures in any way, a QSAR cannot (or should not) be used to extrapolate its knowledge to the new chemical. The same is not true for an experimental testing method, as that same chemical could for example be tested in an in vitro test with a subsequent outcome, even if that chemical was never evaluated in that specific test before.

In chemico method - modified DPRA

An in chemico test such as the modified DPRA is a method that is still relatively fast in terms of required operating time. The modified DPRA also poses few practical difficulties. For example, there are no issues of general toxicity effects on cell cultures that hinder the evaluation of the actual immunological effects. Chemicals that only dissolve in solutions that are toxic to cells can usually still be tested. Yet, differences in applied solvents should be evaluated, as different solvent systems can give rise to different outcomes for the same chemical. This was for example shown by comparing the traditional DPRA and a DPRA method that incorporated a metabolic step [94]. A disadvantage of an in chemico test is that it is a simplification of protein binding, 
as it lacks the full spectrum of proteins available in vivo. In case of the DPRA, two heptapeptides are used, both containing one functional amino acid. In terms of predictivity these peptide sequences were found to predict skin- and respiratory sensitizers best [143]. However, these two amino acids are not the only reactive amino acids present in a biological system. In addition, the DPRA aims to evaluate amino acid binding. If a sensitizer is found to bind the lysine-containing peptide, it is not to say that any lysine-containing peptide in a biological setting will be bound by that sensitizer. The heptapeptides used are so small that tertiary and quaternary protein structures that are present in a biological system are not formed in the DPRA. An implication of this simplification was for example shown in a study by Kristiansson et al. 2003 [108] in which only seven of the lysine residues of the albumin protein were actually bound by hexahydrophthalic anhydride. Another disadvantage is that the DPRA measures peptide binding in general. This implies that it will also identify most skin sensitizers, as they also need to covalently bind proteins before they can be processed by the immune system. This distinction is important from a regulatory perspective, as skin sensitizers and respiratory sensitizers are classified in two different hazard classes [139]. It was proposed by Lalko et al. 2012 [54] that the DPRA is able to make this distinction, as skin sensitizers would preferably bind cysteine-containing peptides whereas respiratory sensitizers would preferably bind lysine-containing peptides. However, as shown in chapter 3, this assumption should not be made this easily. This conclusion was based on data from our own study as well as data from other publications, showing that only specific classes of chemicals preferentially bind lysine- or cysteine containing peptides. Among these are isocyanates that indeed preferentially bind cysteine-containing peptides. However, isocyanates are not only skin sensitizers, but also respiratory sensitizers so there is no clear distinction to be made for isocyanates based on the DPRA. Our DPRA data also shows contradicting binding preferences for anhydrides after 20 minutes of incubation compared to other published data, which was inverted after 24 hours for only some of the anhydrides. Therefore, it is not possible to clearly divide these chemicals in respiratory- and skin sensitizers, as some respiratory- and skin sensitizers clearly show the opposite binding preference. To conclude, the DPRA can be used in the identification of sensitizers but is not able to distinguish respiratory from skin sensitizers.

In vitro methods - monocultures and more complex systems

Chapter 4 describes an in vitro lung epithelial method that could correctly identify respiratory sensitizers based on changes in gene expression that mainly relate to the barrier function of the lungs. In addition, other affected genes were found that could be linked to parts of the immunological pathways involved in respiratory sensitization. One of the advantages of this in vitro model is that it was possible to evaluate sodium hexachloroplatinate, a respiratory sensitizer that cannot be tested currently in the DPRA due to its applicability domain. On the other hand, the in vitro model in chapter 4 did 
not specifically aim to make the distinction between respiratory- and skin sensitizers. It is therefore not possible to conclude that the in vitro monoculture could make this distinction or not and therefore our in vitro model cannot yet be used in this regard. This needs to be further evaluated in subsequent studies using monocultures.

An already existing in vitro method to distinguish between respiratory- and skin sensitizers is the application of complex 3D tricultures with three different cell types interacting with each other [141]. This system replicates the complex biological system of an organism to a higher extent compared to a monoculture. Mizoguchi et al. [141] applied a 3D coculture of human airway epithelial cells, immature dendritic cells and human lung fibroblasts and evaluated the production of several different cytokines related to T-helper 2 cell differentiation, the most likely mechanism that differentiates skin- and respiratory sensitizers. It was found that both types of sensitizers induced cytokines involved in DC maturation markers. However, typical respiratory sensitizers (such as hexamethylene diisocyanate) also induced cytokines associated with T-helper 2 cell stimulation, whereas typical skin sensitizers (such as 2,4-dinitrochlorobenzene) did not induce these cytokines.

Another potential disadvantage of our in vitro can be discussed based on the result that it showed effects on the barrier function, but no effects on expected danger signals. A potential explanation for this observation is that some chemicals require to be hydrolyzed or oxidized to become active respiratory allergens (called pre-haptens). On the other hand, some chemicals might also be deactivated through hydrolysis, thereby losing their potential to interact with the cells. In culture medium, hydrolyzation will readily occur and the solvent used in the DPRA can easily be changed to allow for hydrolyzation. Applying a chemical in culture medium could therefore result in unexpected results that are not found when the same chemical is inhaled, as submerged cell exposure is not relevant for inhalation of chemicals in the lungs. To evaluate a more in vivo like situation, respiratory sensitizers would need to be applied to a cell culture in an air-liquid exposure setting, in which chemicals can be dispersed as vapors and interact with the epithelial cells directly. This approach was for example used to test for in vitro effects of cigarette smoke [144]. Although the use of air-liquid interface exposure mimics the in vivo situation even better than submerged cell lines, it also adds another layer of complexity to the experimental setup.

\section{Reference list of respiratory sensitizers and non-sensitizers}

Each of the described methods show potential to be used for the identification of respiratory sensitizers. However, one of the reasons that they are not yet widely validates is that the methods are developed using a small number of chemicals. These are usually the same set of 'standard' respiratory sensitizers and non-sensitizers. As shown in chapter 2 , when a new set of chemicals is applied to a method, it is not unlikely that it will perform less compared to its original chemical training/development set. Therefore, additional chemicals should be tested in the various methods described to 
define applicability domain issues and overall refine the methods. Only then can they be validated and subsequently become widely accepted as methods for the identification of respiratory sensitizers. To do this, an accepted reference list of chemical respiratory sensitizers and non-sensitizers is required. Some chemicals are widely accepted as such. Anhydrides and isocyanates are commonly stated and used as respiratory sensitizers. However, it is this set of chemicals that was used for the development of a method and therefore no or only a small number of reference chemicals can be used to validate a method. It is therefore crucial that the list of reference chemicals for respiratory sensitization is expanded.

The most biologically relevant way to find validated respiratory sensitizers is a study using humans. As this will likely result in undesirable effects in humans, epidemiological studies and case studies from medical incidents are used instead. However, in the case of respiratory sensitization, this poses a problem. Work-related asthma can be divided into several types. Irritant-induced asthma (IIA) caused by exposure to respiratory irritants is an example. Respiratory irritants induce OA without sensitizing the individual, hence these chemicals cannot be called respiratory sensitizers [145]. However, the diagnosis criteria for IIA resembles the diagnosis criteria of occupational asthma to a high extent. The same can also be stated for chemicals causing work aggravated asthma (WAA) [145]. As both IIA and WAA disease profiles very much resemble the symptoms of OA, it can be concluded that it is clinically very difficult to accurately diagnose occupational asthma caused by a respiratory sensitizer. It can therefore be stated that it is difficult to produce a valid reference list of chemicals that do and do not induce respiratory sensitization. This issue was also addressed in chapter 2. Different in silico models were developed using different criteria for accepting a chemical as respiratory sensitizer and non-sensitizer. All models used clinical data as input for selecting their respiratory sensitizers. However, as discussed, this might lead to ambiguous results, as a training set used to develop a testing method might include respiratory irritants as well. This was clearly shown for several acid-containing chemicals. They were interpreted as being respiratory sensitizers by one model as this type of chemical was interpreted as respiratory sensitizer based on clinical data. Another SAR model interpreted them as being non-sensitizers due to the lack of a chemically reactivity group. It was found that some acid-containing chemicals were identified as respiratory sensitizers by the latter model because they also contained other functional groups associated with respiratory sensitization. Based on the difficulty of diagnosing $\mathrm{OA}$, and subsequently correctly identifying a respiratory sensitizer, it can be argued that acid-containing chemicals should not be used as respiratory sensitizers in a training set. It was therefore concluded that it is more likely that acid-containing chemicals are respiratory irritants, but more insight in immunological versus non-immunological causes of $\mathrm{OA}$ is still required. In terms of expanding (and possibly even re-evaluating) the list of accepted respiratory sensitizers and non-sensitizers, progress in the field of diagnosing OA and correctly identifying respiratory sensitizers should be prioritized. 


\section{Testing strategies}

The described animal-free alternative testing methods were discussed to have several advantages and disadvantages. Whichever method is ultimately deemed the most advantageous, they are all limited by nature, as they represent only a small part of an entire organism or toxicological process. Even a combined air-liquid exposure $3 \mathrm{D}$ coculture in vitro model, with all its complexity, still does not reflect the complex biological situation of an entire organism. In addition, even when a testing method very closely mimics one biological aspect involved in a toxicological process, it then usually lacks the interaction with other aspects of the biological processes evaluated by other tests. Increasing awareness of these limitations of applying one individual testing method has stimulated the concept of combining several methods to conclude on a specific toxicological endpoint. Although understanding of the biological effects of exposure of a chemical on a human is often lacking, combining these methods could potentially be used to conclude on the hazard of a chemical. This general concept is called an integrated testing strategy (ITS) or integrated approach to testing and assessment (IATA).

\section{Concepts of testing strategies}

There are two major approaches in the world that can fuel an ITS. One of them is described by the ToxCast project and the Tox 21 project, in which many chemicals are being tested in a high throughput fashion. Several different assays that are expected to address different pathways of toxicity and modes of action in humans are used. Based on this data, prioritization of chemicals based on potential human health risks is achieved [146]. The advantage of this approach is that enormous amounts of data are generated which could be used in an ITS. The limitation is that a useful combination of assays needs to be found to address a specific toxicological endpoint and hence it is possible that many experiments are done without the data actually being used. For LMW chemical induced asthma, such a combination of assays has yet to be found, although chapter 5 has provided a general direction.

The other approach aims to develop and combine testing methods using an AOP as a mechanistic framework [147]. The advantage is that no excessive tests are performed, as the testing methods are each specifically designed to address one key element in an AOP. The downside is that an AOP for a toxicological endpoint has to be developed to a certain extent before an ITS can be devised. In the case of skin sensitization for example, the AOP is well defined [93]. In the case of LMW respiratory sensitization, an AOP is recently published in which several key elements are described, such as protein binding and DC activation [33]. It is by virtue of these AOPs that specific knowledge gaps can be identified and methods to address these gaps can be developed with the specific purpose of filling these gaps, instead of generating lots of potentially useful or useless information.

\section{Designs of testing strategies}

There are several ways to compose a testing strategy. Probably the simplest approach is to test a chemical in an uneven number of assumed equally important tests. 
When the outcome of most tests is positive, the chemical is considered positive for the evaluated toxicological endpoint. When all tests are performed simultaneously (to generate as much data as possible), this design is called an integrated testing strategy and the decision is based on majority voting [148]. The difficulty is to determine whether the different testing methods are equally contributing to the endpoint under evaluation or not. A variation on this strategy is to include a weight to each test. In other words, what is the impact of a result in one test compared to a contradictory result from another test for the conclusion? It might be argued that a positive in vitro test result should outweigh a negative QSAR outcome, as the in vitro test is more biologically relevant compared to the QSAR model. But what if the prediction accuracy of the QSAR is much higher? This is called a weight of evidence approach (WoE) [148]. Both the integrated approach and the WoE approach require that all involved tests are performed and based on each individual outcome, a decision is made. While this is not necessarily a wrong approach, considerable amounts of work are required to test a chemical in each testing method present in these strategies. This is especially true when one of the involved testing methods is time consuming.

To reduce the amount of time and money required to conclude on the toxic potential of a chemical, a third type of testing strategy that does not require each test present in the strategy to be carried out is also possible. This is called a tiered testing strategy [148]. In a tiered testing strategy, one or more tests are selected to be done first (tier 1). The outcome of the first tier defines which other tests are required to conclude on the toxicological potential of a chemical in a subsequent tier. For example, a positive QSAR result could only require that one in vitro method confirms this finding, while a negative QSAR result would need to be confirmed by at least a few other testing methods before the chemical is assumed safe. In this example, a positive QSAR result reduces the number of tests to be performed. This approach only works if the certainty of the initial prediction is high, as the first testing method to be used determines the follow-up steps. In addition, this approach only makes sense when the selected testing methods apply to one or more known key elements in the AOP of the toxicological endpoint. For example, the proposed tiered testing strategy for skin sensitization by Van der Veen et al. [132] applied a combination of QSARs and the DPRA to test for binding of a chemical to a protein, resulting in a hapten-protein conjugate. This binding is the first step in the AOP for skin sensitization [93]. A second, in vitro, test is then performed depending on the outcome of the SAR/DPRA result. The different in vitro tests relate to other critical events in the skin sensitization AOP. The application of tiered testing strategies was also successfully applied in chapter 2 and chapter 5 of this thesis.

\section{Conclusion and future perspectives}

Validation and acceptance of individual testing methodologies for predicting respiratory sensitizing activity of low molecular weight of chemicals is hampered because of two 
major issues. First, a reference list of chemicals that do and do not induce respiratory sensitization is not publicly accepted. The reason is that in a clinical setting it is difficult to identify chemicals that cause occupational asthma which ultimately leads to uncertainties in the results of individual testing methods. Therefore, it is necessary to further the field of diagnosing occupational asthma to correctly identify respiratory sensitizers (not irritants) in a work environment. This should increase the number of accepted respiratory sensitizers, which can subsequently be used to further develop and validate the existing testing methods. In that respect, the development of an air-liquid interface exposure system combined with a 3D coculture model seems the way forward. This system mimics the in vivo situation best with respect to the primary type of exposure as well as part of the immunological pathways involved in respiratory sensitization. It is to be expected that this approach will resolve several false positive and negative predictions that now occur due to the inability of methods to correctly identify pre- and pro-haptens. Furthermore, this method can also provide the necessary insights in the immunological pathways involved in respiratory sensitization. Currently, the immunological pathways involved in respiratory sensitization are largely unknown. This is the second issue that hampers the validation and acceptance of individual testing methods. It is unclear whether individual methods address relevant pathways for respiratory sensitization, or sensitization in general. This issue is partially resolved by the recent publication of the respiratory sensitization AOP. However, from this AOP it remains clear that more effort is required to elucidate the pathways leading to LMW respiratory sensitization. On the other hand, chapter 5 showed that it is possible to come to a statistically reliable conclusion based on a small set of chemicals. In addition, the individual methods selected for the testing strategy address relevant pathways in the respiratory sensitization AOP (chemical binding to a peptide and a potential biological relevant exposure site epithelial barrier in the lungs). It can therefore be stated that the proposed testing strategy is one step further towards the prospective identification of low molecular weight respiratory sensitizers compared to each individual testing method available to date. 



\section{$A D D E N \cup M \quad \&$}

NEDERLANDSE SAMENVATTING VALORISATION PARAGRAPH TO THE PHD THESIS

REFERENCES

DANKWOORD

LIST OF PUBLICATIONS

CURRICULUM VITAE 


\section{NEDERLANDSE SAMENVATTING}

Volgens de wereld gezondheidsorganisatie waren er aan het einde van het jaar 2017 meer dan 235 miljoen mensen die aan de ziekte astma lijden. Astma is een longziekte die ontstaat door een allergische reactie na het inademen van stoffen. Een veelvoorkomend voorbeeld hiervan is een allergie voor huisstofmijt. Wanneer deze mensen in contact komen met huisstofmijt krijgen ze last van nies- en hoestaanvallen en ademnood. Een minder voorkomende vorm van astma, maar net zo vervelend als hooikoorts, is werk gerelateerde astma. Net als bij hooikoorts ademt een persoon een bepaalde stof in waarna een allergische reactie met alle symptomen van astma optreedt. Dit type astma heeft zijn naam gekregen omdat het type stoffen dat in dit geval ingeademd worden alleen in werksituaties voorkomen. Voorbeelden van werkplekken waar vaak astma opgelopen wordt zijn mijnen, de gezondheidszorg, fabrieken, de kapper en schoonmaakbedrijven. Het type verbinding waar medewerkers in deze situaties aan blootgesteld worden zijn vaak chemische stoffen. Het hebben van werk gerelateerde astma heeft in de meeste gevallen een zeer grote impact op de sociaaleconomische status van de werknemer, omdat de getroffen werknemer in de meeste gevallen niet meer het werk kan doen waarbij hij in contact is gekomen met de stof. Er wordt geschat dat ongeveer een kwart van alle astmapatiënten last hebben van werk gerelateerde astma, dus is het zeer wenselijk om dit probleem op te lossen.

Er bestaat geen medicijn voor werk gerelateerde astma. Dit komt omdat er nog te weinig bekend is over de manier waarop dit type astma ontstaat. Dit geldt voornamelijk voor astma wat ontstaat door het inademen van chemische stoffen, ook wel long allergenen genoemd. Het inademen van long allergenen resulteert net als bij bijvoorbeeld huisstofmijt in een astmatische reactie, maar de manier waarop dit tot stand komt in het lichaam is niet hetzelfde en vooralsnog zelfs voor een groot deel onbekend. Wanneer men praat over het bestrijden van werk gerelateerde astma zal dat zich dus vooral moeten richten op het voorkomen van blootstelling. Als een fabrikant weet dat een bepaalde stof astma veroorzaakt, dan kunnen beschermende (persoonlijke) maatregelen genomen worden zoals het gebruik van mondkapjes of een productieproces in een afgesloten ruimte plaatsen. Op die manier komen werknemers niet of in ieder geval minder in aanraking met de stof en zullen ze minder snel last van astma krijgen. Echter, de wetenschap is op dit moment niet in staat om van een nieuwe chemische stof te kunnen bepalen of een werknemer er astma van zal krijgen als de stof ingeademd wordt. Bestaande voorzorgsmaatregelen zijn alleen getroffen voor chemische stoffen waarvan al bekend is dat ze astma veroorzaken en dat weet men alleen omdat er al veel mensen ziek door zijn geworden. Er zijn wel manieren om werknemers te beschermen, maar dit gebeurt alleen nadat er al werknemers zijn blootgesteld aan een long allergeen, als het al gebeurt. Daarom willen we kunnen voorspellen welke chemische stoffen astma gaan veroorzaken wanneer ze toegepast zullen worden op de werkvloer, om zo werknemers te kunnen beschermen. 
Er bestaan al wetenschappelijke methodes om een voorspelling te kunnen doen of een chemische stof astma gaat veroorzaken of niet. Echter, deze methoden zijn om verschillende redenen nog niet geaccepteerd en geïmplementeerd in de regelgeving. Dit proefschrift heeft daarom als doel om die verschillende bestaande wetenschappelijke testmethoden te evalueren dan wel te verbeteren of aan te vullen, om zo een mogelijkheid te creëren om van tevoren van een chemische stof te kunnen zeggen of werknemers daar astma van gaan krijgen of niet. Als extra criterium voor dit onderzoek is gesteld dat alleen naar dierproefvrije testmethoden wordt gekeken, omdat binnen het onderzoeksveld van werk gerelateerde astma is gebleken dat dierproeven niet goed in staat zijn de menselijke situatie na te bootsen en omdat er een algehele trend is in de wetenschap om naar dierproefvrije onderzoeken te streven.

In hoofdstuk 2 wordt als eerste gekeken naar vijf verschillende computermodellen die reeds bestaan om een voorspelling over werk gerelateerde astma te kunnen doen. Deze vijf modellen zijn grofweg onder te verdelen in twee typen: het eerste type is ontwikkeld door van een aantal bekende long allergenen en niet-allergenen de chemische structuur te vergelijken. Als een bepaald type substructuur vaak voorkomt in de set van long allergenen, maar niet in de andere groep, dan is het aannemelijk dat die bepaalde substructuur een oorzaak kan zijn voor het ontstaan van astma. Dit is een statistische aanpak gebaseerd op de kennis dat bepaalde stoffen al astma op de werkvloer hebben veroorzaakt of niet. Het tweede type computermodel kijkt ook naar chemische substructuren, maar kijkt alleen naar de reactiviteit van die substructuur. Met reactiviteit wordt bedoeld dat die substructuur in staat moet zijn om een binding te maken met lichaamseigen stoffen (eiwitten) in de long. Dit is noodzakelijk omdat chemische long allergenen te klein zijn om door het immuunsysteem herkend te worden. Deze herkenning vindt pas plaats als de long allergeen gebonden is aan een eiwit, waardoor het voor het immuunsysteem lijkt alsof dat eiwit niet meer lichaamseigen is. Daar reageert het immuunsysteem vervolgens op. Hoofdstuk 2 heeft deze verschillende modellen dus geëvalueerd, en elk van deze modellen laat een goed resultaat laten zien voor de door hen geselecteerde set chemische stoffen. Vervolgens is voor elk model een nieuwe set chemische stoffen samengesteld met daarin bekende long allergenen en niet-allergenen. Die set stoffen is vervolgens geanalyseerd door elk model en daaruit blijkt dat diezelfde modellen minder goed presteren ten opzichte van hun eigen set chemische stoffen. Hierdoor is geconcludeerd dat het niet zinvol is om één van die modellen te gebruiken om voorspellingen te genereren voor nieuwe chemische stoffen. Echter, in hoofdstuk 2 is vervolgens gekeken of de voorspelling verbeterd kan worden als een combinatie wordt gemaakt van verschillende modellen waarbij de sterke punten van ieder model gebruikt worden. Wanneer deze combinatie van modellen gebruikt werd op een representatieve set chemische stoffen bleek dat de voorspellende waarde van de combinatie veel hoger ligt dan die van de individuele modellen zelf. Dit is dus een grote stap voorwaarts in de mogelijkheid om betrouwbare voorspellingen te genereren voor nieuwe chemische stoffen. Het grote minpunt 
van deze aanpak is dat slechts voor één op de drie geëvalueerde chemische stoffen een voorspelling gegenereerd wordt. Daarom is er voor de overige stoffen dus meer informatie nodig voordat er een betrouwbare voorspelling gegeven kan worden.

Mede om meer informatie over die resterende groep chemische stoffen te krijgen wordt in hoofdstuk 3 een andere testmethode voor werk gerelateerde astma geëvalueerd, namelijk de 'Direct Peptide Reactivity Assay' (DPRA). Dit is een chemische methode waarbij in een reageerbuis onderzocht wordt of een chemische stof kan binden aan een eiwit. Zoals eerder gezegd, voordat een chemische stof herkend kan worden door het immuunsysteem moet het binden aan lichaamseigen eiwitten. De DPRA meet of een chemische stof die binding aan kan gaan of niet, wat dus iets kan zeggen over de mogelijkheid dat de chemische stof astma zal veroorzaken. Naast het toepassen van de methodiek die al beschikbaar was hebben we ook gekeken of kleine aanpassingen aan het protocol kon zorgen voor betrouwbaardere informatie over een chemische stof. Zo zijn de geteste stoffen op meerdere tijdspunten gemeten om een indruk te krijgen hoe snel een chemische stof bindt aan een eiwit. Daarnaast is ook massaspectrometrie toegepast. Door het toepassen daarvan kon meer informatie verzameld worden over hoe een chemische stof aan een eiwit bindt. Die informatie kan bijvoorbeeld gebruikt worden om de computermodellen uit het vorige hoofdstuk te verbeteren. De DPRA werd getest op een aantal stoffen waarvan de computermodellen al wel een voorspelling hadden gedaan en een aantal stoffen waar meer informatie voor nodig was. Uit de resultaten bleek dat de DPRA zeer goed in staat was om long allergenen van nietallergenen te onderscheiden. Uit dezelfde resultaten bleek ook dat de toevoeging van metingen op verschillende tijdspunten en massaspectrometrie bij hebben gedragen aan de betrouwbaarheid van de voorspellingen. Er waren sommige stoffen die al heel vroeg een binding aan gingen met het eiwit, maar na 24 uur weer los hadden gelaten. Als de DPRA alleen na 24 uur zou meten, dan zou die stof gemist worden. Aan de andere kant bleek ook dat een bepaald type stoffen (chemische stoffen met een amine substructuur) niet herkend worden door de DPRA omdat die in dit testsysteem niet binden aan de eiwitten. Dit was een vals negatieve uitkomst, want aminen zijn wel in staat om in het lichaam aan eiwitten te binden en astma te veroorzaken. Dit resultaat kon verklaard worden doordat de DPRA niet in staat is om chemische stoffen te activeren; iets wat in het lichaam wel gebeurt en voor aminen noodzakelijk is om astma te kunnen veroorzaken.

Omdat de DPRA niet alle stoffen kon voorspellen is een derde type testmethode onderzocht en ontwikkeld binnen dit promotieonderzoek, namelijk een test gebaseerd op long epitheelcellen. Epitheelcellen vormen in de long de buitenste laag cellen om daar een fysieke barrière te vormen tegen lichaamsvreemde stoffen. Het is dus ook het eerste type cellen dat een lichaamsvreemde stof tegenkomt in de long. In hoofdstuk 4 is een kleine set van chemische stoffen getest en geanalyseerd met een zogenoemde ' microarray'. Met deze techniek kan gekeken worden naar het effect van een blootstelling aan een chemische stof op ongeveer 20000 genen die in de cellen zitten. Van veel van 
die genen is de biologische functie bekend, en het idee van deze test is om te kijken of long allergenen een specifieke set genen aan- of uitzetten waardoor er biologische processen beïnvloed worden. In dit specifieke geval bleek dat long allergenen specifiek genen aan- en uit zetten die te maken hebben met de barrièrefunctie van de epitheelcellen. Dit is een belangrijke vinding, want als de barrièrefunctie niet meer goed werkt, dan kan dat betekenen dat een long allergeen door kan dringen in de dieperliggende cellagen waar hij sneller opgepikt kan worden door het immuunsysteem. Echter, genen die te maken hebben met immunologische reacties werden niet gevonden, dus is vervolgonderzoek nodig om te bepalen of het aantasten van de barrièrefunctie voldoende informatie oplevert om een betrouwbare voorspelling te kunnen doen of een chemische stof astma gaat veroorzaken of niet.

Elk van de beschreven methoden in dit proefschrift heeft voordelen en nadelen als het gaat om de mogelijkheid en betrouwbaarheid van het maken van een voorspelling over astma. Elk model is in staat om, binnen de gekozen set van chemische stoffen, een goede voorspelling te doen of een chemische stof astma gaat veroorzaken of niet. Aan de andere kant, de computermodellen kunnen maar voor een klein deel van alle stoffen een betrouwbare voorspelling genereren, de DPRA mist bepaalde typen chemische stoffen omdat die biologisch geactiveerd moeten worden en de epitheelcellen laten weliswaar een duidelijk beeld zien als het gaat om barrièrefunctie, maar de vraag is of dit relevant is voor het krijgen van astma. Deze aspecten zullen in vervolgonderzoek aangepakt kunnen en moeten worden. Aan de andere kant zijn ook veel positieve resultaten behaald door elke individuele methode. Daarom beschrijft hoofdstuk 5 een zogenaamde teststrategie waarin de verschillende testmethoden gecombineerd worden om te evalueren of een slimme combinatie van testmethoden bij kan dragen aan het correct voorspellen van long allergenen in het algemeen. De opzet van deze teststrategie is dat verschillende, reeds bekende, aspecten van long allergie bekeken worden door de verschillende testmethoden. Zo evalueren de computermodellen en de DPRA de belangrijkste gebeurtenis in het biologische proces wat leidt tot astma, namelijk dat een chemische stof moet binden aan een lichaamseigen eiwit. Aan de andere kant, de epitheelcellen leveren juist informatie over het proces dat volgt op de eiwitbinding. Deze set van testen is vanuit het volledige proces dat leidt tot astma gezien een logische combinatie. Dit blijkt ook uit hoofdstuk 5 , waarin het slim inzetten van iedere test leidt tot een zeer betrouwbare voorspelling voor een groot deel van de chemische stoffen die getest zijn. Daar moet bij vermeld worden dat dit een relatief klein aantal stoffen betrof en dat er nog steeds veel vragen over blijven. Echter, daar waar elke individuele methode gebreken heeft, blijkt heel duidelijk uit de evaluatie van de teststrategie dat een slim gekozen combinatie van testen kan resulteren in zeer betrouwbare voorspellingen wat betreft de mogelijkheid dat een chemische stof astma zal veroorzaken op de werkvloer. En zodra daar een betrouwbaar antwoord op komt kunnen er, voordat er ook maar één werknemer blootgesteld wordt aan die stof, juiste voorzorgsmaatregelen getroffen worden en daarmee veel leed bespaard worden. 


\section{VALORISATION PARAGRAPH TO THE PHD THESIS}

\section{Towards a testing strategy for the identification of respiratory sensitizing chemicals}

Occupational asthma, asthma obtained through exposure to a chemical at the workplace, is a prevalent condition among workers. Compared to most other types of work related diseases, occupational asthma has very severe consequences for a worker. When a worker is exposed and sensitized to a specific chemical, the worker usually is not able to come near the workplace and potentially not even near the building itself. Compared to for example a work-related injury such as breaking a leg at a construction site, the socioeconomic consequences are much harsher for occupational asthma. It is therefore highly desirable to identify chemicals that can cause occupational asthma and take precautionary measures to prevent exposure to those chemicals. The problem is that prospective identification of these chemicals is currently not possible due to the lack of widely accepted testing methods (both animal and animal-free methods). In addition, with the current mindset of replacing, reducing and refining animal testing, the challenge to develop a method to identify these chemicals has not become easier. Nevertheless, this thesis aims to evaluate and develop different testing methods that are specifically designed to identify chemicals that cause occupational asthma.

The first type of methods evaluated are (quantitative) structure activity relationship models (QSARs). These in silico methods provide predictions on respiratory sensitization potential of chemicals based on their chemical structure. They roughly apply two different approaches to interpret the query chemical. Some in silico models evaluate the query chemical structure and search for similarities between the query chemical and a database of chemical structures known to cause occupational asthma. The other type searches the query chemical structure for specific chemical subdomains known to be protein reactive. Both applications are deemed valid, although a slight emphasis on the latter approach can be found in recent publications regarding respiratory sensitization as protein binding is known to be the molecular initiating event of respiratory sensitization that leads to occupational asthma. Further development of such in silico models, or at least, more insight in the actual chemistry involved in respiratory sensitization can result in highly efficient (time-wise and money-wise) tools for this toxicological end-point.

The second method evaluated in this thesis is the Direct Peptide Reactivity Assay (DPRA). This method measures the binding potential of chemicals to heptapeptides that mimic human proteins to which chemicals can bind. This method was originally designed to identify chemicals that cause skin sensitization, but it can also be applied to the field of respiratory sensitization as covalent binding between chemicals and proteins is the molecular initiating event for respiratory sensitization as well. The published methodology was evaluated and improved upon to increase the reliability of predictions and to obtain information on reaction chemistry. This information can be directly used by QSAR developers to improve their in silico models. In addition, the DPRA can provide predictions for chemicals that are (currently) not able to be predicted by 
QSARs due to issues in their applicability domain. Together, QSARs and the DPRA can provide a chemically relevant reliable prediction on the respiratory sensitization potential of chemical. However, the process that ultimately leads to occupational asthma involves many biological processes as well.

The third method developed in this thesis specifically addresses a small part of these biological processes. Specifically, an in vitro method was developed based on the first cell layer a chemical encounters when it enters the lungs, the epithelial lung barrier. It was found that several different genes were affected by respiratory sensitizers that are shown to be involved in the process of respiratory sensitization. However, these processes are mostly associated with the barrier function of the cells themselves, and less involved in immunological processes. Although this is not a major issue in terms of predictivity and biological relevance, it can be argued that an in vitro model based on more immunological relevant genes might be more appropriate, especially when it comes to applying the obtained gene set for a patent.

This thesis shows that by combining the abovementioned methods for the prediction of respiratory sensitization potential of chemicals, a prediction accuracy higher than any individual method can be obtained. This application, generally called a testing strategy, is becoming to be more relevant in the scientific community in general. The general consensus is that focus should shift to the development of these types of strategies instead of focusing solely on development of individual methods. Obviously, testing strategies only function when individual methods are combined, so sufficient attention should be given to that aspect as well. Increasing predictive performance of a model or strategy for respiratory sensitization is required as it will lead to better protection of workers. It is also important for industries working with potential respiratory sensitizers as it is more economical to adapt a manufacturing process beforehand than afterwards. One specific branch that could benefit from the developments in testing strategies for respiratory sensitization is contract research laboratories, as they could provide a prediction service based on a respiratory sensitizer testing strategy for affected industries.

It is concluded in this thesis that combining different individual testing methods is the way forward to allow for fast evaluation of chemicals that can potentially cause occupational asthma. This is deemed highly necessary as many workers are affected by this disease and therefore the impact on society is high. With the advancement of individual methods, the development of a knowledgebase regarding this toxicological endpoint in the form of an adverse outcome pathway, and the insights that the individual methods can be combined according to the different aspects of the AOP, it is likely that a strategy for the prospective identification of low molecular weight respiratory sensitizers is to be validated and accepted. 


\section{REFERENCES}

1. WHO. Fact sheet $N^{\circ}$ 307; Asthma. 2013; Available from: http://www.who.int/mediacentre/factsheets/ fs307/en/.

2. Sigsgaard, T., et al., ERS position paper: work-related respiratory diseases in the EU. European Respiratory Journal, 2010. 35(2): p. 234-238.

3. Jaakkola, J.J., R. Piipari, and M.S. Jaakkola, Occupation and asthma: a population-based incident casecontrol study. American journal of epidemiology, 2003. 158(10): p. 981-7.

4. Zock, J.P., World at work: cleaners. Occupational and environmental medicine, 2005. 62(8): p. 581-4.

5. Jaakkola, M.S. and J.J. Jaakkola, Assessment of public health impact of work-related asthma. BMC Med Res Methodol, 2012. 12: p. 22.

6. Goe, S.K., et al., A descriptive study of work aggravated asthma. Occup Environ Med, 2004. 61(6): p. 512-7.

7. Bradshaw, L. and D. Fishwick, Work aggravated asthma: A review of reviews. 2014, Health and Safety Laboratory.

8. Mapp, C.E., et al., Occupational asthma. Am J Respir Crit Care Med, 2005. 172(3): p. 280-305.

9. Toren, K. and P.D. Blanc, Asthma caused by occupational exposures is common - a systematic analysis of estimates of the population-attributable fraction. BMC Pulm Med, 2009. 9: p. 7.

10. Tarlo, S.M. and C. Lemiere, Occupational asthma. N Engl J Med, 2014. 370(7): p. 640-9.

11. Blanc, P.D. and K. Toren, How much adult asthma can be attributed to occupational factors? Am J Med, 1999. 107(6): p. 580-7.

12. CSST. List of agents causing occupational asthma. 2013 July 2014]; Available from: http://www.asthme. csst.qc.ca.

13. Cartier, A., New causes of immunologic occupational asthma, 2012-2014. Curr Opin Allergy Clin Immunol, 2015. 15(2): p. 117-23.

14. Sastre, J., O. Vandenplas, and H.S. Park, Pathogenesis of occupational asthma. Eur Respir J, 2003. 22(2): p. 364-373.

15. Smith, T.A., K.P. Lumley, and E.H. Hui, Allergy to flour and fungal amylase in bakery workers. Occup Med (Lond), 1997. 47(1): p. 21-4.

16. Gautrin, D., et al., Incidence and host determinants of probable occupational asthma in apprentices exposed to laboratory animals. Am J Respir Crit Care Med, 2001. 163(4): p. 899-904.

17. Rideout, K., et al., Considering risks to healthcare workers from glutaraldehyde alternatives in high-level disinfection. J Hosp Infect, 2005. 59(1): p. 4-11.

18. Lindstrom, M., et al., Dentist's occupational asthma, rhinoconjunctivitis, and allergic contact dermatitis from methacrylates. Allergy, 2002. 57(6): p. 543-5.

19. Moscato, G., et al., Occupational asthma and occupational rhinitis in hairdressers. Chest, 2005. 128(5): p. $3590-8$.

20. Pronk, A., et al., Respiratory symptoms, sensitization, and exposure response relationships in spray painters exposed to isocyanates. Am J Respir Crit Care Med, 2007. 176(11): p. 1090-7.

21. Dewitte, J.D., M. Chan-Yeung, and J.L. Malo, Medicolegal and compensation aspects of occupational asthma. Eur Respir J, 1994. 7(5): p. 969-980.

22. ECHA, Identification of Substances as SVHCs Due to Equivalent Level of Concern to CMRs (Article 57(f)) Sensitisers as an Example. 2013.

23. ECHA, EU - ECHA launches first SVHC consultation in 2018 on eight proposals. SGS, 2018 (033/18).

24. Vellore, A.D., et al., Occupational asthma and allergy to sevoflurane and isoflurane in anaesthetic staff. Allergy, 2006. 61(12): p. 1485-6.

25. Malo, J.L., et al., Asthma and the Workplace, in Asthma, Health and Society; A Public Health Perspective, A. Harver and H. Kotses, Editors. 2010, Springer: New York, NY. p. 303-323.

26. Holgate, S.T., The airway epithelium is central to the pathogenesis of asthma. Allergol Int, 2008. 57(1): p. 1-10.

27. Georas, S.N. and F. Rezaee, Epithelial barrier function: at the front line of asthma immunology and allergic airway inflammation. J Allergy Clin Immunol, 2014. 134(3): p. 509-20.

28. Rezaee, F. and S.N. Georas, Breaking barriers. New insights into airway epithelial barrier function in health and disease. Am J Respir Cell Mol Biol, 2014. 50(5): p. 857-69. 
29. Enoch, S.J., D.W. Roberts, and M.T. Cronin, Electrophilic reaction chemistry of low molecular weight respiratory sensitizers. Chem Res Toxicol, 2009. 22(8): p. 1447-53.

30. Valenta, R., The future of antigen-specific immunotherapy of allergy. Nat Rev Immunol, 2002. 2(6): p. 446-53.

31. Arts, J.H., C. Mommers, and C. de Heer, Dose-response relationships and threshold levels in skin and respiratory allergy. Crit Rev Toxicol, 2006. 36(3): p. 219-51.

32. Cochrane, S.A., et al., Thresholds in chemical respiratory sensitisation. Toxicology, 2015. 333: p. 179-194.

33. Sullivan, K., et al., An Adverse Outcome Pathway for Sensitization of the Respiratory Tract by LowMolecular-Weight Chemicals: Building Evidence to Support the Utility of In Vitro and In Silico Methods in a Regulatory Context. Vol. 3. 2017.

34. Stone, K.D., C. Prussin, and D.D. Metcalfe, IgE, mast cells, basophils, and eosinophils. Journal of Allergy and Clinical Immunology, 2010. 125(2): p. S73-S80.

35. Kimber, I., et al., Chemical respiratory allergy: reverse engineering an adverse outcome pathway. Toxicology, 2014. 318: p. 32-9.

36. Redlich, C.A. and C.A. Herrick, Lung/skin connections in occupational lung disease. Curr Opin Allergy Clin Immunol, 2008. 8(2): p. 115-9.

37. Arts, J.H., et al., The respiratory local lymph node assay as a tool to study respiratory sensitizers. Toxicol Sci, 2008. 106(2): p. 423-34.

38. Dearman, R.J., D.A. Basketter, and I. Kimber, Variable effects of chemical allergens on serum IgE concentration in mice. Preliminary evaluation of a novel approach to the identification of respiratory sensitizers. J Appl Toxicol, 1992. 12(5): p. 317-23.

39. Zeiss, C.R., et al., Trimellitic anhydride-induced airway syndromes: clinical and immunologic studies. The Journal of allergy and clinical immunology, 1977. 60(2): p. 96-103.

40. Kimber, I., D.A. Basketter, and R.J. Dearman, Chemical allergens-What are the issues? Toxicology, 2010. 268(3): p. 139-142.

41. Wisnewski, A.V. and C.A. Redlich, Recent developments in diisocyanate asthma. Current opinion in allergy and clinical immunology, 2001. 1(2): p. 169-75.

42. Shin, Y.S., et al., Cells and mediators in diisocyanate-induced occupational asthma. Current Opinion in Allergy and Clinical Immunology, 2013. 13(2): p. 125-131.

43. Scheerens, H., et al., Long-term Topical Exposure to Toluene Diisocyanate in Mice Leads to Antibody Production and In Vivo Airway Hyperresponsiveness Three Hours after Intranasal Challenge. American Journal of Respiratory and Critical Care Medicine, 1999. 159(4): p. 1074-1080.

44. Pauluhn, J. and U. Mohr, Experimental approaches to evaluate respiratory allergy in animal models. Experimental and Toxicologic Pathology, 2005. 56(4): p. 203-234.

45. Arts, J.H. and C.F. Kuper, Animal models to test respiratory allergy of low molecular weight chemicals: a guidance. Methods, 2007.41(1): p. 61-71.

46. Pauluhn, J., et al., Respiratory hypersensitivity to trimellitic anhydride in Brown Norway Rats: a comparison of endpoints. Journal of Applied Toxicology, 2002. 22(2): p. 89-97.

47. De Jong, W.H., et al., Contact and respiratory sensitizers can be identified by cytokine profiles following inhalation exposure. Toxicology, 2009. 261(3): p. 103-11.

48. Dearman, R.J., et al., Chemical allergy: considerations for the practical application of cytokine profiling. Toxicol Sci, 2003. 71(2): p. 137-45.

49. Van Och, F.M., et al., Cytokine production induced by low-molecular-weight chemicals as a function of the stimulation index in a modified local lymph node assay: an approach to discriminate contact sensitizers from respiratory sensitizers. Toxicol Appl Pharmacol, 2002. 184(1): p. 46-56.

50. Cunningham, A.R., et al., Development of an information-intensive structure-activity relationship model and its application to human respiratory chemical sensitizers. SAR QSAR Environ Res, 2005. 16(3): p. 273-285.

51. Enoch, S.J., et al., Development of mechanism-based structural alerts for respiratory sensitization hazard identification. Chem Res Toxicol, 2012. 25(11): p. 2490-2498.

52. OECD, Test No. 442C: In Chemico Skin Sensitisation: Direct Peptide Reactivity Assay (DPRA), OECD Guidelines for the Testing of Chemicals., O. Publishing, Editor. 2015: Paris. 
53. Lalko, J.F., et al., The selective peptide reactivity of chemical respiratory allergens under competitive and noncompetitive conditions. J Immunotoxicol, 2012.

54. Lalko, J.F., et al., The direct peptide reactivity assay: selectivity of chemical respiratory allergens. Toxicol Sci, 2012. 129(2): p. 421-431.

55. Verstraelen, S., et al., Cell types involved in allergic asthma and their use in in vitro models to assess respiratory sensitization. Toxicol In Vitro, 2008. 22(6): p. 1419-31.

56. Verstraelen, S., et al., Gene profiles of THP-1 macrophages after in vitro exposure to respiratory (non-) sensitizing chemicals: identification of discriminating genetic markers and pathway analysis. Toxicol In Vitro, 2009. 23(6): p. 1151-62.

57. Verstraelen, S., et al., Gene profiles of a human alveolar epithelial cell line after in vitro exposure to respiratory (non-)sensitizing chemicals: identification of discriminating genetic markers and pathway analysis. Toxicol Lett, 2009. 185(1): p. 16-22.

58. Verstraelen, S., et al., Gene profiles of a human bronchial epithelial cell line after in vitro exposure to respiratory (non-)sensitizing chemicals: identification of discriminating genetic markers and pathway analysis. Toxicology, 2009. 255(3): p. 151-9.

59. Huang, S., et al., Potential of in vitro reconstituted 3 D human airway epithelia (MucilAir) to assess respiratory sensitizers. Toxicol In Vitro, 2013. 27(3): p. 1151-6.

60. Lauenstein, L., et al., Assessment of immunotoxicity induced by chemicals in human precision-cut lung slices (PCLS). Toxicol In Vitro, 2014. 28(4): p. 588-99.

61. Pralong, J.A., et al., Occupational asthma: new low-molecular-weight causal agents, 2000-2010. J Allergy, 2012. 2012.

62. Bloemen, K., et al., The collection and evaluation of data on incidence and severity of skin and respiratory allergy related to exposure of chemicals from non-food sources. Report, European Commission Health \& Consumer Protection Directorate, 2009.

63. Quirce, S. and J. Sastre, New causes of occupational asthma. Curr Opin Allergy Clin Immunol, 2011. 11(2): p. 80-85.

64. EU. Classification, labelling and packaging of substances and mixtures. Official Journal of the European Union 2008; Available from: http://eur-lex.europa.eu/LexUriServ/LexUriServ.do?uri=OJ:L:2008:353:00 01:1355:EN:PDF.

65. EU. Guidance on information requirements and chemical safety assessment Chapter R7.a: Endpoint specific guidance. Source: European Chemicals Agency. 2012; 219-248]. Available from: http://echa.europa.eu/ documents/10162/13632/information_requirements_r7a_en.pdf.

66. UN. Globally Harmonized System of Classification and Labelling of Chemicals (GHS). New York and Geneva. 2007 [cited 2013; Available from: http://www.unece.org/trans/danger/publi/ghs/ghs_rev02/02files_e. html.

67. Boverhof, D.R., et al., Respiratory sensitization and allergy: current research approaches and needs. Toxicol Appl Pharmacol, 2008. 226(1): p. 1-13.

68. Vandebriel, R.J. and H. van Loveren, Non-animal sensitization testing: state-of-the-art. Crit Rev Toxicol, 2010. 40(5): p. 389-404.

69. Enoch, S.J., D.W. Roberts, and M.T. Cronin, Mechanistic Category Formation for the Prediction of Respiratory Sensitization. Chem Res Toxicol, 2010. 23(10): p. 1547-1555.

70. Graham, C., H.S. Rosenkranz, and M.H. Karol, Structure-activity model of chemicals that cause human respiratory sensitization. Regul Toxicol Pharmacol, 1997. 26(3): p. 296-306.

71. Jarvis, J., et al., Relationship between chemical structure and the occupational asthma hazard of low molecular weight organic compounds. Occup Environ Med, 2005. 62(4): p. 243-250.

72. Sanderson, D.R. and C.G. Earnshaw, Computer prediction of possible toxic action from chemical structure: The DEREK system. Human Experimental Toxicology, 1991. 10: p. 261-273.

73. Lhasa Ltd. Derek Nexus. 2014; Available from: http://www.lhasalimited.org/products/derek-nexus.htm.

74. Klopman, G., MULTICASE 1. A Hierarchical Computer Automated Structure Evaluation Program. Quantitative Structure-Activity Relationships, 1992. 11(2): p. 176-184.

75. Danish (Q)SAR database. Available from: http://qsar.food.dtu.dk/.

76. Quirce, S. and J.A. Bernstein, Old and new causes of occupational asthma. Immunol Allergy Clin North Am, 2011.31(4): p. 677-698. 
77. USDHHS, U.S. Department of Health and Human Services, National Institutes of Health, 1991. 90.

78. NICEATM-ICCVAM database. 2013 May-2014]; Available from: http://ntp.niehs.nih.gov/iccvam/ methods/immunotox/NICEATM-LLNAdatabase-23Dec2013.xls.

79. Dearman, R.J., D.A. Basketter, and I. Kimber, Inter-relationships between different classes of chemical allergens. J Appl Toxicol, 2013. 33(7): p. 558-565.

80. Accelrys, Accord for Excel v7.1.2010; Available from: http://accelrys.com/products/informatics/desktopsoftware.html.

81. Cooper, J.A., 2nd, R. Saracci, and P. Cole, Describing the validity of carcinogen screening tests. Br J Cancer, 1979. 39(1): p. 87-89.

82. Doubilet, P., A mathematical approach to interpretation and selection of diagnostic tests. Med Decis Making, 1983. 3(2): p. 177-95.

83. Rorije, E., et al., The OSIRIS Weight of Evidence approach: ITS for skin sensitisation. Regul Toxicol Pharmacol, 2013.67(2): p. 146-56.

84. Soreide, K., Receiver-operating characteristic curve analysis in diagnostic, prognostic and predictive biomarker research. J Clin Pathol, 2009. 62(1): p. 1-5.

85. Burge, P.S., V.C. Moore, and A.S. Robertson, Sensitization and irritant-induced occupational asthma with latency are clinically indistinguishable. Occup Med (Lond), 2012. 62(2): p. 129-133.

86. Weltzien, H.U., et al., T cell immune responses to haptens. Structural models for allergic and autoimmune reactions. Toxicology, 1996. 107(2): p. 141-151.

87. Aasen, T.B., et al., Diagnostic approach in cases with suspected work-related asthma. J Occup Med Toxicol, 2013. 8(17).

88. Potts, R.O. and R.H. Guy, Predicting skin permeability. Pharm Res, 1992. 9(5): p. 663-9.

89. Patlewicz, G., et al., Skin-sensitization structure-activity relationships for aldehydes. Contact Dermatitis, 2001. 44(6): p. 331-6.

90. Stenton, S.C., J.H. Dennis, and D.J. Hendrick, Occupational asthma due to ceftazidime. Eur Respir J, 1995. 8(8): p. 1421-3.

91. Isola, D., et al., Chemical respiratory allergy and occupational asthma: what are the key areas of uncertainty? J Appl Toxicol, 2008. 28(3): p. 249-53.

92. Dik, S., et al., Evaluation of in silico models for the identification of respiratory sensitizers. Toxicol Sci, 2014. 142(2): p. 385-94.

93. OECD, AOP for Skin Sensitization Series on Testing and Assessment No. 168, Part 1 and Part 2., OECD, Editor. 2012: Paris.

94. Lalko, J.F., et al., Reactivity of chemical respiratory allergens in the Peroxidase Peptide Reactivity Assay. Toxicol In Vitro, 2012.

95. OECD, Test No. 442C: In Chemico Skin Sensitisation: Direct Peptide Reactivity Assay (DPRA), OECD Guidelines for the Testing of Chemicals. 2015, Paris: OECD Publishing.

96. Natsch, A. and H. Gfeller, LC-MS-based characterization of the peptide reactivity of chemicals to improve the in vitro prediction of the skin sensitization potential. Toxicol Sci, 2008. 106(2): p. 464-78.

97. Chipinda, I., et al., Rapid and simple kinetics screening assay for electrophilic dermal sensitizers using nitrobenzenethiol. Chem Res Toxicol, 2010. 23(5): p. 918-25.

98. Enoch, S.J., et al., Development of an in silico profiler for respiratory sensitisation. Altern Lab Anim, 2014. 42(6): p. 367-75.

99. Eggleston, P.A., A. Kagey-Sobotka, and L.M. Lichtenstein, A comparison of the osmotic activation of basophils and human lung mast cells. Am Rev Respir Dis, 1987. 135(5): p. 1043-8.

100. Soni, M.G., et al., Evaluation of the health aspects of methyl paraben: a review of the published literature. Food Chem Toxicol, 2002. 40(10): p. 1335-73.

101. Gerberick, G.F., et al., Compilation of historical local lymph node data for evaluation of skin sensitization alternative methods. Dermatitis, 2005. 16(4): p. 157-202.

102. Chipinda, I., J.M. Hettick, and P.D. Siegel, Haptenation: chemical reactivity and protein binding. J Allergy (Cairo), 2011.2011: p. 839682.

103. Lepoittevin, J.P., Metabolism versus chemical transformation or pro- versus prehaptens? Contact Dermatitis, 2006. 54(2): p. 73-4. 
104. Gerberick, G.F., et al., Development of a peptide reactivity assay for screening contact allergens. Toxicol Sci, 2004. 81(2): p. 332-43.

105. Yemm, E.W., E.C. Cocking, and R.E. Ricketts, The determination of amino-acids with ninhydrin. Analyst, 1955. 80(948): p. 209-214.

106. Waxman, D.J. and J.L. Strominger, Penicillin-binding proteins and the mechanism of action of beta-lactam antibiotics. Annu Rev Biochem, 1983. 52: p. 825-69.

107. Hopkins, J.E., et al., Selective haptenation of cellular or extracellular protein by chemical allergens: association with cytokine polarization. Chem Res Toxicol, 2005. 18(2): p. 375-81.

108. Kristiansson, M.H., C.H. Lindh, and B.A. Jonsson, Determination of hexahydrophthalic anhydride adducts to human serum albumin. Biomarkers, 2003. 8(5): p. 343-59.

109. OECD, The adverse outcome pathway for skin sensitisation initiated by covalent binding to proteins. OECD Environment, Health and Safety publications; Series on testing and assesment, 2012(168).

110. Natsch, A., The Nrf2-Keap1-ARE toxicity pathway as a cellular sensor for skin sensitizers--functional relevance and a hypothesis on innate reactions to skin sensitizers. Toxicol Sci, 2010. 113(2): p. 284-92.

111. Cozens, A.L., et al., CFTR expression and chloride secretion in polarized immortal human bronchial epithelial cells. Am J Respir Cell Mol Biol, 1994. 10(1): p. 38-47.

112. Morgan, D.M.L., Tetrazolium (MTT) Assay for Cellular Viability and Activity, in Polyamine Protocols, D.M.L. Morgan, Editor. 1998, Humana Press. p. 179-184.

113. Eijssen, L.M., et al., User-friendly solutions for microarray quality control and pre-processing on ArrayAnalysis.org. Nucleic Acids Res, 2013. 41(Web Server issue): p. W71-6.

114. Bolstad, B.M., et al., A comparison of normalization methods for high density oligonucleotide array data based on variance and bias. Bioinformatics, 2003. 19(2): p. 185-93.

115. Dai, M., et al., Evolving gene/transcript definitions significantly alter the interpretation of GeneChip data. Nucleic Acids Res, 2005. 33(20): p. e175.

116. R Development Core Team, A Language and Environment for Statistical Computing, in R Foundation for Statistical Computing. 2010.

117. van der Veen, J.W., et al., Applicability of a keratinocyte gene signature to predict skin sensitizing potential. Toxicol In Vitro, 2013. 27(1): p. 314-22.

118. Vandebriel, R.J., et al., Keratinocyte gene expression profiles discriminate sensitizing and irritating compounds. Toxicol Sci, 2010. 117(1): p. 81-9.

119. Rifkin, R., et al., An Analytical Method for Multiclass Molecular Cancer Classification. SIAM Review, 2003. 45(4): p. 706-723.

120. Breiman, L., Random Forests. Machine Learning, 2001. 45(1): p. 5-32.

121. Tibshirani, R., et al., Diagnosis of multiple cancer types by shrunken centroids of gene expression. Proc Natl Acad Sci U S A, 2002. 99(10): p. 6567-72.

122. Huang da, W., B.T. Sherman, and R.A. Lempicki, Systematic and integrative analysis of large gene lists using DAVID bioinformatics resources. Nat Protoc, 2009. 4(1): p. 44-57.

123. Brown, F.C., C.H. Schindelhaim, and S.R. Pfeffer, GCC185 plays independent roles in Golgi structure maintenance and AP-1-mediated vesicle tethering. J Cell Biol, 2011. 194(5): p. 779-87.

124. Jones, M.H., et al., A novel family of bromodomain genes. Genomics, 2000. 63(1): p. 40-5.

125. Pinto, S.M., et al., Quantitative phosphoproteomic analysis of IL-33-mediated signaling. Proteomics, 2015. 15(2-3): p. 532-44.

126. Oboki, K., et al., IL-33 and Airway Inflammation. Allergy Asthma Immunol Res, 2011. 3(2): p. 81-8.

127. Feng, J., et al., Inhibitory phosphorylation site for Rho-associated kinase on smooth muscle myosin phosphatase. J Biol Chem, 1999. 274(52): p. 37385-90.

128. Guittard, G., et al., Absence of both Sos-1 and Sos-2 in peripheral CD4 T cells leads to PI3K pathway activation and defects in migration. Eur J Immunol, 2015.

129. Oldenburger, A., et al., A-kinase anchoring proteins contribute to loss of E-cadherin and bronchial epithelial barrier by cigarette smoke. Am J Physiol Cell Physiol, 2014. 306(6): p. C585-97.

130. Xiao, C., et al., Defective epithelial barrier function in asthma. J Allergy Clin Immunol, 2011. 128(3): p. 549-56 e1-12. 
131. Toxicity Testing in the 21st Century: A Vision and a Strategy. 2007, Washington, DC: The National Academies Press. 216.

132. van der Veen, J.W., et al., Evaluating the performance of integrated approaches for hazard identification of skin sensitizing chemicals. Regul Toxicol Pharmacol, 2014. 69(3): p. 371-9.

133. Bauch, C., et al., Putting the parts together: combining in vitro methods to test for skin sensitizing potentials. Regul Toxicol Pharmacol, 2012. 63(3): p. 489-504.

134. Forreryd, A., et al., Prediction of chemical respiratory sensitizers using GARD, a novel in vitro assay based on a genomic biomarker signature. PLoS One, 2015. 10(3): p. e0118808.

135. Remy, S., et al., Gene expressions changes in bronchial epithelial cells: markers for respiratory sensitizers and exploration of the NRF2 pathway. Toxicol In Vitro, 2014. 28(2): p. 209-17.

136. Verstraelen, S., et al., Gene expression profiling of in vitro cultured macrophages after exposure to the respiratory sensitizer hexamethylene diisocyanate. Toxicol In Vitro, 2008. 22(4): p. 1107-14.

137. Dik, S., et al., Can the Direct Peptide Reactivity Assay Be Used for the Identification of Respiratory Sensitization Potential of Chemicals? Toxicological Sciences, 2016. 153(2): p. 361-371.

138. Dik, S., et al., Development of an in vitro test to identify respiratory sensitizers in bronchial epithelial cells using gene expression profiling. Toxicology in Vitro, 2015. 30(1, Part B): p. 274-280.

139. North, C.M., et al., Developing a framework for assessing chemical respiratory sensitization: A workshop report. Regulatory Toxicology and Pharmacology, 2016. 80: p. 295-309.

140. Lambrecht, B.N. and H. Hammad, The role of dendritic and epithelial cells as master regulators of allergic airway inflammation. The Lancet, 2010. 376(9743): p. 835-843.

141. Mizoguchi, I., et al., Prediction of Chemical Respiratory and Contact Sensitizers by OX40L Expression in Dendritic Cells Using a Novel 3D Coculture System. Frontiers in Immunology, 2017. 8(929).

142. Basketter, D., A. Poole, and I. Kimber, Behaviour of chemical respiratory allergens in novel predictive methods for skin sensitisation. Regulatory Toxicology and Pharmacology, 2017. 86: p. 101-106.

143. Lalko, J.F., et al., Chemical reactivity measurements: potential for characterization of respiratory chemical allergens. Toxicol In Vitro, 2010. 25(2): p. 433-445.

144. Mathis, C., et al., Human bronchial epithelial cells exposed in vitro to cigarette smoke at the air-liquid interface resemble bronchial epithelium from human smokers. American Journal of Physiology - Lung Cellular and Molecular Physiology, 2013. 304(7): p. L489-L503.

145. Tarlo, S.M., Irritant-induced asthma in the workplace. Curr Allergy Asthma Rep, 2014. 14(1): p. 406.

146. Adeleye, Y., et al., Implementing Toxicity Testing in the 21st Century (TT21C): Making safety decisions using toxicity pathways, and progress in a prototype risk assessment. Toxicology, 2015. 332: p. 102-11.

147. Tollefsen, K.E., et al., Applying Adverse Outcome Pathways (AOPs) to support Integrated Approaches to Testing and Assessment (IATA). Regul Toxicol Pharmacol, 2014. 70(3): p. 629-40.

148. Rovida, C., et al., Integrated Testing Strategies (ITS) for safety assessment. ALTEX, 2015. 32(1): p. 25-40. 


\section{DANKWOORD}

Het heeft even geduurd en ik heb zelfs meermaals gedacht of het niet beter was te stoppen. Mijn contract was afgelopen en ik besloot om een onwijs drukke baan als docent te nemen. Je zult snappen hoe trots en vooral ook blij ik ben dat ik het toch heb afgemaakt, met dit mooie proefschrift als resultaat. Dit werk is natuurlijk niet alleen tot stand gekomen door mijzelf, maar met mij vele anderen op het werk en in de privésfeer. Een aantal van deze mensen wil ik speciaal bedanken.

Allereerst de man door wie mijn avontuur überhaupt begonnen is, mijn promotor Henk van Loveren. Dank je wel voor al je begeleiding en je kritische vragen die mij geholpen hebben het onderzoek in een goede richting te sturen. Maar misschien nog wel meer omdat jij degene was die mij, ondertussen ruim 7 jaar geleden, aan de telefoon vertelde dat je nóg een $\mathrm{PhD}$ positie had. Ik weet niet of jij het nog weet, maar in eerste instantie belde ik met vragen over een ander project. Daar werd ik niet enthousiast van, en toen vertelde jij dat er nog een ander project werd opgestart. Zonder die tip was ik misschien wel nooit bij jou terecht gekomen.

Uiteraard mag ook Janine, mijn co-promotor, niet ontbreken in dit dankwoord. Mijn dank is enorm, vooral voor jouw steun op het werk wat betreft het omgaan met de vele anderen met wie ik te maken heb gehad. Dat was zeker niet altijd even makkelijk voor mij. Gelukkig kon ik altijd bij jou terecht om het daarover te hebben. Jij was wat dat betreft altijd mijn steun en toeverlaat op de werkvloer.

Dit gehele project omvatte veel verschillende elementen uit de natuurwetenschappen. Mijn passie heeft altijd het meest bij de chemische aspecten gelegen. De twee personen die mij daar het meest in hebben bijgestaan wil ik ook heel graag bedanken. Emiel, met jou heb ik onnoemelijk veel discussies gehad over de zin en onzin van bepaalde QSAR-uitkomsten. We hebben uren data gecrunched met Derek en dan kwam ik toch later weer met nog een stofje. Nooit was dat een probleem. Met Paul heb ik ook heel veel uren doorgebracht, maar dan vooral op het lab met de HPLC-MS. Geweldige tijden vond ik dat en mijn dank is groot dat ik die tijd met jou heb mogen besteden. Het mooiste waren toch de vroege ochtenden waarop de MS het niet meer bleek te doen na een lange nacht draaien omdat blijkbaar de stroom er kort af was geweest. Samen hebben we heel wat gebaald van zoiets simpels als de opstarttijd van een noodgenerator.

In het andere lab, het microbiologie lab, heb ik de meeste tijd doorgebracht met Eric. Ik wil je bedanken voor alle hulp bij het kweken van de cellen, het mij aanleren van alle voor mij toen onbekende technieken en alle gezelligheid. Ook hebben we maar mooi het hele chemicaliën bestand hanteerbaar gemaakt en de chemicaliën kast meermaals opnieuw ingedeeld. Ik hoop dat die nog steeds zo netjes is.

Daarnaast wil ik al mijn andere collega's bedanken voor de leuke tijd die ik op het RIVM heb gehad. In het speciaal Jochem en Hedwig, die ook mijn paranimfen willen zijn. Jochem, jij hebt mij door jouw soortgelijke onderzoek vaak weten te helpen mijn eigen onderzoek in de goede richting te sturen. Hedwig, jij was voor mij altijd 
het perfecte voorbeeld van hoe ik het als AIO misschien ook had kunnen doen, was het niet dat ik zoveel aan het dansen was. Maar jouw inzet voor jouw eigen project is altijd een voorbeeld voor mij geweest.

Als laatste wil ik mijn dierbare naasten ontzettend bedanken. Mijn papa en mama voor hun altijd onuitputtelijke steun, vooral toen ik door mijn docentschap meermaals heb overwogen niet door te zetten. En uiteraard ook Daphne, destijds mijn vriendinnetje die heel vaak uit Groningen naar Bilthoven kwam om op de zolderkamer met mij te logeren, nu mijn liefste vrouw van wie ik zo ontzettend veel hou. 


\section{LIST OF PUBLICATIONS}

Evaluation of in silico models for the identification of respiratory sensitizers.

Dik, S., Ezendam, J., Cunningham, A. R., Carrasquer, C. A., van Loveren, H., Rorije, E. Toxicological Sciences, 142(2), 2014, 385-394

Can the direct peptide reactivity assay be used for the identification of respiratory sensitization potential of chemicals?

Dik, S., Rorije, E., Schwillens, P., van Loveren., Ezendam, J. Toxicological Sciences, 153(2), 2016, 361-371

Development of an in vitro test to identify respiratory sensitizers in bronchial epithelial cells using gene expression profiling.

Dik, S., Pennings, J.L.A., van Loveren., Ezendam, J. Toxicology in Vitro 30 (2015) 274-280 


\section{CURRICULUM VITAE}

Sander Dik werd geboren op 18 december 1988 te Oss. In 2006 behaalde hij zijn vwo-diploma op de Koninklijke Scholengemeenschap in Apeldoorn. Aansluitend studeerde hij moleculaire levenswetenschappen aan de Radboud Universiteit Nijmegen, met bio-organische chemie en moleculaire toxicologie als afstudeerrichting. Tijdens zijn eerste afstudeerstudie bij de afdeling bio-organische chemie, onder supervisie van Dr. René P. Brinkhuis, verrichte hij onderzoek aan het functionaliseren van polymersomen met als doel die als medicijntransporters over de bloedhersenbarrière te krijgen. Tijdens zijn tweede afstudeeronderzoek op de afdeling arbeids- en milieugeneeskunde aan de universiteit van Leuven hield hij zich bezig met het ontwikkelen van een gestandaardiseerd protocol voor het bepalen van chroom(VI) accumulatie in een subpopulatie van T-lymphocyten onder supervisie van Dr. Lode Godderis. In 2011 behaalde hij zijn Masters diploma, waarna hij startte met zijn promotieonderzoek bij de vakgroep Toxicogenomics aan de Universiteit van Maastricht en de afdeling Gezondheidsbeschermingsonderzoek van het Rijksinstituut voor Volksgezondheid en Milieu (RIVM) te Bilthoven, alwaar het onderzoek is uitgevoerd. De resultaten van zijn onderzoek staan beschreven in dit proefschrift. Sinds september 2015 werkt Sander als docent scheikunde op 't Hooghe Landt college in Amersfoort waarvoor hij in 2016 zijn eerstegraads lesbevoegdheid heeft behaald op de Vrije Universiteit van Amsterdam.

Sander Dik was born in Oss on December 18th, 1988. In 2006 he finished his secondary education at the Koninklijke Scholengemeenschap in Apeldoorn. He then started his study molecular life sciences at the Radboud University Nijmegen, with a major in bio-organic chemistry and molecular toxicology. During his study he conducted two separate studies. The first was aimed at functionalizing polymersomes as drug-delivery vesicles across the blood-brain barrier at the department of bio-organic chemistry, under the supervision of Dr. René Brinkhuis. The second study was performed at the department of occupational-, environmental- and insurance medicine at the University of Leuven, under the supervision of Dr. Lode Godderis. In that study he aimed to develop a standardized protocol for determining the extent of chromium(VI) accumulation in a subset of T-lymphocytes. He received his Masters degree in 2011, after which he enrolled as a Ph.D. student at the department of Toxicogenomics at Maastricht University and the department for Health protection research at the National Institute of Public Health and the Environment (RIVM) in Bilthoven, where his research was conducted. The results of his studies are described in this dissertation. Since September 2015 he is working as a chemistry teacher at the secondary school 't Hooghe Landt in Amersfoort, for which he obtained his proof of proficiency in 2016 at the Vrije Univeristeit in Amsterdam. 
